\title{
Steel fibre reinforced geopolymer concrete (SFRGC) with improved microstructure and enhanced fibre-matrix interfacial properties
}

\author{
Mohammed Al-Majidi ${ }^{1,2}$, Andreas Lampropoulos ${ }^{1}$, Andrew B. Cundy ${ }^{3}$ \\ ${ }^{1}$ School of Environment and Technology, University of Brighton, Moulsecoomb, Brighton BN2 4GJ, UK \\ ${ }^{2}$ Department of Civil Engineering, College of Engineering, University of Basrah, Basrah, Iraq \\ ${ }^{3}$ School of Ocean and Earth Science, University of Southampton, Southampton SO14 3ZH, UK.
}

\begin{abstract}
Geopolymers are aluminosilicate materials formed by mixing by-product materials with alkaline solutions, and which have several desirable properties compared to Portland cement concrete in terms of strength and durability. Most of the previous research on steel fibre reinforced geopolymer concrete (SFRGC) has focused on the properties of single or binary mixes hardened under heat curing conditions, which is a severe limitation for on-site, cast-inplace applications. In the current study, a novel plain and steel fibre reinforced geopolymer concrete (SFRGC), containing various types of commercial Silica Fume (SF) (densified, undensified and slurry silica fume) and varying Ground Granulated Blast Furnace Slag (GGBS) content in a ternary binder mixture, cured under ambient (room) temperature has been examined. An extensive experimental investigation was conducted to evaluate the fresh properties, mechanical characteristics and microstructure of the examined material. The experimental results indicate that the mechanical characteristics of all the examined mixes are enhanced by increasing the GGBS content, in both plain and steel fibre reinforced geopolymer concrete. Geopolymer concrete with undensified silica fume showed better mechanical strength compared to that with densified and slurry SF, due to the agglomeration and ineffective dispersion of the latter fume types. SEM microstructural observations and porosity measurements were also conducted. The results indicate that the inclusion of silica fume and increasing GGBS content leads to higher pozzolanic activity and pore infilling, providing relatively homogeneous, compact and dense microstructures and subsequently improved mechanical properties.
\end{abstract}

\section{Introduction.}

With growing pressure on concrete industries to reduce their greenhouse gas emissions, it has become increasingly important to find alternative binders to ordinary Portland cement (OPC). Geopolymer concretes are produced by mixing industrial aluminosilicate waste materials such as fly ash, GGBS and metakaolin with an alkaline solution, and have been the focus of much research as effective, more environmentally-friendly, construction materials [1]. It has been estimated that full replacement of OPC by geopolymer materials could generate an $80 \%$ reduction in carbon dioxide emissions compared to standard industrial cement, and a significant reduction in the consumption of primary raw materials [2-4].

Fly Ash (FA) is a by-product material collected from coal-fired power plants. Lowcalcium_FA (Class F) has been found to be a suitable material for geopolymer production and can be used as an effective Portland cement replacement because of its wide availability, useful 
silica $\left(\mathrm{SiO}_{2}\right)$ and alumina-based composition, and reduced water demand [5, 6]. Most previous studies on FA-based geopolymer cured at ambient temperature highlight, however, its relatively poor early strength development due to a slow polymerisation process $[1,7,8]$. Some of the main parameters affecting the potential reactivity of FA include the vitreous phase content, reactive silica content, and the particle size distribution [9-11]. Therefore, researchers have attempted to enhance the reactivity of FA-based geopolymer by reducing the FA particle size, or by adding quantities of calcium-containing materials to react with the fly ash particles. Inclusion of GGBS as source of calcium together with FA in a binary mix has been investigated, with favourable results [6]. The inclusion of ultra-fine particles of amorphous silica, or Silica Fume (SF), which are available commercially in various forms depending on the material handling techniques (i.e. as densified, undensified and water-based slurries), has been shown to improve the mechanical properties of both high performance and conventional concretes [12], and may also provide a reactive silica source for improved geopolymer performance. The addition of silica fume during the production of high strength concrete (HSC) has also been observed to improve interfacial cement paste-aggregates bonding, which is the weakest zone in the matrix [13-15], and is discussed further below in relation to fibrereinforcement.

While a number of studies have been published on the performance of binary fly ash/slag-based geopolymer mixes cured under ambient temperature $[4,10,16,17]$, and in most cases promising results have been achieved, in general the geopolymer literature has focused on use of heat curing to harden and strengthen geopolymer materials. The effect of curing time (1- $48 \mathrm{hrs}$ ) and curing temperature $\left(21^{\circ} \mathrm{C}-90^{\circ} \mathrm{C}\right)$ on the properties of geopolymer concretes has been examined in previous studies $[18,19]$, which indicates that $70 \%$ of the mechanical strength of the geopolymer is developed within the first $12 \mathrm{hrs}$ of the curing process [20], and that optimum strength can be achieved by curing at temperatures ranging from $40{ }^{\circ} \mathrm{C}$ to $80{ }^{\circ} \mathrm{C}$

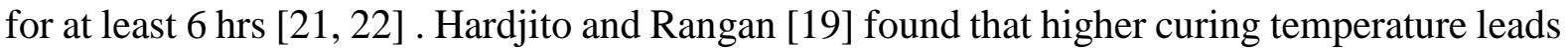
to improvements in compressive strength. However, based on this study [19], raising curing temperature above $60{ }^{\circ} \mathrm{C}$ did not considerable affect compressive strength development. Elevated temperature treatment however is somewhat counter to the concept of geopolymer concrete as a sustainable material, as heat curing leads to increased energy consumption in order to attain the required curing temperature, with subsequent additional cost, and also limits in situ applications [23]. There are number of parameters influence the energy cost and resulting $\mathrm{CO}_{2}$ emissions for heat curing such as curing process, climate weather (summer or winter), curing temperature and time, and the most important parameter is the energy source used for heat treatment system, e.g. electricity, solid fuel or thermal energy [24]. As an example, the operation of a commercial walk-in curing oven normally uses electricity at 43 kilowatt $(\mathrm{KW})$ per cubic meter of concrete, which, applying a typical UK electricity cost of approximately 10.5 pence per KWh, would give an average energy consumption cost (for 624 hour curing) of $£(25-110) / \mathrm{m}^{3}$ material, based on the curing time. The cost-saving produced by ambient temperature curing, along with reduced $\mathrm{CO}_{2}$ emissions (depending on the energy source used) and simplification of the manufacturing process for cast-in-place applications, is a major driver in development of ambient-temperature cured geopolymer materials. 
Despite the potential advantages of geopolymer application, using pozzolanic materials such as FA and GGBS as a replacement for conventional OPC can also cause deterioration in some key mechanical properties. For example, use of these materials can increase brittleness, and cause development of cracks over time due to plastic shrinkage in the pre-hardened state as well as drying shrinkage in hardened concrete [25]. These cracks reduce the material durability and subsequently its service life. Limiting brittleness and crack propagation, while at the same time improving the early strength and reactivity of geopolymer materials, is therefore of key importance for the development of effective geopolymer materials which can be cured or produced under ambient (i.e. on-site) temperatures. It is well-known that brittleness and cracking effects can be mitigated by the addition of fibre reinforcements into the matrix, which control the propagation or coalescence of cracks [26], and reduce the tendency for brittle material failure. Steel fibres are commonly used for reinforcing conventional concretes in this way, and are manufactured from cold-drawn wire, steel sheet and other forms of steel [27]. The main improvements in the engineering properties of the concrete following inclusion of fibres are strain hardening after the peak load, fracture toughness, and resistance to fatigue and thermal shock [27]. A number of authors have examined the mechanical and durability properties of fibre reinforced geopolymer concrete, but to date most of the published work focuses on fibre reinforced geopolymer concrete cured under elevated temperatures, which again limits the application of this material to precast elements [28-32]. Bernal et al. [33] reported the mechanical and durability performance of alkali-activated slag containing steel fibre. Their results indicated that incorporation of steel fibre considerably improved flexural strength and material durability characteristics. However, the compressive strength of the material reduced with steel fibre incorporation. Aydin and Baradan [32] examined the effect of steel fibre volume fraction and aspect ratio on the mechanical properties of slag and silica fumebased geopolymer subject to steam curing at $100{ }^{\circ} \mathrm{C}$ for $12 \mathrm{hrs}$. Their results showed that mechanical properties were considerably improved by increasing the steel fibre length and volume fraction in the geopolymer mixes. Natali et al. [34] investigated the flexural performance of slag and metakaolin-based fibre reinforced geopolymer concrete cured in a humid atmosphere and containing four types of fibres: carbon; E-glass; polyvinyl alcohol (PVA); and polyvinyl chloride (PVC). They concluded that all fibre types, and especially carbon and PVA, lead to improvement in flexural strength and post cracking behaviour. However, Puertas et al.[35] studied the effect of polypropylene fibre inclusion on the properties of different alkali-activated cement composites. Their results showed that incorporation of polypropylene fibres did not positively impact the mechanical behaviour of alkali-activated mortars. These authors also highlighted that the nature of the geopolymer matrix is a crucial parameter in the strength development of fibre reinforced geopolymers.

In summary, while a number of authors have examined the development and performance of fibre reinforced geopolymer concrete [33,36], the published literature focuses on geopolymer materials hardened under heat curing conditions with single/ binary geopolymer binders. To date, there is no published study examining the fresh properties, and mechanical and microstructural characteristics, of plain and steel fibre reinforced geopolymer concrete (SFRGC) cured under ambient temperatures, in a ternary binder mixture. Previous experimental results have shown that the addition of fibres in geopolymer mixes cured under 
ambient temperature is relatively ineffective due to the poor bond between the geopolymer matrix and the fibres [37, 38]. The current study aims to address these limitations, by developing a fibre reinforced, ambient-temperature cured, ternary-blend geopolymer concrete which uses silica fume to improve fibre-matrix interfacial bond properties, and which is appropriate for in-situ applications.

In the present study, various types of silica fume have been used together with FA and GGBS for the production of a ternary geopolymer matrix with improved early strength and interfacial bonding properties. Potassium silicate has been used as an alkaline solution in order to provide sustainable and user-friendly characteristics while steel fibres have been used as the main reinforcement. Extensive experimental investigations have been conducted to examine the influence of GGBS content and variant silica fume (SF) forms on the characteristics of ambient temperature-cured SFRGC, and the main findings validated through Scanning Electronic Microscopy (SEM) analysis.

\section{Experimental Program.}

\subsection{Materials}

FA category S [39], GGBS and SF were used in the current study as the geopolymer binder, and silica sand (particle size less than $0.5 \mathrm{~mm}$ ) was used as an aggregate. The chemical properties of the FA, GGBS and silica sand have been presented in detail in a previous study [2]. A $2 \%$ volume fraction of straight steel fibres with a length of $13 \mathrm{~mm}$ and $0.16 \mathrm{~mm}$ diameter was used as the fibre reinforcement (Table 1). For the alkaline activator, a combination of potassium hydroxide with potassium silicate solution was used [1].

\subsection{Characterization of Silica Fume.}

Various types of silica fume with different physical properties were utilised in this study (Table 2). The densities and specific gravity for all silica fume forms as received from the manufacturer are shown in Table 2. The particle size distribution was determined via laser diffraction particle size analysis (Fig. 1 and Table 3).

Table 3 shows the mean particle size $(\mathrm{d}(0.5))$, and $\mathrm{d}(0.1)$ and $\mathrm{d}(0.9)$ (the particle sizes where $10 \%$ and $90 \%$ of the sample population are smaller than this size). The aqueous suspension (slurry) with a dry silica fume content of $50 \%$ by mass (SSF) showed the smallest mean particle size followed by undensified silica fume (USF) and finally densified silica fume (DSF). These results are due to particle agglomeration during the production and packaging procedure of the silica fume.

\subsection{Experimental methodology.}

Thirty two different mixes (Table 4) were prepared to evaluate the effect of GGBS content and SF particle size distribution on the mechanical behaviour of plain geopolymer and 
steel-fibre reinforced geopolymer (SFRGC). Partial replacement (10\% by weight) of FA with dry silica fume (densified silica, undensified silica) was examined in samples with the suffix "DSF" or "USF", whereas 5\% of FA content was replaced in samples containing slurry silica fume (samples with the suffix "SSF"). GGBS was also added at varying GGBS to binder weight ratios, of 10\%, 20\%, 30\% and 40\% (samples with prefix 10S, 20S, 30S and 40S respectively), while steel fibre was added at $2 \%$ volume fraction. Reference geopolymer mortar specimens with similar GGBS to binder weight ratios of 10\%, 20\%, 30\% and 40\%, with silica fume but without steel fibre (ST) were prepared as controls, to allow assessment of the impact of ST on material performance.

\subsection{Mix preparation and testing.}

All geopolymer mortars were mixed using a 5 litre Hobart mixer. Potassium silicate solution with modulus equal to 1.25 was used an alkaline activator following the procedure described in a previous study [1, 40]. For mortar mixtures with dry powder silica fume (Densified and Undensified), the liquid phase was prepared in advance by mixing potassium silicate solution with water and superplasticizer for 5 minutes prior to mixing with the solid phase. The binder powder materials (FA, GGBS, and SF) were dry mixed for 5 minutes and then the liquid phase was added and the mixer run for another 5 minutes. After that, steel fibres were gradually added after sieving through an appropriate steel mesh at the top of the mixer, in order to ensure uniform fibre dispersion in the geopolymer mix._Finally, sand was added to the mixer, and the mixer was run for another 3 minutes to give a total mixing time of 13 minutes. In the case of mixes with slurry silica, the mixing step was slightly different, with the sand added to the mix prior to the slurry silica. This revised mixing procedure was necessary to avoid flash setting, as the high reactivity of the slurry silica can lead to gelation of the geopolymer binder without sand.

The fresh geopolymer was immediately cast into moulds. After 24 hours, all specimens were covered with plastic film after de-moulding in order to prevent water evaporation and then they were stored at ambient temperature $\left(21-23^{\circ} \mathrm{C}\right)$. The fresh properties of the geopolymer mortar were examined via setting time and workability analysis. The initial and final setting times of plain geopolymer mortars without steel fibres were measured using a vicat needle according to EN 480-2:2006 [41]. Setting time tests were conducted under room temperature $\left(21-23{ }^{\circ} \mathrm{C}\right)$. Flow tests were undertaken immediately at the end of the mixing based on ASTM C230 [42] (Fig.2).

Compressive and direct tensile tests were carried out to evaluate the strength characteristics of hardened plain and steel fibre reinforced geopolymer composites. Compressive strength tests were conducted according to ASTM C109 [43], using a compression machine (Avery Denison 7227) with a capacity of $2000 \mathrm{KN}$ and a constant loading rate of $45 \mathrm{KN}$ per minute. Three cubic specimens with $50 \mathrm{~mm}$ sides were used to determine compressive strength for each curing age, specifically after 3, 7, 14 and 28 days. Direct tensile strength was also determined to evaluate the effect of silica fume forms and GGBS content on the behaviour of SFRGC 
under tension. An Instron testing machine was used for the direct tensile tests and the tests were performed under displacement control with a rate of $0.4 \mathrm{~mm} / \mathrm{min}$ [44]. For each mixture, twelve 'dog bone' shaped specimens with mid-cross section dimensions of $13 \mathrm{~mm}$ X $50 \mathrm{~mm}$ were cast and cured under ambient temperatures (Fig. 3a). The average extension was measured using Linear Variable displacement Transducers (LVDT) attached to a steel frame, as shown in Fig.3b.

Sample porosity was measured through the vacuum saturation technique, as reported in previous studies $[45,46]$. Porosity tests were carried out on at least two cylindrical samples (20 $\mathrm{mm}$ X $50 \mathrm{~mm}$ ) for each mixture. Specimen microstructure was assessed by SEM. Primary material particles (i.e. FA, silica fume and GGBS) and plain geopolymer and SFRGC samples (taken post-failure from 28 day cured samples used in tensile strength testing) were carbon sputter coated prior to analysis.

\section{Results and discussion.}

\subsection{Fresh characteristics of geopolymer mortar}

Flow tests results are presented in Fig. 4. Based on these results, the workability of the mixes is considerably affected by the geopolymer binder composition (Fig. 4). As the GGBS content is increased from $10 \%$ to $40 \%$, the slump of the geopolymer mortar is reduced from $250 \mathrm{~mm}$ to $175 \mathrm{~mm}$. This reduction in workability is attributed to the enhanced reactivity of the FA - GGBS mix, and in particular the rapid reaction between the geopolymer binder and the alkaline solution (potassium silicate). The incorporation of ultra-fine silica fume (USF and $\mathrm{SSF}$ ) in the mixtures also reduces the workability compared with the respective control geopolymer mixtures (without silica fume). Since very fine silica fume particles have large effective surface area, they rapidly absorb water and thus the workability of the geopolymer mortar is reduced.

It is also evident from the results presented in Fig. 4 that both initial and final setting time are considerably reduced as the GGBS content is increased from $10 \%$ to $40 \%$. This is attributed to the increment in $\mathrm{CaO}$ content, which is the main chemical component of GGBS, and the subsequent acceleration of hydration reactions. The incorporation of silica fume in the mixture also affects both initial and final setting time for all the examined mixtures. The initial and final setting times were reduced when undensified (USF) and slurry silica fume (SSF) were added to the mix (a trend seen most clearly in the lower GGBS content samples). This reduction is related to the finer particle size and higher surface area of the USF and SSF compared to densified silica fume (DSF), which accelerates the geopolymerization process and hardening of the geopolymer mortar.

\subsection{Mechanical Properties}

\subsubsection{Porosity}

The results of the porosity measurements are presented in Fig. 5, and show a clear reduction of porosity values as the GGBS content is increased. The reaction of GGBS with FA causes formation of more hydration products, which leads to a denser matrix. 
The inclusion of silica fume plays an important role in controlling the porosity of geopolymer mortar with low \% GGBS content. The total porosity of geopolymer mortar containing undensified and slurry silica fume particles is considerably lower than the control mixture (without silica fume) for the $10 \mathrm{~S}$ mixture. However, this effect is not observed in mixes with higher GGBS content. The increment of the GGBS content in the geopolymer binder from $10 \%$ to $40 \%$ leads to an improvement of geopolymer matrix reactivity which is sufficient to reduce the effect of inclusion of undensified and slurry silica fumes on the total porosity. As noted above, inclusion of GGBS as highly pozzolanic material increases the geopolymerization products and produces a denser matrix. In contrast, the results clearly indicate that the total porosity of the geopolymer mortar is increased with inclusion of larger particle sizes of silica fume (DSF), for all mixes. The total porosity of the 10 s mixture decreases from $30 \%$ to $23.5 \%$ and $25.31 \%$ with the addition of USF and SSF, while it increases to $31.2 \%$ using DSF. Therefore while the use of undensified and slurry silica tends to reduce porosity, as they compact the matrix by filling pore spaces and improving reactivity and bonding at the geopolymer paste-silica sand interfacial zone [13, 14], densified silica fume (which is much coarser) has a much lower reactivity, negative pore filling effect, and subsequently causes increased porosity.

\subsubsection{Compressive strength test}

The compressive strengths of each plain geopolymer mix with different GGBS replacement content and silica fume forms at 3, 7 and 28 days are shown in Fig. 6, while the respective results for steel fibre reinforced mixes are presented in Fig. 7 and Fig. 8.

The compressive strength of plain geopolymer mortar increased with increasing GGBS content for all mixtures (Fig. 6), at both early and late stage curing. This improvement in strength is due to an increase in calcium content in the mixture, which leads to a compacted microstructure (see also section 3.2.1).

Utilization of densified silica fume negatively affected compressive strength at all curing ages (Fig. 6). Inclusion of Undensified (USF) and slurry (SSF) silica fume however enhanced the compressive strength, by 50\%-74\%, 17.4\%-18.6\%, 66.4\%-50.2\%, and 56.7\%$16.3 \%$ for $10 \mathrm{~S}, 20 \mathrm{~S}, 30 \mathrm{~S}$ and $40 \mathrm{~S}$ mixtures, respectively. This improvement in the compressive strength relates to the fine particle sizes of undensified (USF) and slurry (SSF) silica, with high specific surface area leading to acceleration of the geopolymerization of aluminosilicate gel, which in turn leads to high early strength gain and compacts the matrix structure by filling pore spaces. In contrast, the agglomerated particles of densified (DSF) silica fume have larger size and lower pozzolanic activity, leading to a more porous microstructure (see above) and loss of strength. The dispersion of silica into smaller primary particle sizes or the smallest agglomerates possible is a crucial parameter for further improvement of the compressive strength.

Addition of steel fibres to the geopolymer samples had a clear impact on compressive strength development in the geopolymer (Fig. 7 and Fig. 8). Steel fibre addition reduced the 
compressive strength of the lower strength geopolymer matrix with $10 \%$ and $20 \%$ of GGBS to binder weight ratios. At higher GGBS content however the compressive strength of SFRGC was significantly improved compared to the respective mixes without steel fibres. The low strength values observed for SFRGC mixes with lower GGBS content are apparent from early curing ages onwards, and reflect reduced pozzolanic activity (and reactivity) and lower reaction product formation, which weakens the interfacial bonds between the steel fibre and the geopolymer matrix. The small scatter in the results confirms the uniform dispersion of the steel fibre in the geopolymer mixture.

When considering the effect of silica fume form, the compressive strength of steel fibre reinforced geopolymer composites with incorporated silica fume was equivalent to or higher than the plain geopolymer with the exception of samples with very low GGBS content (10\% GGBS, Fig. 8). Inclusion of silica fume in the SFRGC mixture with $20 \%$ GGBS content increased the compressive strength by $18 \%, 9 \%$ and $5 \%$ for DSF, USF and SSF, respectively. However, the compressive strength is reduced by $8 \%$ for the $20 \%$ GGBS mixture without silica fume. At high GGBS content, the compressive strength of the steel fibre reinforced geopolymer composite with USF showed the highest recorded strength value at around $63 \mathrm{MPa}(40 \%$ GGBS mixture), and SFRGC samples containing USF showed the largest and most consistent increase in compressive strength over the control SFRGC (i.e. without added silica fume).

\subsubsection{Direct tensile test}

The tensile stress-strain behaviours for the plain and steel fibre reinforced geopolymer composite mixtures with varying GGBS contents are shown in Fig. 9 and Fig.10.

Based on the observed stress-strain relationships, the geopolymer binder composition and the addition of steel fibre significantly affects the tensile behaviour of the samples. The geopolymer binder composition (GGBS content) impacts on the precracking behaviour (elastic) part of the graphs and the extent to which this ensures effective transfer of stress to the fibres. The linear part is followed by the non-linear plastic state which is a function of the postcrack behaviour at the steel fibre and geopolymer matrix interface. The geopolymer concrete reaches the peak load through non-linear strain-hardening followed by strain softening once micro-cracking increases. The addition of steel fibres in the geopolymer composite considerably improves the post-crack load carrying capacity due to the reinforcing effect of the steel fibres in all examined mixtures which leads to change in the failure mode from fragile (i.e. sudden failure) to ductile failure, due to the bridging effect of the fibres and reduced crack coalescence.

The results show that the peak stress and post crack behaviour of SFRGC mixtures with low GGBS content were poor due to weak bonding between the low strength geopolymer matrix and the steel fibres. However, as GGBS content was increased in all the examined mixtures, the post crack carrying capacity was improved (Fig. 10). This is due to higher GGBS content increasing reaction products such as CSH, CASH and NASH [1], which in turn strengthens the interfacial transition zone with the steel fibres within the geopolymer matrix. 
In order to evaluate the effect of silica fume particle size distribution on the tensile performance of steel fibre reinforced geopolymer, stress strain results of the examined mixtures with different silica fume forms for all GGBS contents are presented in Fig.11.

Incorporation of silica fume improves the load carrying capacity, although this effect is most marked in samples with lower GGBS content (10\% and 20\%) (See Fig. 11 a and b). This is due to replacement of relatively low reactivity material (FA) by highly pozzolanic material (silica fume) in the binder which accelerates the geopolymerization process, and enhances the bond between the matrix and the steel fibres, increasing the energy requirements for the fracture process. This improvement is less marked at higher GGBS contents, where increased GGBS amounts act to enhance the pozzolanic activity and reactivity, reducing the impact of silica fume addition. The influence of silica fume depends on particle size, and the finer silica fume (USF) is more capable of filling pores and producing a more dense geopolymer matrix. However, the ultra fine silica (SSF) has lower tensile strength than USF, possibly due to accelerated agglomeration of this very reactive material during the mechanical mixing of the initial material.

The effect of curing age was also investigated in order to evaluate the evolution of tensile strength and stress-strain behaviour of SFRGC mixtures under ambient temperature curing (Listed in Table 5 and Fig. 12).

The results indicate that curing time plays a major role in the strength development of steel fibre reinforced geopolymer concrete cured under ambient temperature. The data in Table 5 indicate that increasing the curing time gives higher strength compared to the respective values at early age for all geopolymer mixtures (see Fig. 12 for all GGBS content mixtures of SFRGC with USF as an example). The tensile strengths for samples cured under ambient temperature at the age of 3days for $10 \mathrm{~S}, 20 \mathrm{~S}, 30 \mathrm{~S}$ and $40 \mathrm{~S}$ mixes were $0.2 \mathrm{MPa}, 0.3 \mathrm{MPa}, 0.54$ $\mathrm{MPa}$ and $0.96 \mathrm{MPa}$, respectively. For a curing duration of 7 days, the strengths were $0.3 \mathrm{MPa}$, $0.6 \mathrm{MPa}, 0.58 \mathrm{MPa}$ and $1.35 \mathrm{MPa}$ and for a curing duration of 28 days, the strengths were $0.6 \mathrm{MPa}, 1.36 \mathrm{MPa}, 2 \mathrm{MPa}$ and $2.8 \mathrm{MPa}$ respectively. Fig. 12 indicates that curing time also significantly effects the stress-strain relationships of SFRGC. At early ages, the stress-strain relationship of SFRGC mixtures with low GGBS content is lower than the stress-strain relationship for high GGBS content mixtures. However, at later curing ages the stress-strain behaviour improved for all examined mixtures. The mixtures with high percentages of low pozzolanic reactive (FA) material require more time in order to produce more geopolymerization products, increase the compressive strength of the geopolymer matrix, and improve the bond between the steel fibre and geopolymer matrix.

\subsubsection{Tensile stress-strain characteristics of SFRGC with varying slag content and silica fume forms.}

In the tensile stress-strain model, the main parameters are the tensile strength, the modulus of elasticity, fracture energy, and the shape of stress-strain curve. To examine the effect of geopolymer binder composition on the tensile performance of SFRGC specimens more fully, 
the experimental tensile response could be fitted quite accurately to a bi-linear curve showing an initial cracking point and ultimate strength point. It has been suggested that the bi-linear relationship is a sufficient approximation to determine the most important stress-strain parameters for practical engineering applications [47], which reflect the mechanism of the interaction between the varying composition geopolymer matrix and the steel fibres (showing the initial cracking point with matrix cracking, and maximum loading point with slip of fibres) (Fig. 13).

The points defined in Fig. 13 are determined from the experimental tensile stress strain results at first cracking and at ultimate flexural tensile strength, where $\sigma_{1}, \sigma_{2}$ and $\mathrm{E}$ are the first crack and ultimate tensile strength and modulus of elasticity of fibre reinforced geopolymer concrete (in $\mathrm{MPa}$ ), respectively, and $\varepsilon_{1}$ and $\varepsilon_{2}$ represent the strain at first crack and ultimate stress.

The tensile response of SFRGC should exhibit linear elasticity up to the first cracking point, followed by nonlinear behaviour up to the maximum post cracking stress (Fig. 13). Two stages of steel fibre response before destruction under tension loading are defined, the first stage representing the stress distribution during the elastic range before first cracking $E$, and the second stage corresponding to the post-cracking modulus $E_{c r}$. These parameters were calculated from the stress-strain curves (Fig. 10 and Fig. 11) and the results are presented in Table 6, Fig. 14 and Fig. 15.

As can be seen from these results, the Young's modulus of elasticity significantly changes with the binary and ternary binder composition of the geopolymer mixture. As slag content increases in the geopolymer mixture, the first cracking modulus of SFRGC mixtures also increases. The first cracking modulus of SFRGC mixtures increased by $120 \%, 300 \%$, and $500 \%$ for 20S-ST, 30S-ST, 40S-ST mixtures, respectively, compared with the elastic modulus of the respective 10S-ST mixture (Table 6 and Fig. 16). Similarly, the results indicated that the post cracking modulus strength significantly increased with increasing slag content in the geopolymer mixture. The post cracking modulus increased from $140 \mathrm{MPa}$ for 10S-ST mixture to $200 \mathrm{MPa}, 350 \mathrm{MPa}$, and $1000 \mathrm{MPa}$ for 20S-ST, 30S-ST, and 40S-ST mixtures, respectively (Table 6). This increment in the first cracking and post cracking modulus with slag content in the SFRGC mixtures shows development of strain hardening behaviour under tension. This trend is confirmed by the post cracking tensile strain, which increased from 0.0013 to 0.0027 by increasing slag content in the geopolymer mixture from $10 \%$ to $40 \%$. This increment in the first cracking and post cracking modulus is due to the strength improvement of the geopolymer matrix with higher slag content, leading to an enhanced interfacial bond between the steel fibre and the geopolymer matrix.

Inclusion of silica fume in the geopolymer matrix composition also effects the linear stage of the stress strain curve: the first cracking modulus of the 10S-ST mixture increased by $11 \%, 50 \%$ and $100 \%$ with utilization of DSF, USF and SSF, respectively (Fig. 16). However this trend is not apparent at higher slag contents, as inclusion of SSF in the mixture reduced the elastic modulus, and USF incorporation tended to result in the most consistent improvement in elastic modulus values. The modulus of elasticity of the 30S-ST mixture increased from 8000 $\mathrm{MPa}$ to $8500 \mathrm{MPa}, 10625 \mathrm{MPa}$, and $7500 \mathrm{MPa}$ for ternary SFRGC mixtures containing DSF, USF, and SSF, respectively (Fig. 16). Moreover, the post cracking strain capacity improved in the 30S-ST mixture from 0.0016 to 0.002 and 0.0025 for 10DSF, and 10USF, respectively 
(Table 6). The highest values of first and post cracking modulus of elasticity in SFRGC were found for the 40S-10USF-ST mixture, at $15400 \mathrm{MPa}$ and $1125 \mathrm{MPa}$, respectively.

Based on the data listed in Table 6, the post cracking tensile strength increased with increasing slag content. From these results, the average tensile strength was increased by $100 \%$, $250 \%$ and $340 \%$ for $20 \mathrm{~S}-\mathrm{ST}$, 30S-ST and 40S-ST mixtures, respectively, compared with the respective value for the 10S-ST mixture. Combining slag with silica fume had differing effects on the tensile behaviour of SFRGC depending on the silica fume particle size distribution and slag content. The tensile strengths of $20 \%$ and $40 \%$ slag mixtures with $0 \%$ SF, $10 \%$ DSF, $10 \%$ USF and 5\% SSF were 1.36 MPa, 1.46 MPa, 2.4 MPa, 1.6 MPa and 2.8 MPa, 2.8 MPa, 3.1 $\mathrm{MPa}, 2.3 \mathrm{MPa}$, respectively. Steel fibre reinforced geopolymer composites incorporating undensified silica fume showed the highest post cracking tensile strength for all slag content mixtures.

The energy absorption capacity represents the area under the stress-strain curve of the SFRGC up to $2 \%$ strain capacity after appearance of cracking (Fig. 17). The results indicate that increasing the percentage of slag content in the geopolymer matrix generally increases the energy absorption capacity. In addition, the inclusion of different silica fume forms influences the energy absorption capacity, with the sample containing undensified silica fume giving the highest energy absorption, at $40 \%$ slag content. The results also show that inclusion of slurry silica fume in the $10 \%$ slag content mixture gave markedly superior energy absorption capacity than other forms of silica at this low slag content. This behaviour may be a result of the impact of fine-grained SSF on pozzolanic activity, enhancing the bond between the matrix and the steel fibres at lower slag contents. Despite this, Figs. 14, 16 and 17 and other tensile testing data (e.g. Fig.11, Table 5 and related discussion) indicate that USF incorporation overall tends to produce materials with the most improved tensile performance.

\subsection{Scanning electronic microscopy (SEM)}

Scanning electronic microscopy imaging was carried out to examine the microscopic characteristics of the geopolymer binder materials, and the effect of GGBS content and silica fume forms on the microstructure of the geopolymer samples. SEM imaging of the primary materials (Fig. 18) showed that FA and silica fume particles generally consist of spherical and near-spherical primary particles (Fig.18a and 18c); larger agglomerates of silica fume particles are formed in densified silica fume (Fig.18d) while GGBS (Fig.18b) consists dominantly of mixed size angular particles.

To evaluate the effect of GGBS content on sample microstructure, two geopolymer mortars with $10 \%$ and $40 \%$ slag replacement content were examined after 28 -days curing under ambient temperature (Fig. 19).

Fig. 19 shows the area on a surface of $10 \mathrm{~S}$ and $40 \mathrm{~S}$ mixtures at various magnifications (x10000 and x20000). A high number of remaining FA particles, which were only partially reacted, and agglomerated slag particles were detected in the case of the 10S mix (Fig. 19a). This is attributed to the low pozzolanic reactivity of FA with low slag content cured under ambient temperature. At higher magnification, the geopolymer sample with high slag content (40S mixture) (Fig.19 (c and d)) shows different microstructures, which form a denser matrix 
than the 10S mixture. Glassy crusts covering FA particles can be observed, as a result of reactions on the surface of the particles (Fig.19d). As the percentage of GGBS is increased a higher calcium content in the mix is produced, and subsequently a calcium alumino-silicate hydrate $(\mathrm{C}-\mathrm{A}-\mathrm{S}-\mathrm{H})$ gel is created.

In order to compare the microstructures of geopolymer mortars with different incorporated silica fume forms, four geopolymer mortar mixtures were prepared by replacing FA with $10 \%$ DSF, $10 \%$ USF and 5\% SSF. These were imaged with a control mortar mixture with $10 \%$ Slag (without silica fume, Fig. 20).

Inclusion of silica fume had varying effects on sample microstructure. The texture of the hydration products of the geopolymer mortar with DSF was visibly different from samples with USF and SSF. For 10\%DSF (Fig. 20a) the observed SEM image shows no significant difference from the control mix at x10000 magnification (Fig. 20a), as the large densified silica fume particles cause lower packing and lower the pozzolanic activity of the silica fume. At higher magnification (x20000), the micrographs show that the geopolymerization products of the mixtures containing smaller particle sizes of silica fume (for undensified $(37 \mu \mathrm{m})$ and slurry silica (200nm)) consisted of well-connected structures, and compacted formations of hydration products were observed. In addition to acting as a physical filler in the matrix structure, silica fume acts as a source of high (85\%-95\%) reactive silica content leading to formation of more calcium alumino-silicate hydrate $(\mathrm{C}-\mathrm{S}-\mathrm{A}-\mathrm{H})$ gels which co-exist with sodium alumina-silicate hydrate (N-A-S-H) [48]. This is also indicated by quantitative porosity results, as total porosity of the $10 \%$ slag replacement mixture considerably reduced from 30 to $23-25 \%$ by inclusion of USF and SSF. These reductions in total porosity indicate an increase in the matrix density, and also improve the compressive strength of the geopolymer mortar.

SEM imaging of the steel fibre-geopolymer matrix interface and fibre surface texture were also conducted in order to assess the effect of the SFRGC microstructural characteristics on mechanical performance. SEM images of steel fibre reinforced geopolymer for 10S-10USF2ST, 40S-10DSF-2ST and 40S-10USF-2ST mixtures are shown in Fig. 21. These samples were taken from specimens which had failed during tensile testing, and were collected from regions of the specimens adjacent to failure planes.

As can be observed from Fig. 21, the steel fibre surface is considerably effected by the geopolymer matrix composition. Increasing the slag content and inclusion of silica fume leads to enhanced interfacial properties. A relatively smooth steel fibre surface is seen in the geopolymer mixture containing 10\% slag content (Fig. 21a). Conversely the high slag (40\%) content samples show the steel fibre surface covered with geopolymer matrix (Fig. 21b). In addition, the inclusion of different forms of silica fume in the geopolymer composite effects the steel fibre-matrix contact, which is evidenced by the presence of more hydration production on the steel surface in the case of USF geopolymer mixtures (Fig. 21c). These hydration products create a stronger bond at the interface between the matrix and the steel fibres, and resist pull-out failure of the examined specimens, which leads to an increase in the ultimate load and increases sample ductility by improving the carrying capacity in the post cracking stage. These enhanced interfacial properties have a direct effect on the tensile strength characteristics, in agreement with the mechanical testing results presented in Section 3.2. 


\section{Conclusions}

Novel cement-free geopolymer composites, reinforced with steel fibres and cured under ambient temperatures, have been developed in this study. The present study investigated the fresh, hardened and microstructural properties of plain geopolymer mortar and SFRGC, using a ternary geopolymer blend. Thirty two geopolymer mixtures were used to examine the effect of (a) varying slag contents, and (b) varying silica fume forms on engineering performance. The following conclusions can be drawn from the results presented in this paper:

\subsection{Fresh geopolymer mortar characteristics.}

1. Increasing the slag content in the FA and slag based geopolymer mortar decreases the workability and accelerates the setting times (initial and final) and mortar hardening.

2. The inclusion of silica fume in the geopolymer mortar has various effects on the flow characteristics of FA and slag based geopolymer mortar. In the case of undensified and slurry silica, the workability and setting time were considerably reduced. This is attributed to the instantaneous interactions between the very fine silica particles and the alkaline solution, and the formation of a gel characterised by high water retention capacities. The addition of densified silica fume did not significantly affect workability.

\subsection{Hardened geopolymer mortar and SFRGC characteristics.}

1. The compressive strength of plain geopolymer mortar and SFRGC was increased as the slag content was increased and with the age of the specimens.

2. Ternary geopolymer mixtures based on combined use of silica fume, GGBS and FA show a notable improvement in the rate of strength development of plain and SFRGC over control binary mixtures containing GGBS and FA.

3. Utilisation of USF and SSF considerably improved the compressive strength of plain geopolymer and SFRGC. However, DSF showed less effect or lower compressive strength than control binary GGBS and FA mixtures. Moreover, these effects are more pronounced at lower slag content rather than at higher slag content.

4. The Young's modulus and ultimate tensile strength improved with increasing slag content in the SFRGC mixtures. Moreover, the inclusion of USF and SSF improved the tensile strength of SFRGC, with the 40S-USF mixture showing the highest tensile strength value of around 3.1 MPa.

5. Post cracking behaviour and energy absorption capacity was considerably improved by increasing the slag content and inclusion of fine particle sizes of silica fume (USF).

6. Overall, increasing the curing time considerably improved the compressive, tensile and post cracking behaviour of SFRGC cured under ambient temperature.

\subsection{Microstructural properties.}

1. Microstructural observation by SEM and porosity results confirm that the incorporation of slag and silica fume as a partial FA replacement in geopolymer 
mortars densified the microstructure, leading to an improvement in mechanical strength.

2. A relatively good bond between the matrix and the steel fibres was also evidenced by the presence of geopolymer hydration products on the surface of the steel fibres in specimens with high slag content and USF.

The findings of the current research show that use of binary geopolymer mixes (FA and GGBS) improved both the mechanical strength and the microstructure of geopolymer materials. Moreover, higher strength with a more compacted microstructure was achieved by utilizing silica fume in a ternary geopolymer blend, in the absence of heat curing treatment, which makes the proposed method potentially suitable for in situ applications. Further studies should investigate the effect of silica fume forms on the rate of strength development at late states of the geopolymerization process, and also the potential role of ultra-fine silica fume in increasing chloride resistance and improving material durability._It is noted that various fibre types could be utilized to generate strain hardening cementitious materials [36, 49]. However, due to the large number of geopolymer matrix composition mixtures assessed in this study, the discussion here is limited to ( $2 \%$ volume fraction) steel fibres. Further investigations on sustainable strain hardening geopolymer concretes could usefully assess the performance enhancements given by alternative fibres, such as glass fibre, Polyvinyl Alcohol (PVA) fibre, and Carbon fibre.

\section{Acknowledgments}

The Iraqi Ministry of Higher Education and Scientific Research is gratefully acknowledged by the lead author for the financial support provided for this study which is part of a PhD Scholarship.

\section{References}

[1] M. H. Al-Majidi, A. Lampropoulos, A. Cundy, and S. Meikle, "Development of geopolymer mortar under ambient temperature for in situ applications," Construction and Building Materials, vol. 120, pp. 198-211, 2016.

[2] F.-Q. Zhao, W. Ni, H.-J. Wang, and H.-J. Liu, "Activated fly ash/slag blended cement," Resources, Conservation and Recycling, vol. 52, pp. 303-313, 12// 2007.

[3] I. Ismail, S. A. Bernal, J. L. Provis, R. San Nicolas, D. G. Brice, A. R. Kilcullen, et al., "Influence of fly ash on the water and chloride permeability of alkali-activated slag mortars and concretes," Construction and Building Materials, vol. 48, pp. 1187-1201, 11// 2013.

[4] P. S. Deb, P. Nath, and P. K. Sarker, "The effects of ground granulated blast-furnace slag blending with fly ash and activator content on the workability and strength properties of geopolymer concrete cured at ambient temperature," Materials \& Design, vol. 62, pp. 32-39, 10// 2014.

[5] G. Görhan and G. Kürklü, "The influence of the $\mathrm{NaOH}$ solution on the properties of the fly ash-based geopolymer mortar cured at different temperatures," Composites Part B: Engineering, vol. 58, pp. 371-377, 3// 2014. 
[6] P. Nath and P. K. Sarker, "Effect of GGBFS on setting, workability and early strength properties of fly ash geopolymer concrete cured in ambient condition," Construction and Building Materials, vol. 66, pp. 163-171, 9/15/ 2014.

[7] D. Adak, M. Sarkar, and S. Mandal, "Effect of nano-silica on strength and durability of fly ash based geopolymer mortar," Construction and Building Materials, vol. 70, pp. 453-459, $11 / 15 / 2014$

[8] M. H. Al-Majidi, A. Lampropoulos, and A. Cundy, "Effect of Alkaline Activator, Water, Superplasticiser and Slag Contents on the Compressive Strength and Workability of Slag-Fly Ash Based Geopolymer Mortar Cured under Ambient Temperature," International Journal of Civil, Environmental, Structural, Construction and Architectural Engineering, vol. 10, pp. 308312, 2016.

[9] S. Riahi and A. Nazari, "The effects of nanoparticles on early age compressive strength of ash-based geopolymers," Ceramics International, vol. 38, pp. 4467-4476, 8// 2012.

[10] M. Chi and R. Huang, "Binding mechanism and properties of alkali-activated fly ash/slag mortars," Construction and Building Materials, vol. 40, pp. 291-298, 2013.

[11] M. Olivia and H. Nikraz, "Properties of fly ash geopolymer concrete designed by Taguchi method," Materials \& Design, vol. 36, pp. 191-198, 2012.

[12] M. H. Al-Majidi, A. Lampropoulos, and A. Cundy, "Experimental investigation of the effect of silica fume on geopolymer mortar cured under ambient temperature," in Rheological Measurement of Building Materials 2016, Regensburg, Germany, 2016.

[13] S. Ivorra, P. Garcés, G. Catalá, L. G. Andión, and E. Zornoza, "Effect of silica fume particle size on mechanical properties of short carbon fiber reinforced concrete," Materials \& Design, vol. 31, pp. 1553-1558, 3// 2010.

[14] E. Güneyisi, M. Gesoğlu, S. Karaoğlu, and K. Mermerdaş, "Strength, permeability and shrinkage cracking of silica fume and metakaolin concretes," Construction and Building Materials, vol. 34, pp. 120-130, 9// 2012.

[15] F. Köksal, F. Altun, i. Yiğit, and Y. Şahin, "Combined effect of silica fume and steel fiber on the mechanical properties of high strength concretes," Construction and Building Materials, vol. 22, pp. 1874-1880, 8// 2008.

[16] N. K. Lee and H. K. Lee, "Setting and mechanical properties of alkali-activated fly ash/slag concrete manufactured at room temperature," Construction and Building Materials, vol. 47, pp. 1201-1209, 10// 2013.

[17] K. Somna, C. Jaturapitakkul, P. Kajitvichyanukul, and P. Chindaprasirt, "NaOH-activated ground fly ash geopolymer cured at ambient temperature," Fuel, vol. 90, pp. 2118-2124, 6// 2011.

[18] T. Bakharev, "Geopolymeric materials prepared using Class F fly ash and elevated temperature curing," Cement and Concrete Research, vol. 35, pp. 1224-1232, 6// 2005.

[19] D. a. R. Hardjito, B. V., 2005. "Development and Properties of Low Calcium Fly, R. R. G. Ash Based Geopolymer Concrete", Curtin University of Technology,, and A. Perth, 93 pp., "Development and Properties of Low Calcium Fly Ash Based Geopolymer Concrete," Curtin University of Technology, Perth, Australia2005.

[20] Z. Yunsheng, S. Wei, C. Qianli, and C. Lin, "Synthesis and heavy metal immobilization behaviors of slag based geopolymer," J Hazard Mater, vol. 143, pp. 206-13, May 082007.

[21] A. Palomo, M. W. Grutzeck, and M. T. Blanco, "Alkali-activated fly ashes: a cement for the future," Cement and concrete research, pp. 1323-1329, 29.8.1999 1999.

[22] R. H. Kupaei, U. J. Alengaram, and M. Z. Jumaat, "The effect of different parameters on the development of compressive strength of oil palm shell geopolymer concrete," ScientificWorldJournal, vol. 2014, p. 898536, 2014.

[23] B. C. McLellan, R. P. Williams, J. Lay, A. van Riessen, and G. D. Corder, "Costs and carbon emissions for geopolymer pastes in comparison to ordinary portland cement," Journal of Cleaner Production, vol. 19, pp. 1080-1090, 2011. 
[24] M. L. M. Michael A. Nisbet, and Martha G. VanGeem, Environmental Life Cycle Inventory of Portland Cement Concrete: Portland Cement Association 2002.

[25] V. Afroughsabet and T. Ozbakkaloglu, "Mechanical and durability properties of high-strength concrete containing steel and polypropylene fibers," Construction and Building Materials, vol. 94, pp. 73-82, 9/30/ 2015.

[26] D. j. Kim, A. E. Naaman, and S. El-Tawil, "Comparative flexural behavior of four fiber reinforced cementitious composites," Cement and Concrete Composites, vol. 30, pp. 917928, 2008.

[27] M. N. Soutsos, T. T. Le, and A. P. Lampropoulos, "Flexural performance of fibre reinforced concrete made with steel and synthetic fibres," Construction and Building Materials, vol. 36, pp. 704-710, 11// 2012.

[28] B. Nematollahi, J. Sanjayan, and F. U. Ahmed Shaikh, "Tensile Strain Hardening Behavior of PVA Fiber-Reinforced Engineered Geopolymer Composite," Journal of Materials in Civil Engineering, vol. 27, p. 04015001, 2015.

[29] N. Ganesan, R. Abraham, and S. Deepa Raj, "Durability characteristics of steel fibre reinforced geopolymer concrete," Construction and Building Materials, vol. 93, pp. 471-476, 9/15/ 2015.

[30] T. Alomayri and I. M. Low, "Synthesis and characterization of mechanical properties in cotton fiber-reinforced geopolymer composites," Journal of Asian Ceramic Societies, vol. 1, pp. 30-34, 3// 2013.

[31] I. I. Bashar, U. J. Alengaram, M. Z. Jumaat, A. Islam, H. Santhi, and A. Sharmin, "Engineering properties and fracture behaviour of high volume palm oil fuel ash based fibre reinforced geopolymer concrete," Construction and Building Materials, vol. 111, pp. 286-297, 2016.

[32] S. Aydın and B. Baradan, "The effect of fiber properties on high performance alkali-activated slag/silica fume mortars," Composites Part B: Engineering, vol. 45, pp. 63-69, 2// 2013.

[33] S. Bernal, R. De Gutierrez, S. Delvasto, and E. Rodriguez, "Performance of an alkali-activated slag concrete reinforced with steel fibers," Construction and Building Materials, vol. 24, pp. 208-214, 2// 2010.

[34] A. Natali, S. Manzi, and M. C. Bignozzi, "Novel fiber-reinforced composite materials based on sustainable geopolymer matrix," Procedia Engineering, vol. 21, pp. 1124-1131, // 2011.

[35] F. Puertas, T. Amat, A. Fernández-Jiménez, and T. Vázquez, "Mechanical and durable behaviour of alkaline cement mortars reinforced with polypropylene fibres," Cement and Concrete Research, vol. 33, pp. 2031-2036, 12// 2003.

[36] F. U. A. Shaikh, "Deflection hardening behaviour of short fibre reinforced fly ash based geopolymer composites," Materials \& Design, vol. 50, pp. 674-682, 9// 2013.

[37] S. W. Zhang Y, Li Z, Zhou X. , "Geopolymer extruded composites with incorporated fly ash and polyvinyl alcohol," ACl material journal, vol. 106, pp. 3-10, 2009.

[38] F. U. A. Shaikh, "Review of mechanical properties of short fibre reinforced geopolymer composites," Construction and Building Materials, vol. 43, pp. 37-49, 6// 2013.

[39] B. E. 450-1, "BS EN 450-1: Fly ash for concrete. Definition, specifications and conformity criteria,31 August 2012.," ed.

[40] J. Davidovits, M.Izquierdo, X.Querol, D. Antennuci, H. Nugteren, V. Butselaar-Orthlieb, et al., "The European Research Project GEOASH: Geopolymer Cement Based On European Coal Fly Ashes, Technical Paper \#22," Geopolymer Institute Library, 2014.

[41] B. E. 480-2, "Admixtures for concrete, mortar and grout. Test methods.," in Determination of setting time., ed, 2006.

[42] "ASTM C230. Standard specification for flow table for use in tests of hydraulic cement, West Conshohocken (PA): ASTM International; 2002.," ed.

[43] "ASTM C109/C109M. Standard test method for compressive strength of hydraulic cement mortars (using 50 mm [2 in.] cube specimens). United States: ASTM Standards; 2007.," ed. 
[44] A. M. T. Hassan, S. W. Jones, and G. H. Mahmud, "Experimental test methods to determine the uniaxial tensile and compressive behaviour of ultra high performance fibre reinforced concrete (UHPFRC)," Construction and Building Materials, vol. 37, pp. 874-882, 2012.

[45] T. Gonen and S. Yazicioglu, "The influence of compaction pores on sorptivity and carbonation of concrete," Construction and Building Materials, vol. 21, pp. 1040-1045, 5// 2007.

[46] O. Keleştemur and B. Demirel, "Corrosion behavior of reinforcing steel embedded in concrete produced with finely ground pumice and silica fume," Construction and Building Materials, vol. 24, pp. 1898-1905, 10// 2010.

[47] B. Cotterell and Y. W. Mai, Fracture Mechanics of Cementitious Materials: Taylor \& Francis, 1995.

[48] R. Siddique, "Utilization of silica fume in concrete: Review of hardened properties," Resources, Conservation and Recycling, vol. 55, pp. 923-932, 9// 2011.

[49] W.-C. Choi, H.-D. Yun, J.-W. Kang, and S.-W. Kim, "Development of recycled strain-hardening cement-based composite (SHCC) for sustainable infrastructures," Composites Part B: Engineering, vol. 43, pp. 627-635, 2012. 


\section{List of Tables}

Table 1: Properties of steel fibre

\begin{tabular}{|c|c|c|c|c|c|c|}
\hline $\begin{array}{c}\text { Length } \\
\left(L_{f}\right) \\
(\mathrm{mm})\end{array}$ & $\begin{array}{c}\text { Diameter } \\
\left(d_{f}\right) \\
(\mathrm{mm})\end{array}$ & $\begin{array}{l}\text { Aspect } \\
\text { ratio } \\
\left(L_{f} / d_{f}\right)\end{array}$ & $\begin{array}{l}\text { Density } \\
\left(\mathrm{g} / \mathrm{cm}^{3}\right)\end{array}$ & $\begin{array}{r}\text { Tensile } \\
\text { strength } \\
f_{t}(M P a)\end{array}$ & $\begin{array}{c}\text { Elastic } \\
\text { modulus } \\
E_{s}(\mathrm{GPa})\end{array}$ & Image \\
\hline 13 & 0.16 & 81.25 & 7.9 & 2500 & 200 & \\
\hline
\end{tabular}

Table 2: Bulk density of silica fume types (as received from the manufacturer)

\begin{tabular}{cc}
\hline & Bulk density $\left(\mathrm{kg} / \mathrm{m}^{3}\right)$ \\
\hline Undensified silica (USF) & $130-430$ \\
Slurry silica (SSF) & $1320-1440$ \\
Densified silica (DSF) & $480-720$ \\
Surface area (BET) $\left(\mathrm{m}^{2} / \mathrm{kg}\right)$ & $13,000-30,000$ \\
Specific gravity & 2.22 \\
\hline
\end{tabular}

Table 3: Particle size analysis data for densified silica fume (DSF), undensified silica fume (USF) and slurry silica (SSF).

\begin{tabular}{cccc}
\hline Particle Size $(\mu \mathrm{m})$ & DSF & USF & SSF \\
\hline $\mathrm{d}(0.1)$ & 36.4 & 4.3 & 0.1 \\
$\mathrm{~d}(0.5)$ & 203.6 & 37.1 & 0.3 \\
$\mathrm{~d}(0.9)$ & 428.8 & 126.7 & 1.5 \\
\hline
\end{tabular}


Table 4. Mixture proportioning of the plain geopolymer mortar and SFRGC used in the present study. See text for discussion of mixture ID notation.

\begin{tabular}{ccccccc}
\hline Mixture ID & $\begin{array}{c}\text { Slag } \\
(\%)\end{array}$ & $\begin{array}{c}\text { Silica fume } \\
\text { type }\end{array}$ & $\begin{array}{c}\text { Slag } \\
(\mathrm{kg} / \mathrm{m} 3)\end{array}$ & $\begin{array}{c}\text { Silica } \\
\text { fume } \\
\left(\mathrm{kg} / \mathrm{m}^{3}\right)\end{array}$ & $\begin{array}{c}\text { Fly Ash } \\
\left(\mathrm{Kg} / \mathrm{m}^{3}\right)\end{array}$ & $\begin{array}{c}\text { Steel Fibre } \\
\left(\mathrm{V}_{\mathrm{f}}\right)\end{array}$ \\
\hline 10S/10S-ST & & -- & 78 & 0 & 698 & $0 / 2 \%$ \\
10S-10DSF/10S-10DSF-ST & $10 \%$ & densified & 78 & 78 & 620 & $0 / 2 \%$ \\
10S-10USF/ 10S-10USF-ST & & undensified & 78 & 78 & 620 & $0 / 2 \%$ \\
10S-5SSF/ 10S-10SSF-ST & & slurry & 78 & 39 & 659 & $0 / 2 \%$ \\
20S/20S-ST & & -- & 155 & 0 & 620 & $0 / 2 \%$ \\
20S-10DSF/20S-10DSF-ST & \multirow{2}{*}{$20 \%$} & densified & 155 & 78 & 543 & $0 / 2 \%$ \\
20S-10USF/ 20S-10USF-ST & & undensified & 155 & 78 & 543 & $0 / 2 \%$ \\
20S-5SSF/ 20S-10SSF-ST & & slurry & 155 & 39 & 581 & $0 / 2 \%$ \\
30S/30S-ST & & -- & 233 & 0 & 543 & $0 / 2 \%$ \\
30S-10DSF/30S-10DSF-ST & \multirow{2}{*}{$30 \%$} & densified & 233 & 78 & 465 & $0 / 2 \%$ \\
30S-10USF/ 30S-10USF-ST & & undensified & 233 & 78 & 465 & $0 / 2 \%$ \\
30S-5SSF/ 30S-10SSF-ST & & slurry & 233 & 39 & 504 & $0 / 2 \%$ \\
40S/40S-ST & & -- & 310 & 0 & 465 & $0 / 2 \%$ \\
40S-10DSF/40S-10DSF-ST & \multirow{2}{*}{$40 \%$} & densified & 310 & 78 & 388 & $0 / 2 \%$ \\
40S-10USF/ 40S-10USF-ST & & undensified & 310 & 78 & 388 & $0 / 2 \%$ \\
40S-5SSF/ 40S-10SSF-ST & & slurry & 310 & 39 & 426 & $0 / 2 \%$ \\
\hline
\end{tabular}

Table 5: Tensile Strength of steel fibre reinforced geopolymer concrete over curing age

\begin{tabular}{|c|c|c|c|c|}
\hline \multirow[t]{2}{*}{ Mix No. } & \multicolumn{4}{|c|}{ Tensile Strength (MPa) } \\
\hline & 3days & 7days & 14days & 28days \\
\hline 10S-ST & 0.22 & 0.30 & 0.54 & 0.60 \\
\hline 10S-10DSF-ST & $\mathrm{nm}$ & $\mathrm{nm}$ & 0.65 & 0.96 \\
\hline 10S-10USF-ST & 0.36 & 0.41 & 1.15 & 2 \\
\hline 10S-10SSF-ST & 0.42 & 1.92 & 2.14 & 2.22 \\
\hline 20S-ST & 0.33 & 0.61 & 0.69 & 1.36 \\
\hline 20S-10DSF-ST & $\mathrm{nm}$ & 0.27 & $\mathrm{~nm}$ & 1.46 \\
\hline 20S-10USF-ST & 0.59 & 0.94 & 1.32 & 2.39 \\
\hline 20S-10SSF-ST & 0.25 & 0.51 & 0.65 & 1.60 \\
\hline 30S-ST & 0.54 & 0.58 & 1.64 & 2 \\
\hline 30S-10DSF-ST & 0.34 & 1.05 & NA & 2.20 \\
\hline 30S-10USF-ST & 0.589 & 1.33 & 1.75 & 2.60 \\
\hline 30S-10SSF-ST & 0.51 & 0.81 & 1.12 & 1.40 \\
\hline 40S-ST & 0.96 & 1.35 & $\mathrm{~nm}$ & 2.80 \\
\hline 40S-10DSF-ST & 0.424 & 1.406 & 1.70 & 2.80 \\
\hline 40S-10USF-ST & 1.10 & 1.43 & 2 & 3.10 \\
\hline 40S-10SSF-ST & 1.30 & 1.60 & 1.67 & 2.30 \\
\hline
\end{tabular}

*nm; not measured, due to failure to test in target date 
Table 6: Tensile test results

\begin{tabular}{cccccc}
\hline Mix ID & $\begin{array}{c}\text { First cracking } \\
\text { strength (MPa) }\end{array}$ & $\begin{array}{c}\text { Post cracking } \\
\text { strength (MPa) }\end{array}$ & $\begin{array}{c}\text { Tensile strain } \\
\text { capacity }\end{array}$ & $\begin{array}{c}\text { First cracking } \\
\text { modulus } \\
E(\mathrm{MPa})\end{array}$ & $\begin{array}{c}\text { Post-cracking } \\
\text { modulus } E_{c r} \\
(\mathrm{MPa})\end{array}$ \\
\hline 10S-ST & 0.45 & 0.6 & 0.0013 & 2045 & 140 \\
10S-10DSF-ST & 0.8 & 0.96 & 0.0012 & 4000 & 160 \\
10S-10USF-ST & 1.6 & 2 & 0.0018 & 4000 & 290 \\
10S-5SSF-ST & 1.87 & 2.22 & 0.002 & 2600 & 185 \\
20S-ST & 0.75 & 1.36 & 0.002 & 4400 & 200 \\
20S-10DSF-ST & 1 & 1.46 & 0.0014 & 5500 & 300 \\
20S-10USF-ST & 1.75 & 2.4 & 0.002 & 8400 & 290 \\
20S-5SSF-ST & 1.26 & 1.6 & 0.0012 & 3400 & 340 \\
30S-ST & 1.6 & 2 & 0.0016 & 8000 & 350 \\
30S-10DSF-ST & 1.7 & 2.2 & 0.002 & 8500 & 275 \\
30S-10USF-ST & 1.7 & 2.6 & 0.0025 & 10625 & 385 \\
30S-5SSF-ST & 1.2 & 1.5 & 0.0012 & 7500 & 340 \\
40S-ST & 1.4 & 2.8 & 0.0027 & 11700 & 1000 \\
40S-10DSF-ST & 2 & 2.8 & 0.0027 & 11800 & 1025 \\
40S-10USF-ST & 2.3 & 3.1 & 0.0028 & 15400 & 1125 \\
40S-5SSF-ST & 1.65 & 2.3 & 0.0005 & 9100 & 4500 \\
\hline
\end{tabular}




\section{List of figures' captions`}

Fig. 1. Particle size distribution of (a) SSF, (b) DSF and USF, and (c) FA and GGBS.

Fig. 2. Flow table test as per ASTM C230 (a) before removal of flow mould, (b) immediately after the removal of the flow mould, and (c) after 25 drops.

Fig. 3. (a) The geometry of FRGC specimen, and (b) direct tensile set up.

Fig. 4. The fresh properties of geopolymer mortar.

Fig. 5. Porosity (\%) of fly ash/ slag based geopolymer mortar with variant forms of silica fume.

Fig. 6. The compressive strength of plain geopolymer mixes containing binary and ternary mixes at 3 days, 7 days and 28 days curing at ambient temperatures. Error bars are shown for $\mathrm{n}=3$.

Fig. 7. The compressive strength of SFRGC mixes containing binary and ternary mixes at 3 days, 7 days and 28 days curing at ambient temperatures. Error bars are shown for $n=3$.

Fig. 8. Percentage increase in 28 days compressive strength of SFRGC over that of plain geopolymer mortar.

Fig. 9. Stress-Strain relationship of plain geopolymer.

Fig. 10. Effect of slag content on the stress-strain curve of SFRGC.

Fig. 11. Stress-strain relationship of steel fibre reinforced of geopolymer composites: (a) shows effect of variant silica fume forms on samples at 10\% slag; (b) 20\% slag; (c) 30\% slag; and (d) $40 \%$ slag content.

Fig. 12. Tensile stress-strain curve of SFRGC mixture with USF at different slag contents:

(a) $10 \%$ slag, (b) $20 \%$ slag, (c) 30\% slag and (d) $40 \%$ slag at 3 days, 7 days, 14 days and 28 days.

Fig. 13. Bi-linear stress-strain curve of SFRGC.

Fig. 14. Stress versus strain models for binary blended SFRGC mixtures with variant slag content.

Fig. 15. Stress versus strain models for ternary blended SFRGC mixtures with various silica fume types at different slag contents: (a) 10\% slag, (b) 20\% slag, (c) $30 \%$ slag and (d) $40 \%$ slag.

Fig. 16. Elastic Modulus of steel fibre reinforced geopolymer concrete (SFRGC).

Fig. 17. Energy absorption capacity of SFRGC.

Fig. 18. SEM images of (a) Fly ash, (b) slag, (c) USF, and (d) DSF

Fig. 19. SEM analysis of 28 days geopolymer mortar (a) $10 \mathrm{~S} \times 10,000$ magnification (b) $10 \mathrm{~S}$ x20,000 magnification (c) 40S x10,000 magnification and (d) 40S x20,000 magnification. 
Fig. 20. SEM images of $10 \%$ slag replacement geopolymer mortar, after 28 days ambient temperature curing, containing varying SF forms: (a) shows the control sample (no added SF), (b) 10\%DSF, (b) 10\%USF, (c) 5\% SSF.

Fig. 21. SEM micrographs of steel fibre reinforced geopolymer composite, imaged perpendicular to the fracture surface following failure during tensile tests; 10S-2St (a), 40S10DSF-2ST (b) and 40S-10USFSF-2ST (c). 


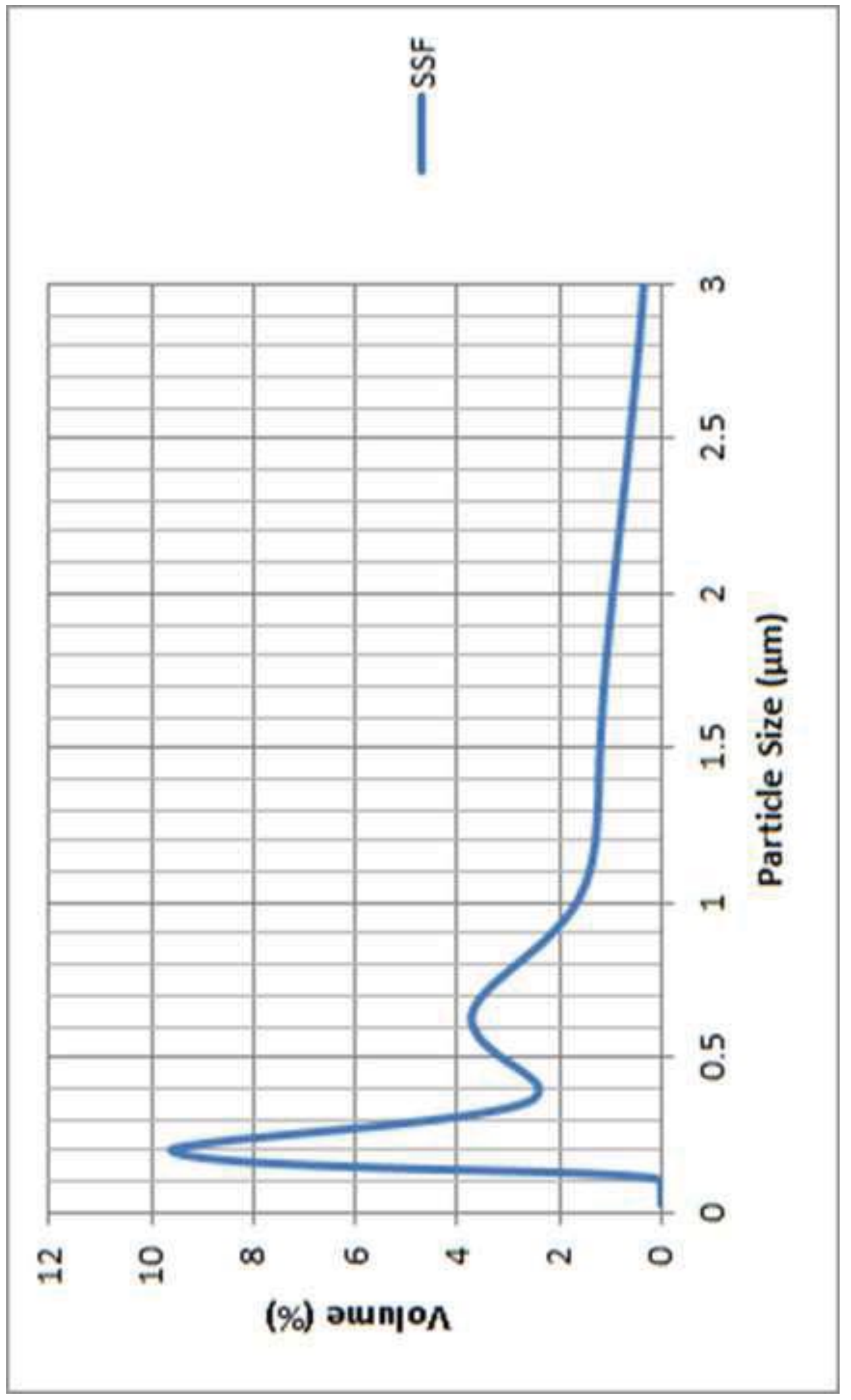

띵

옹 


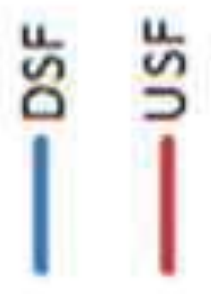

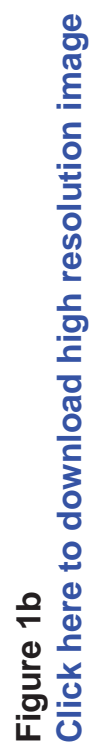

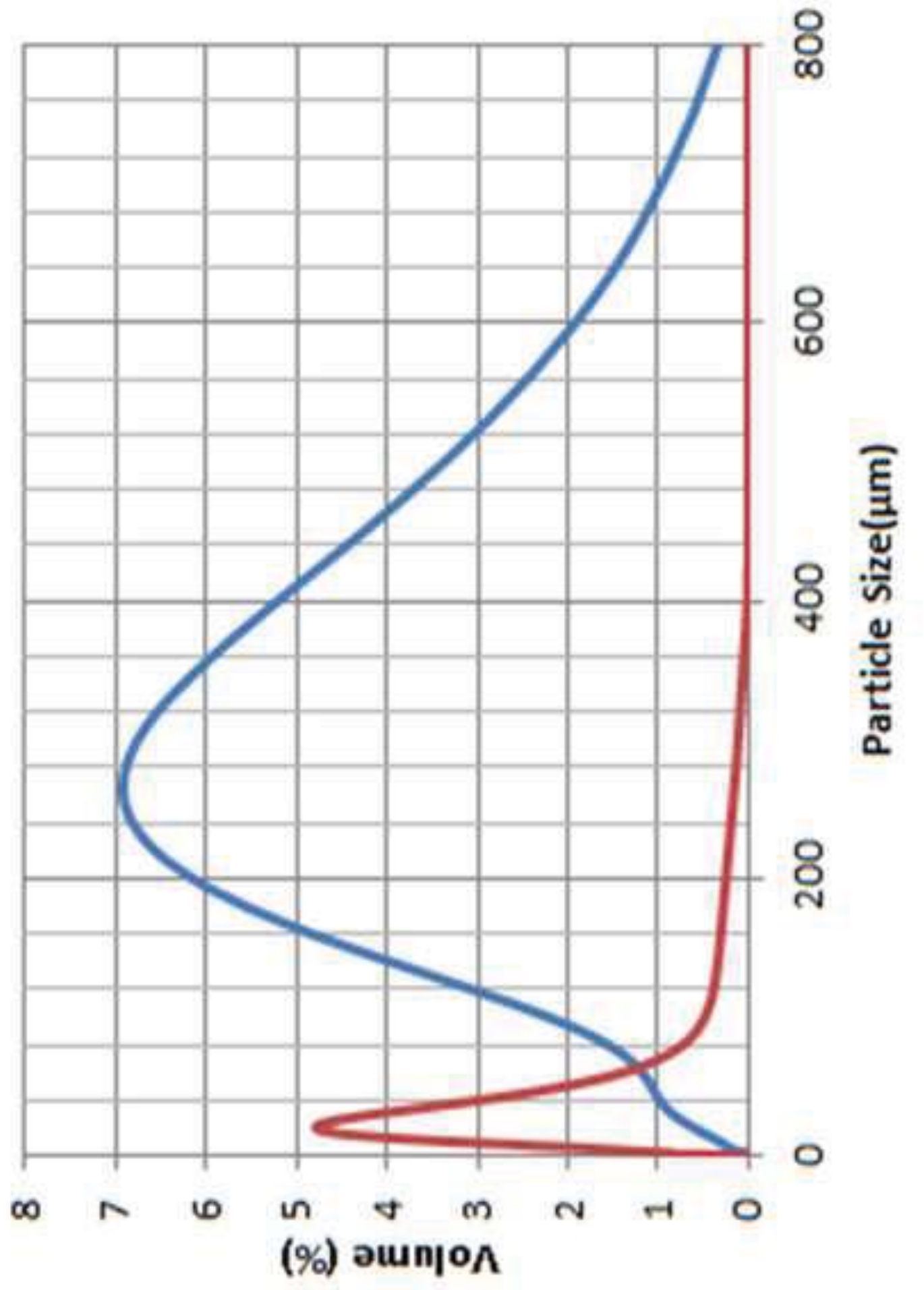




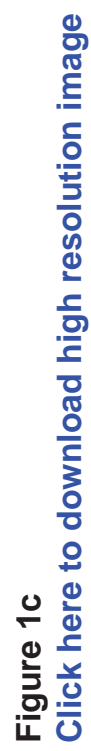
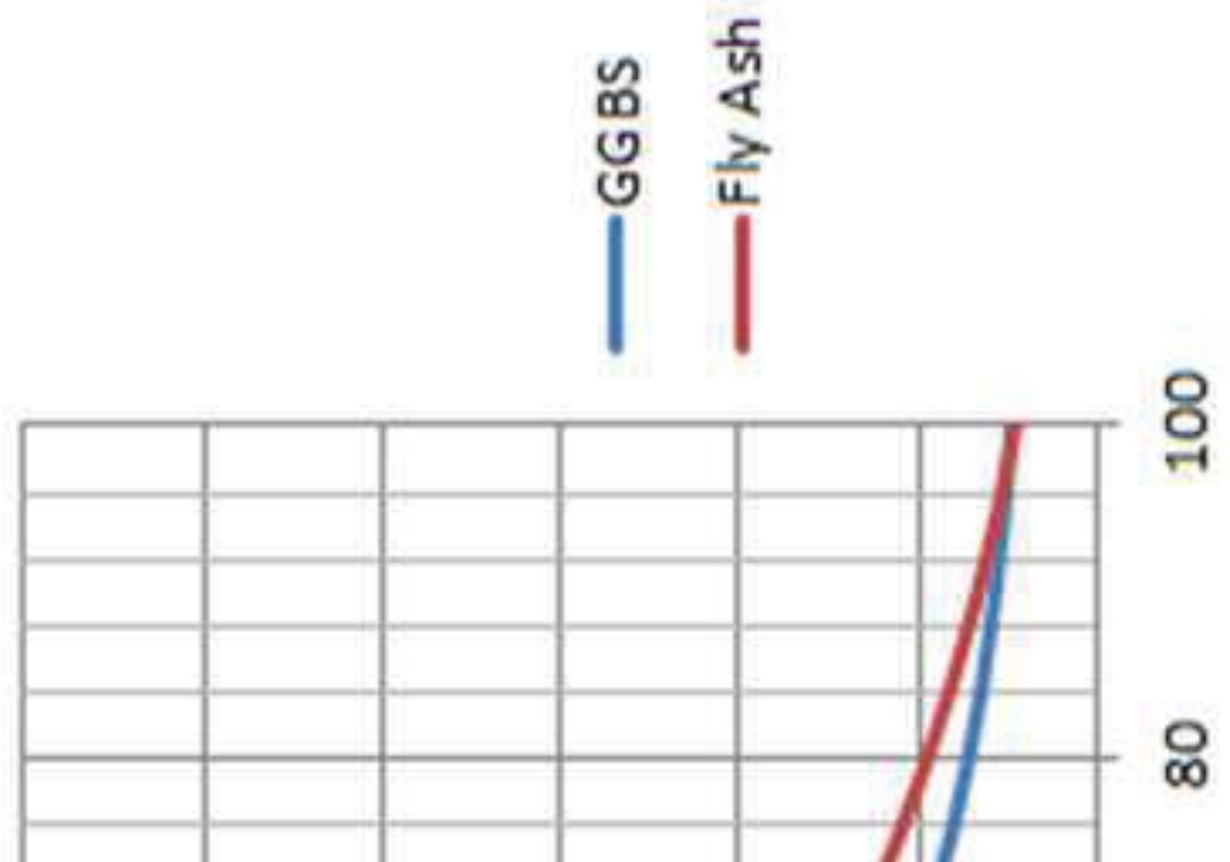

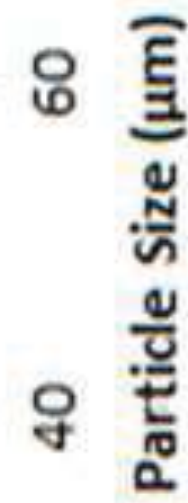

$\underset{N}{ }$

0

บ

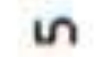

寸

$m$

N

$\pi$

o

(\%) כunฺo $\wedge$ 


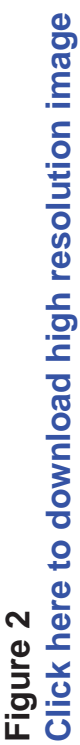
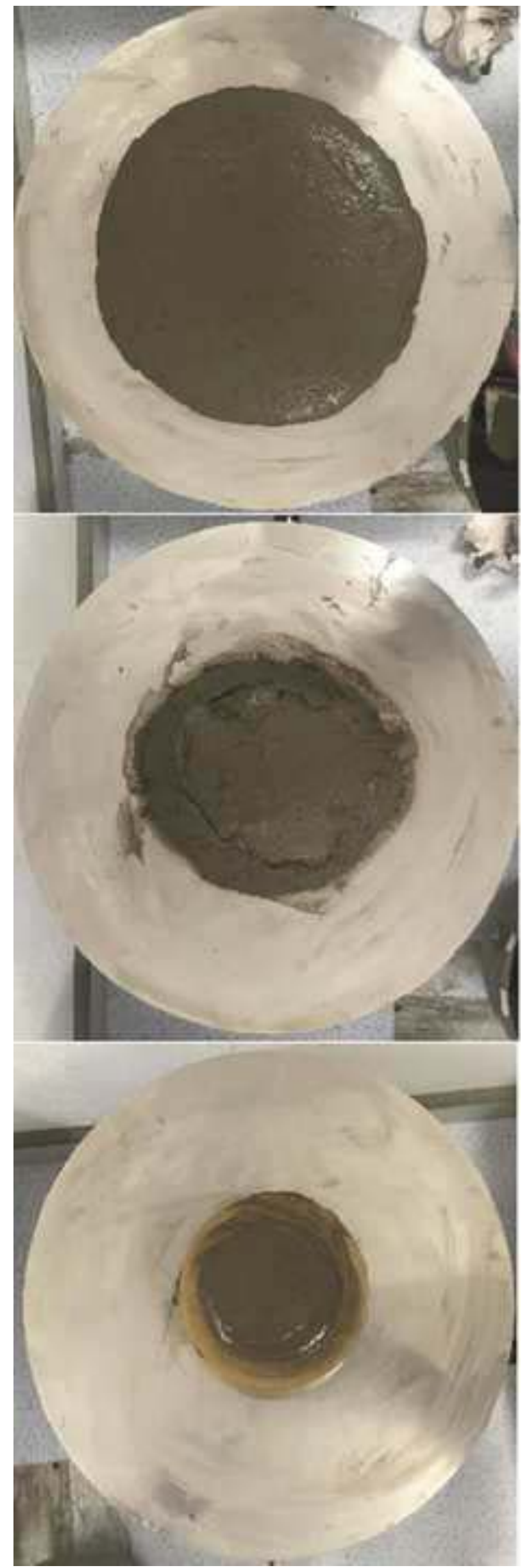
WWOST

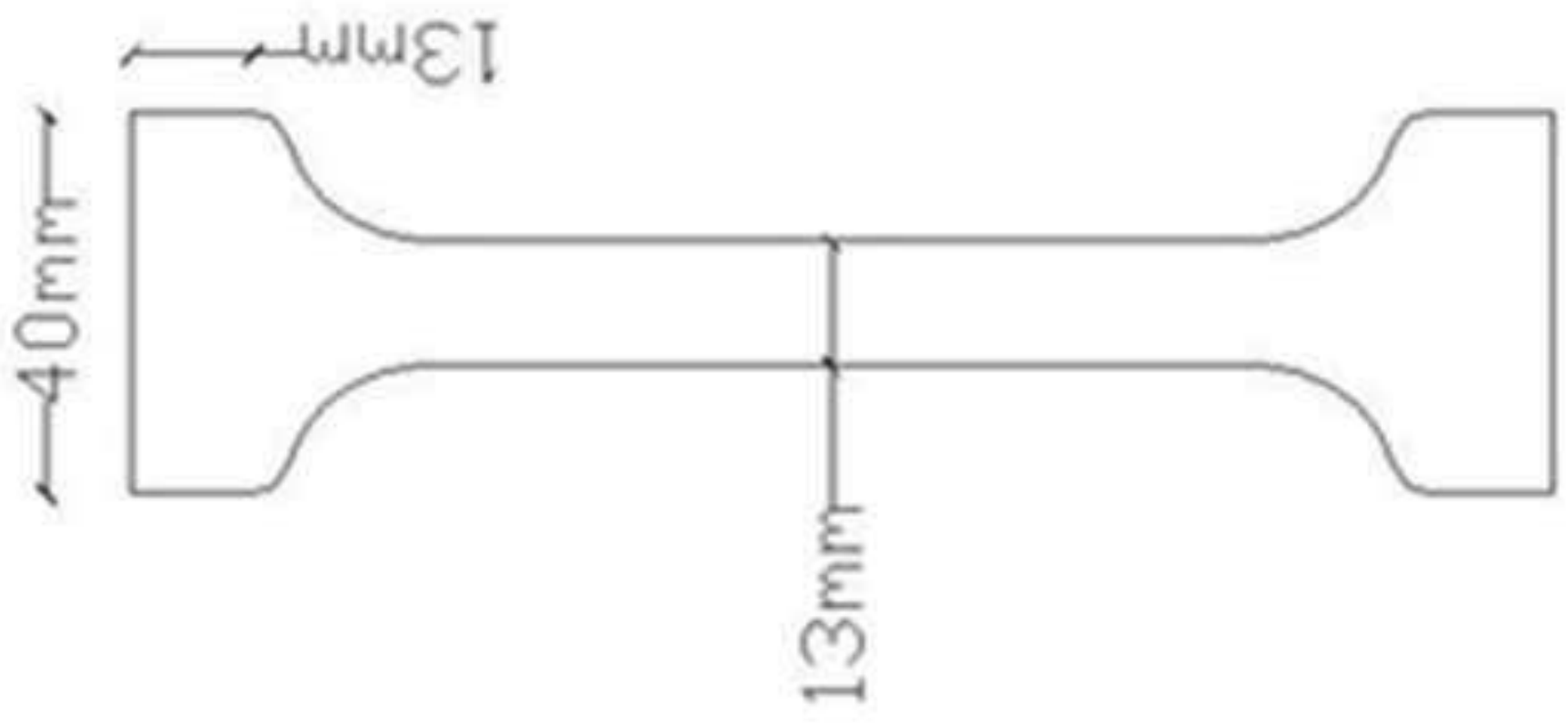

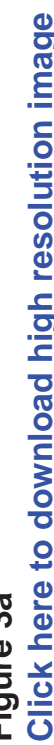




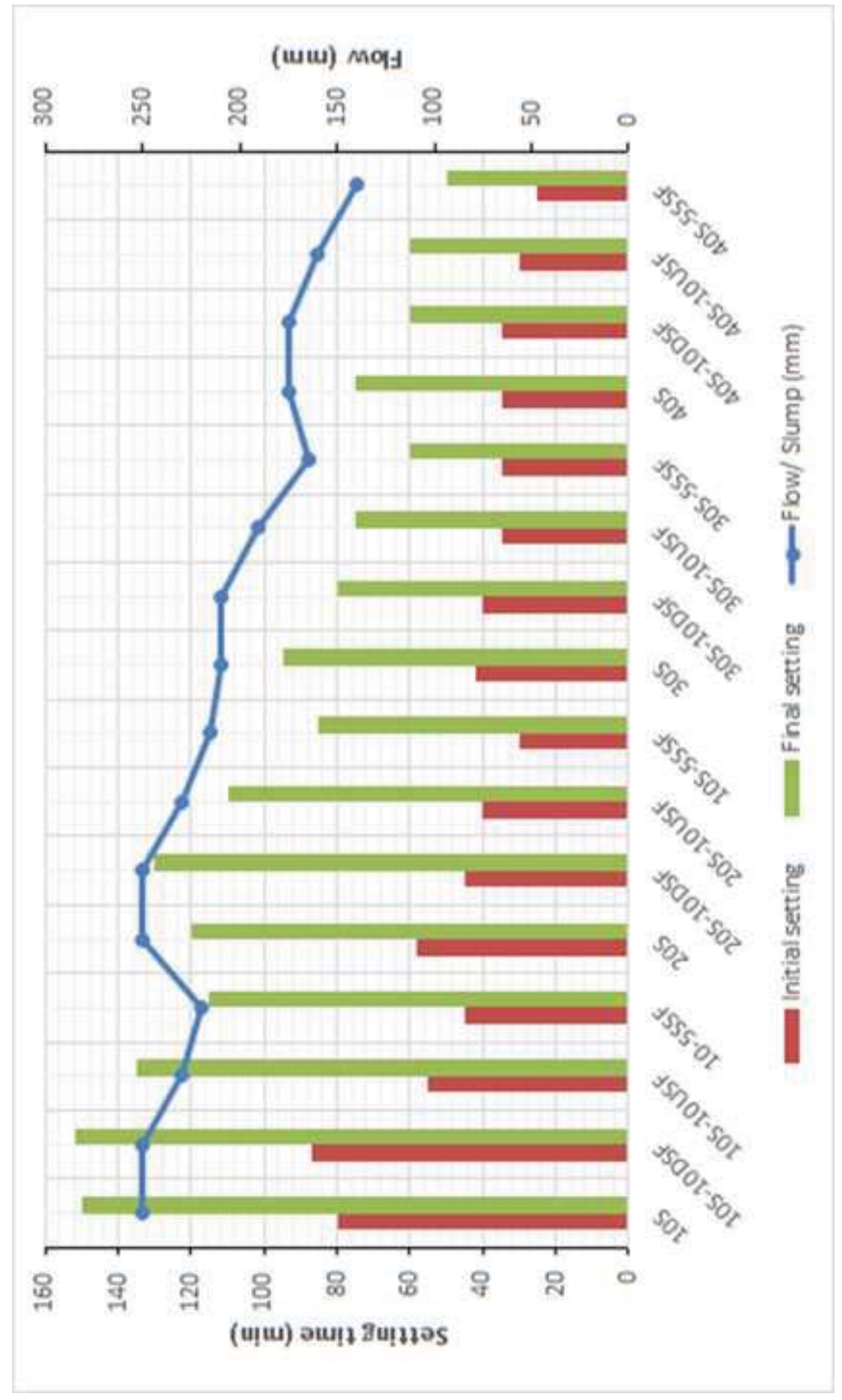

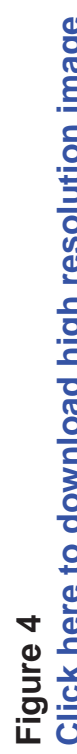




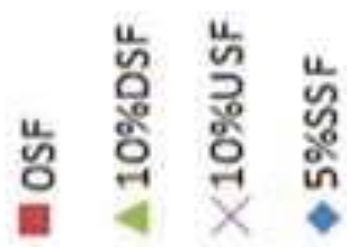

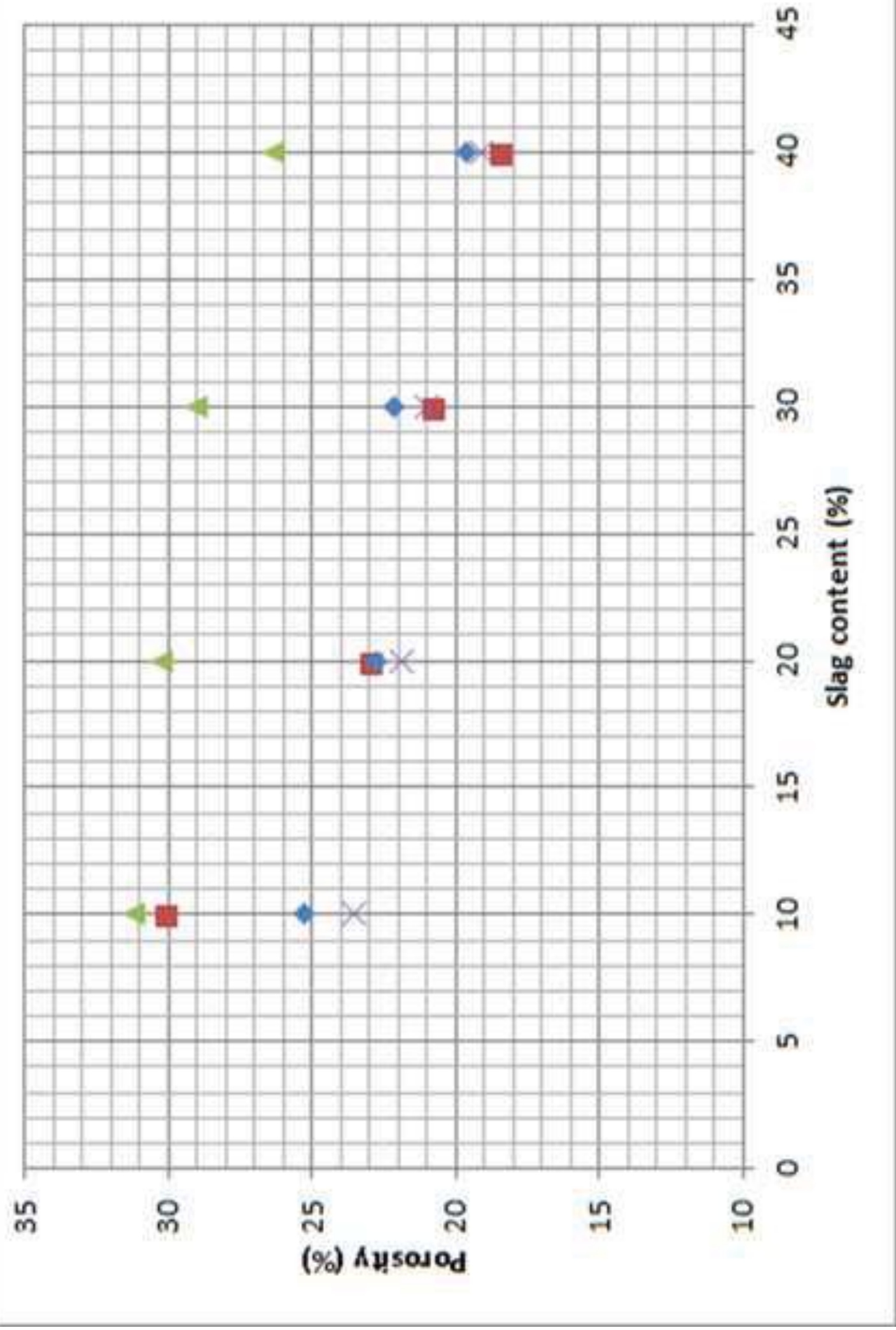

는 


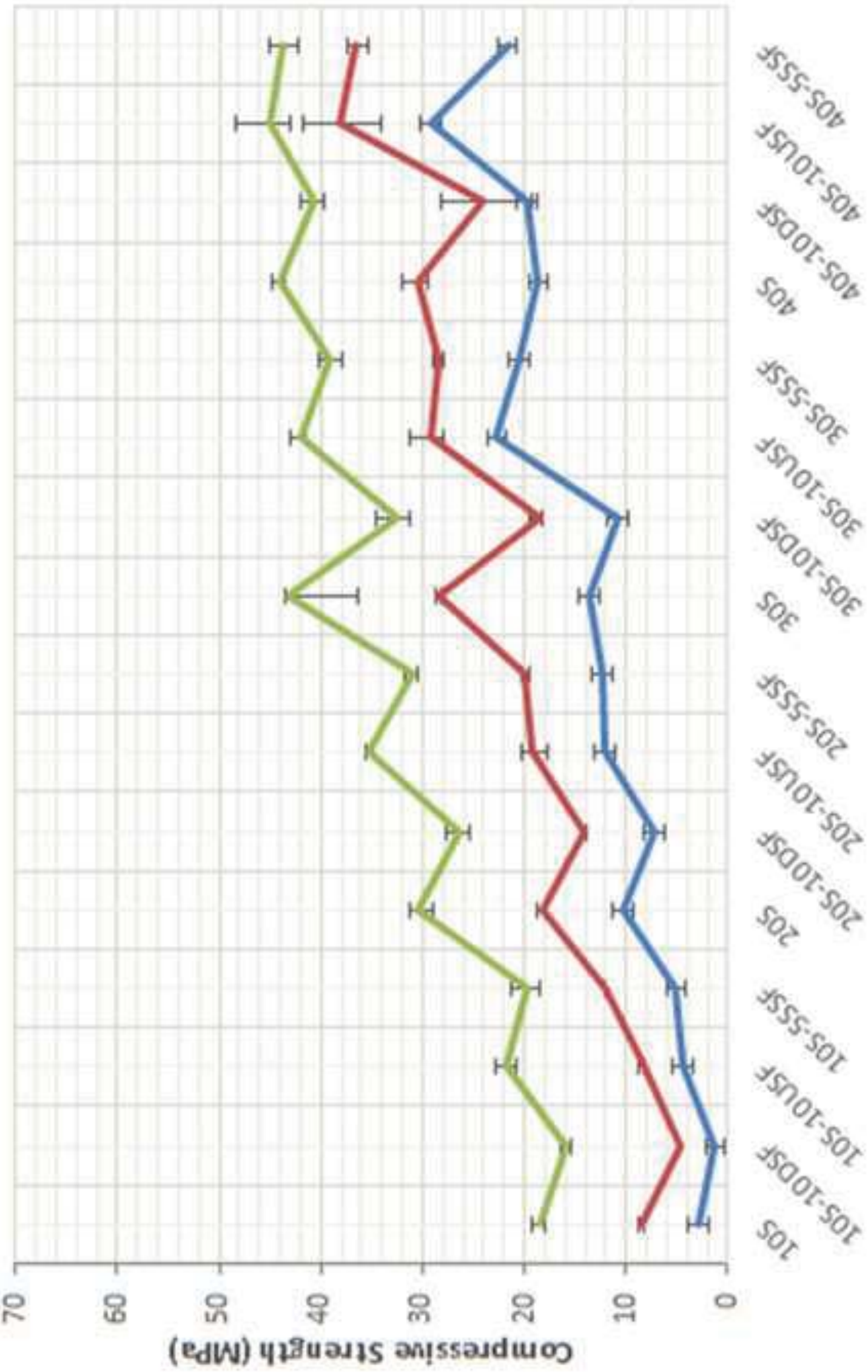




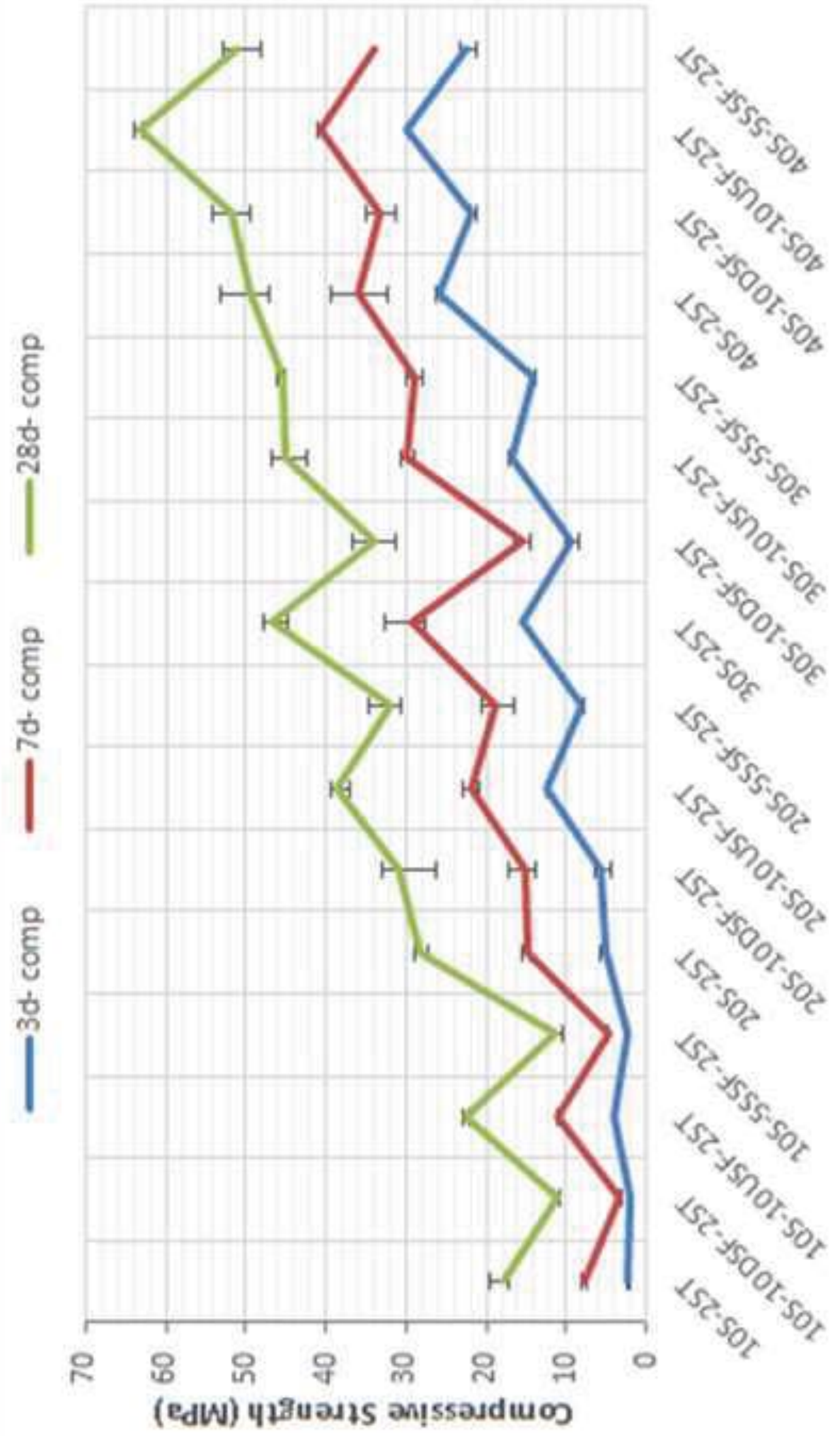




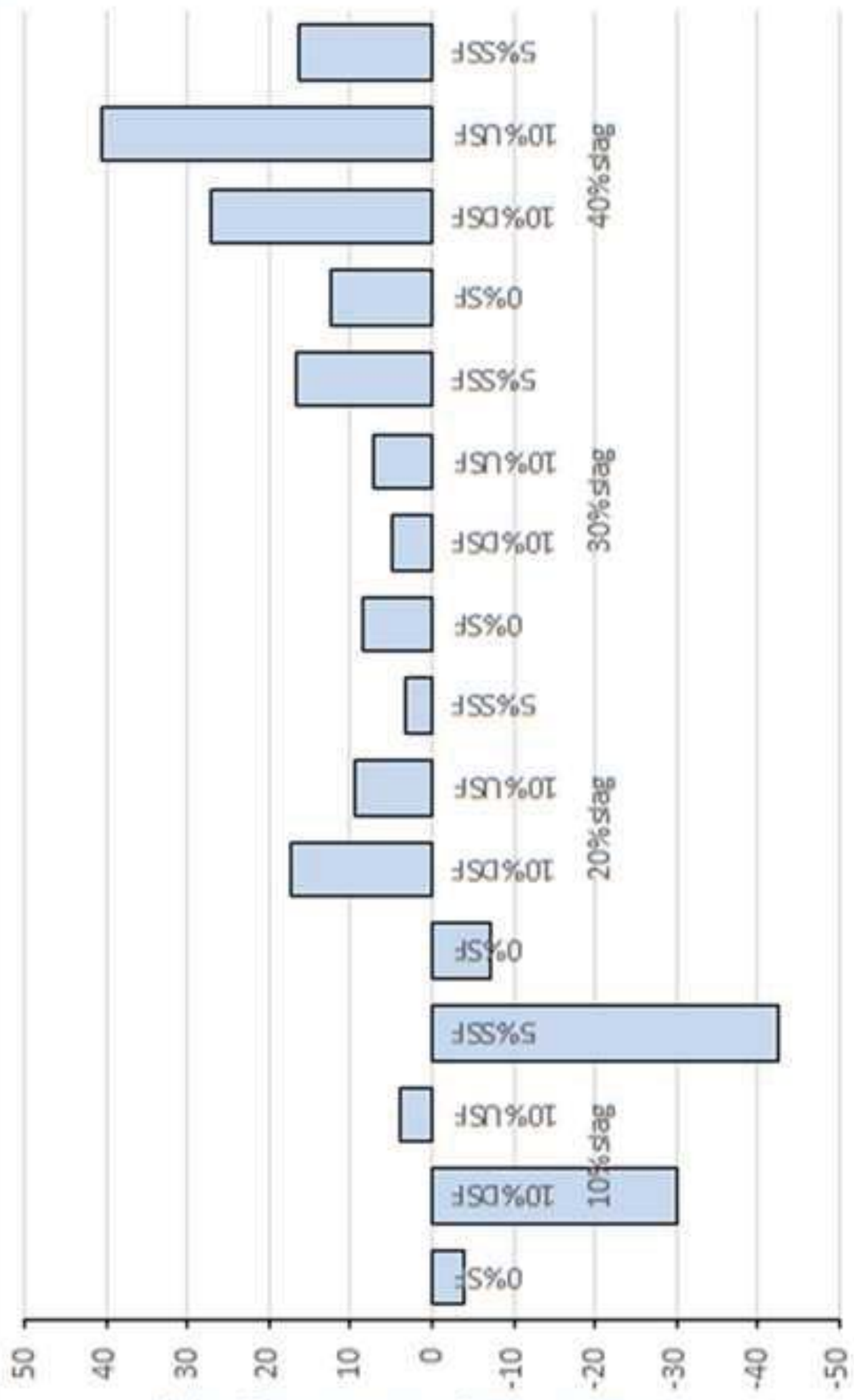

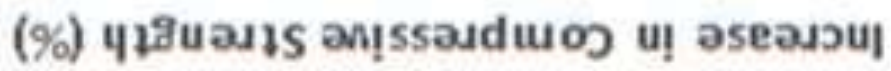


\

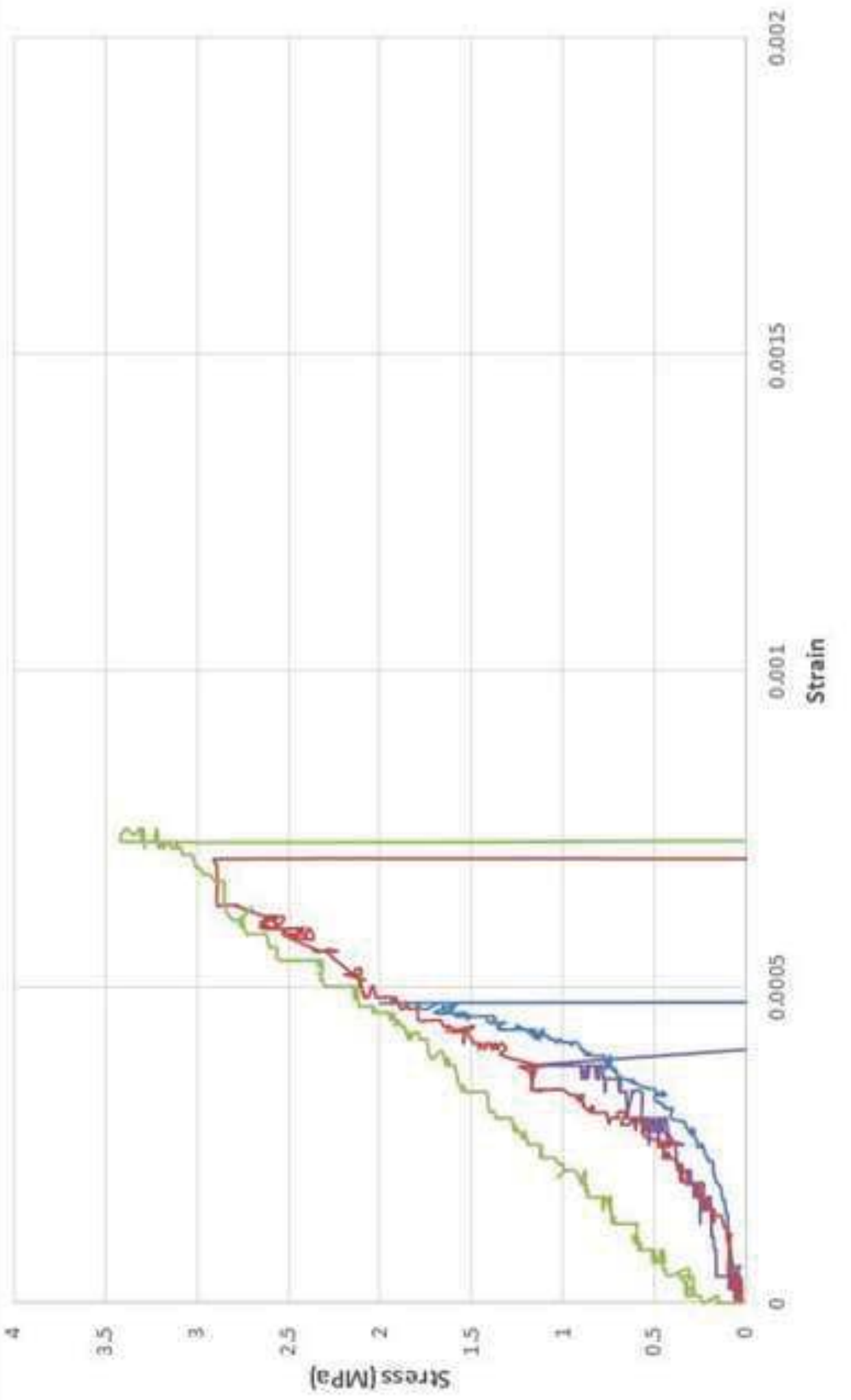




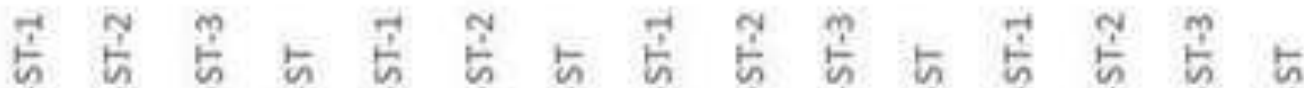

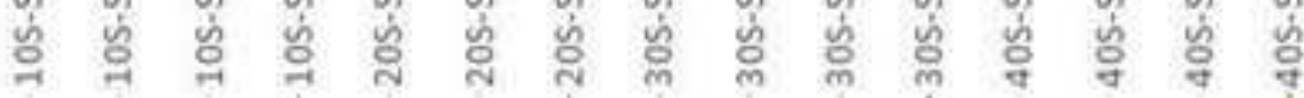
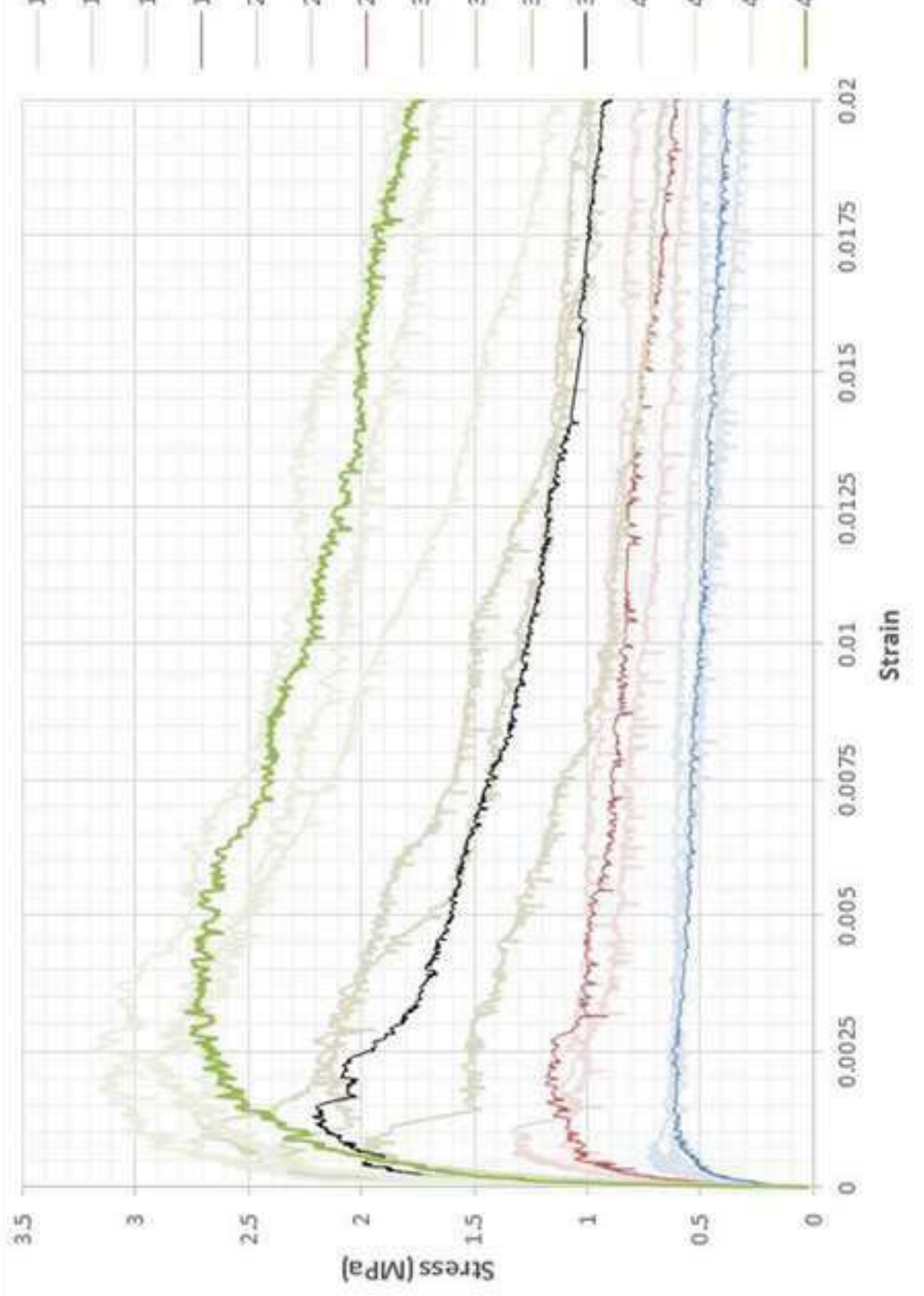

으원 

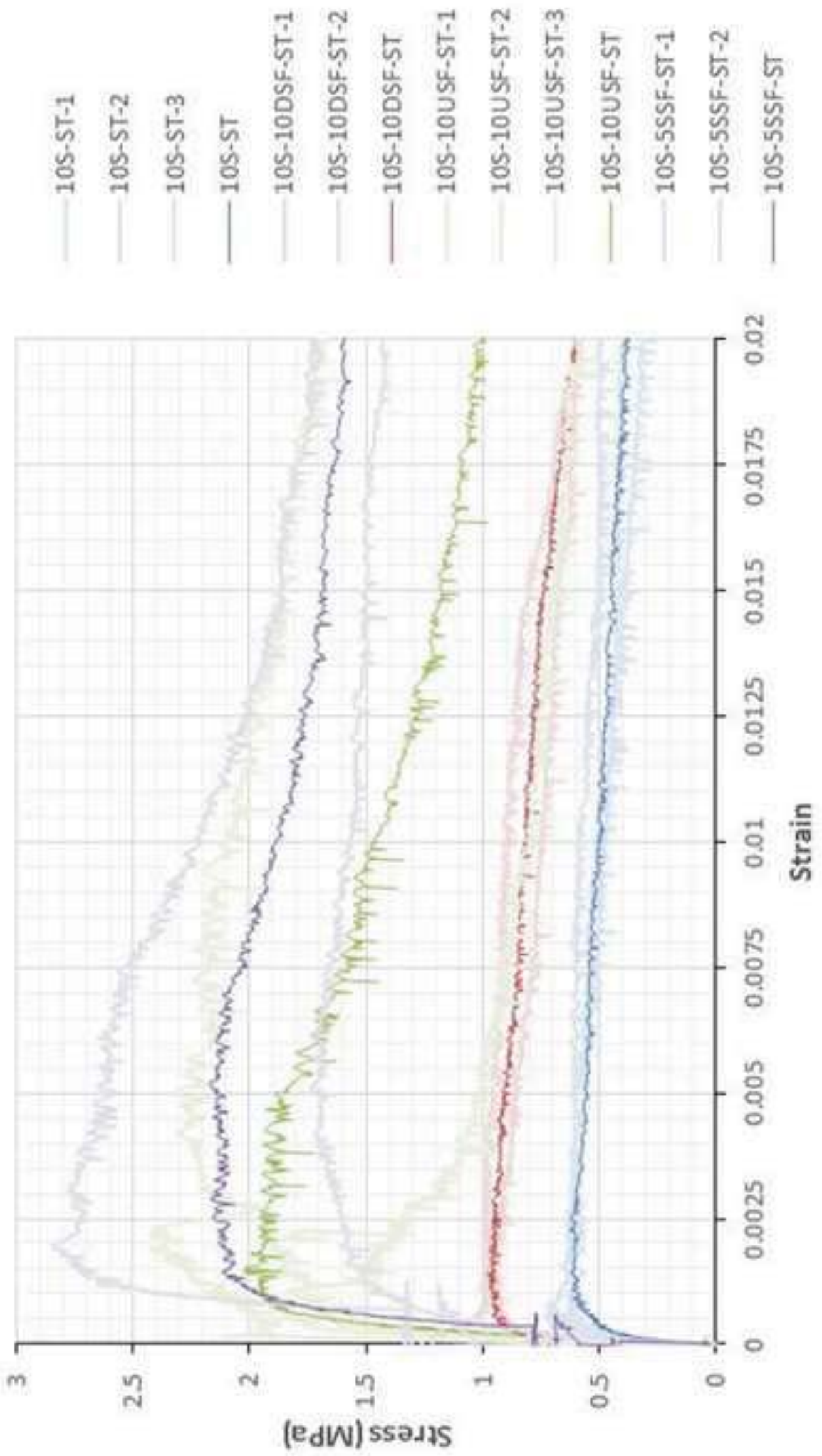

뜯 


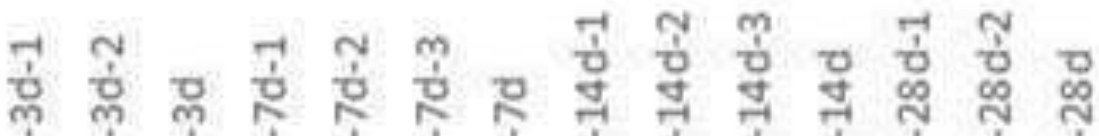

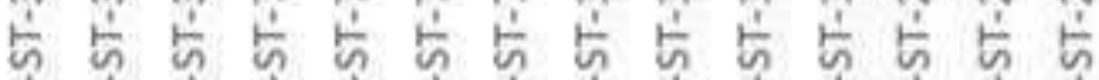

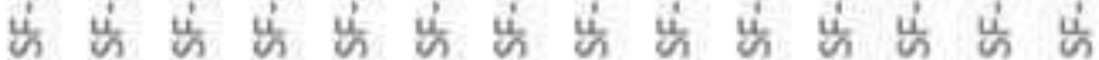

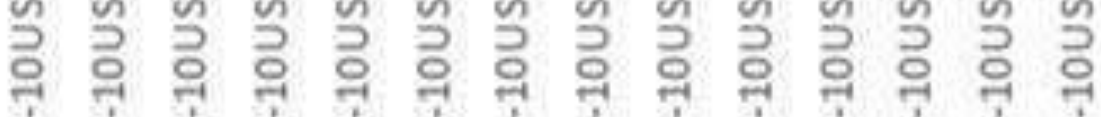

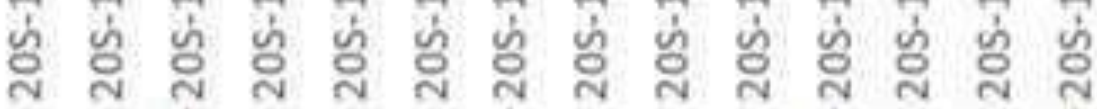

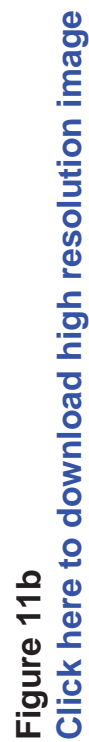

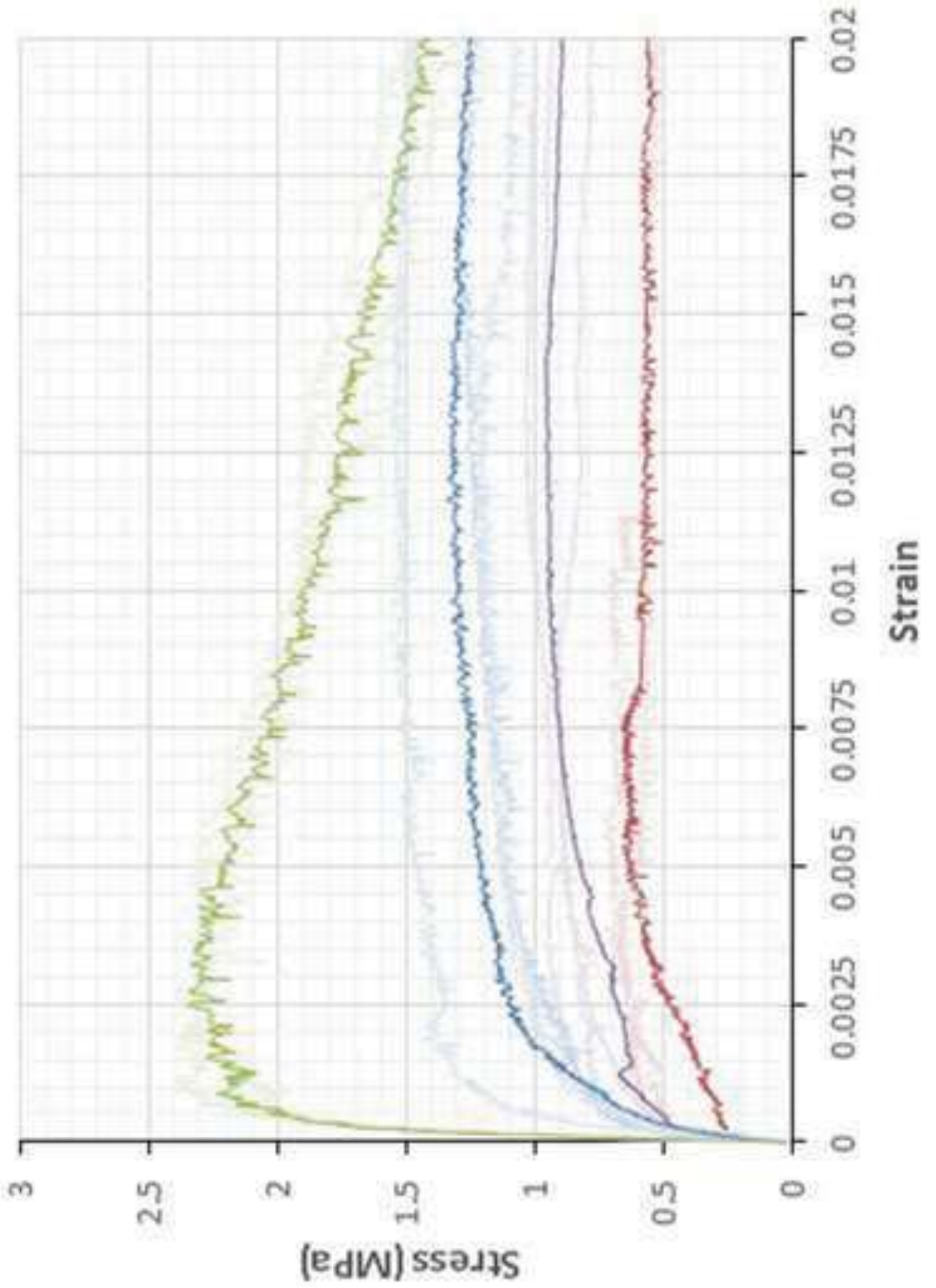




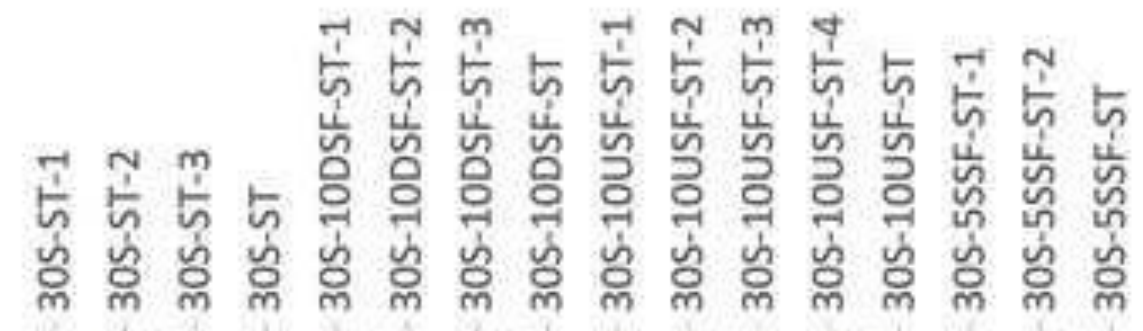

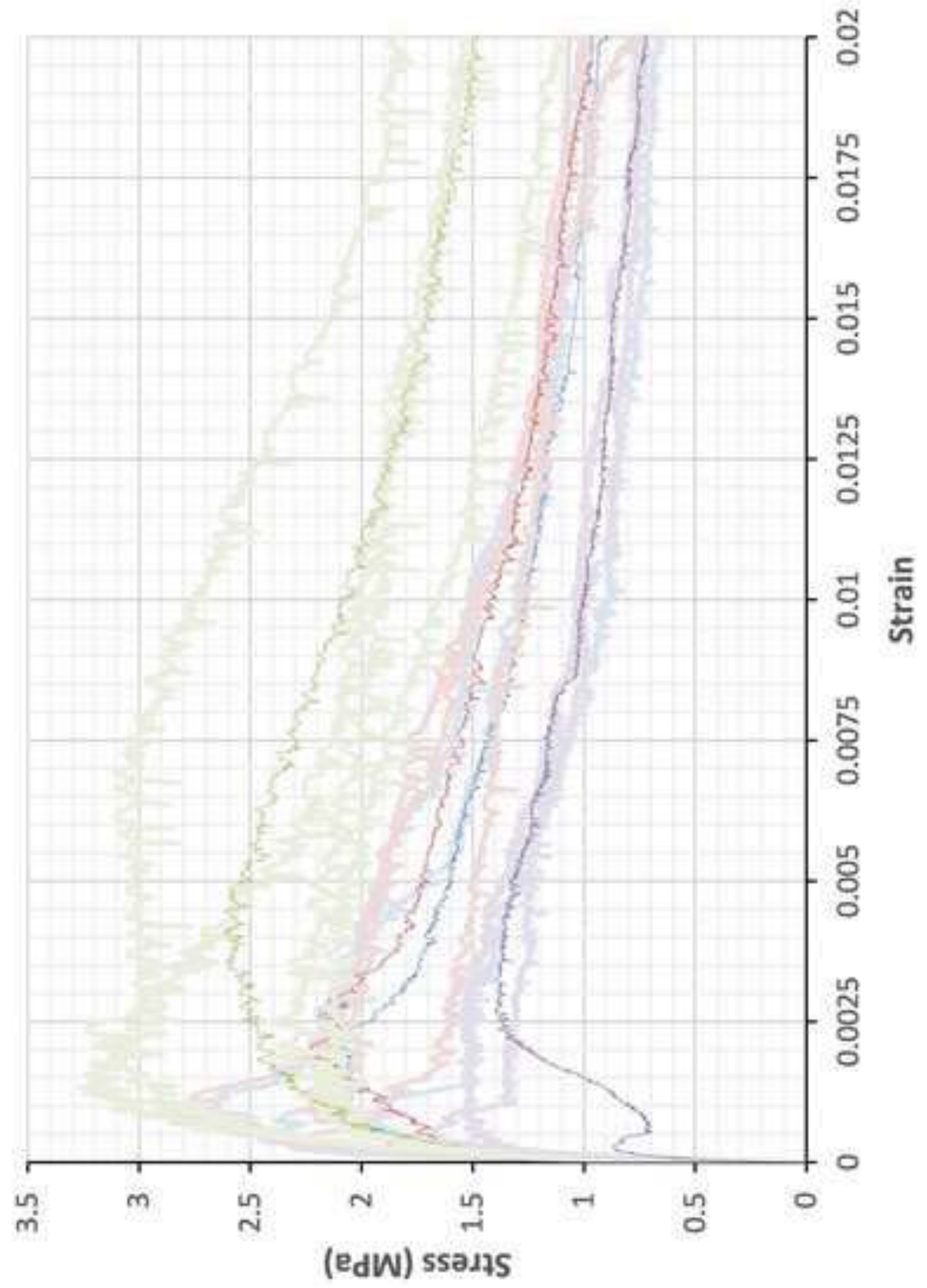

읃 


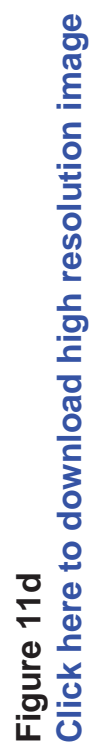

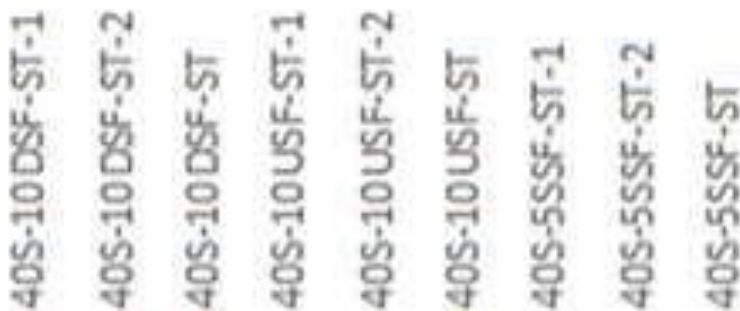

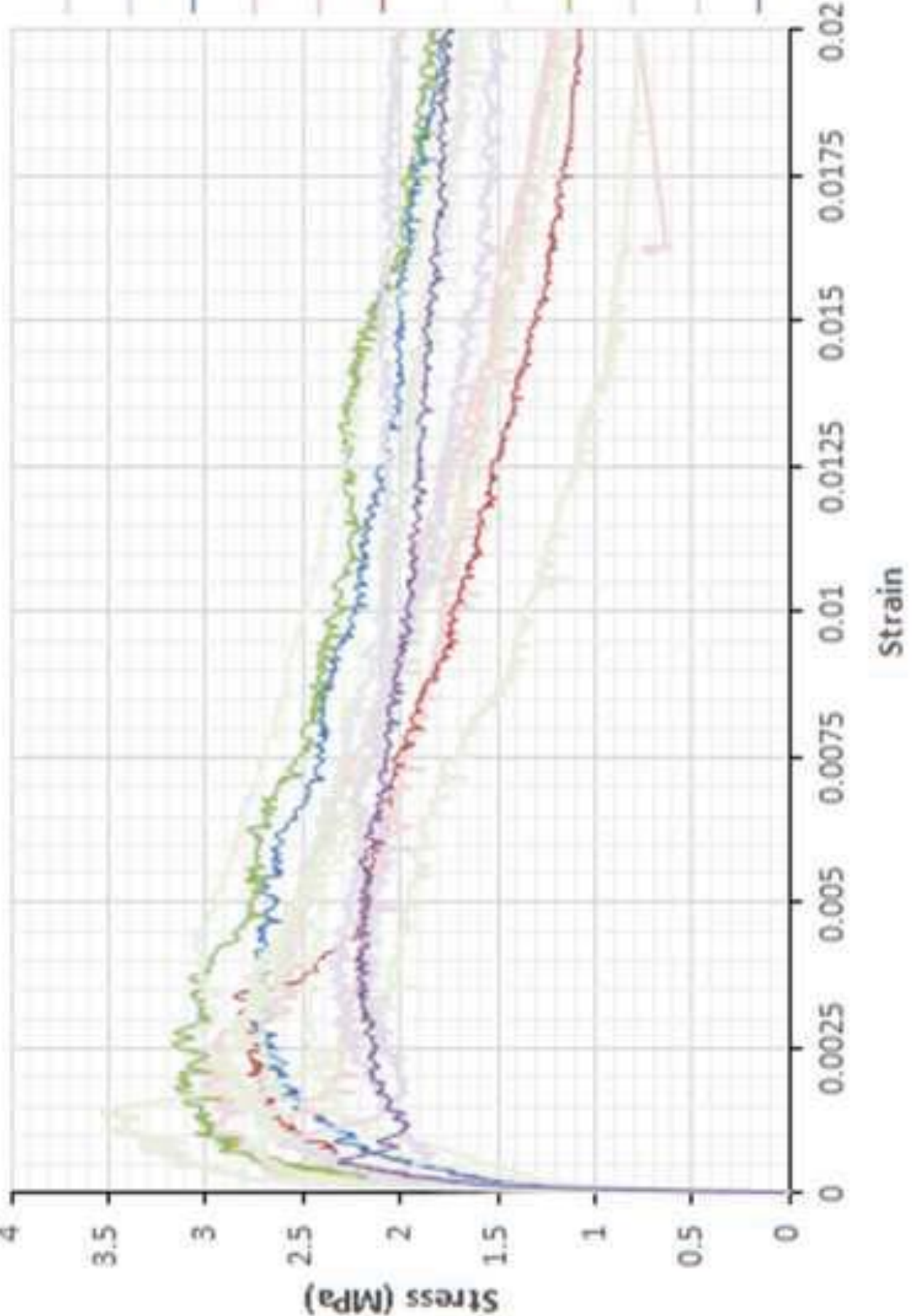




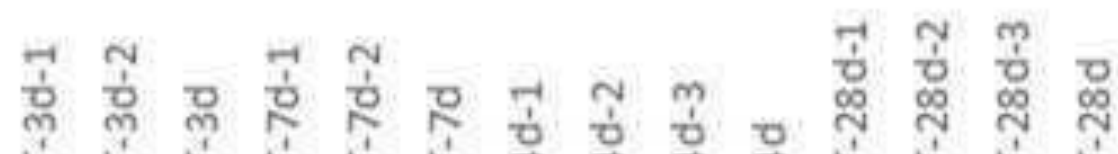

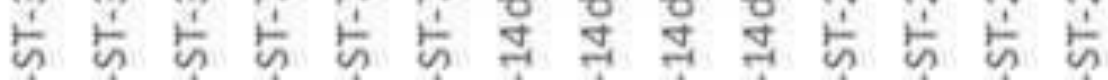
范

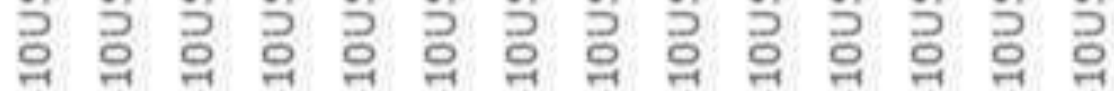

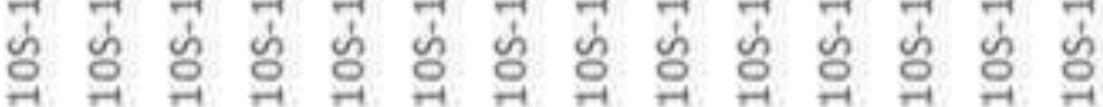

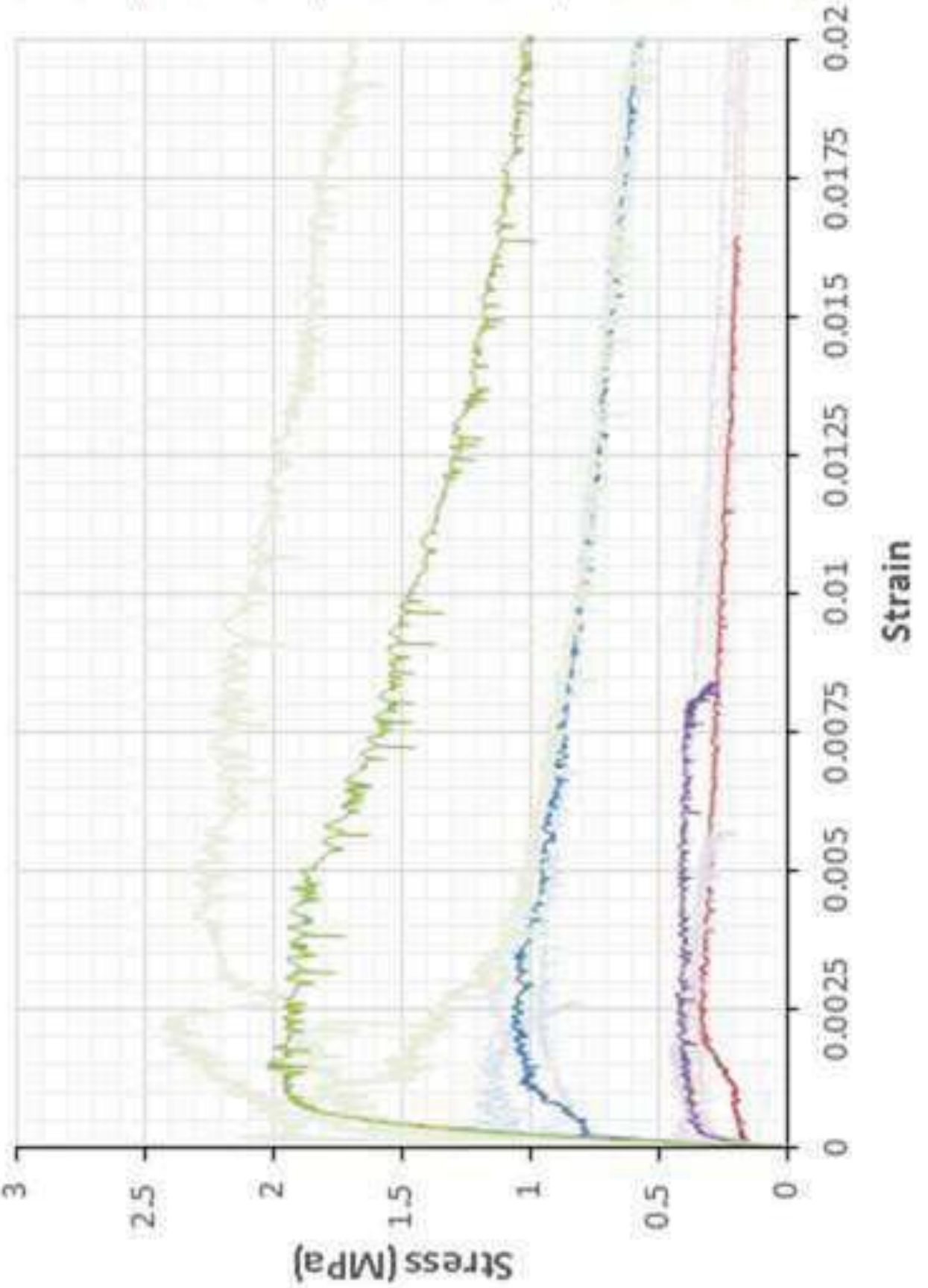




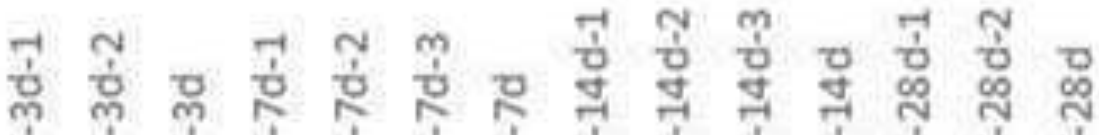

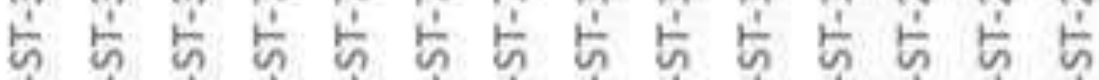

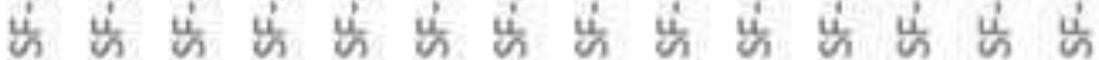

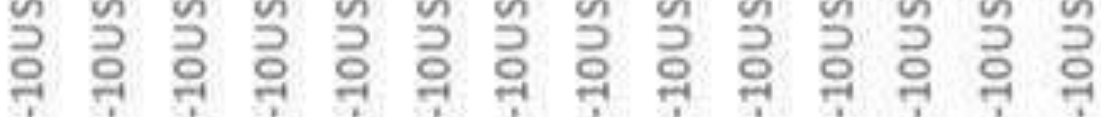

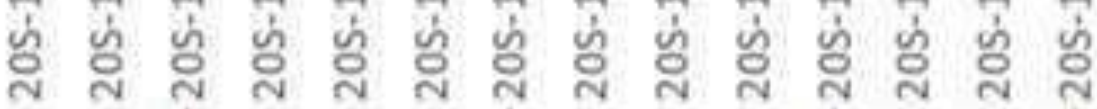

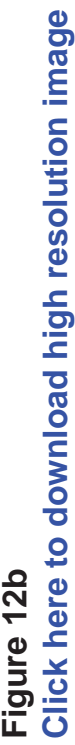

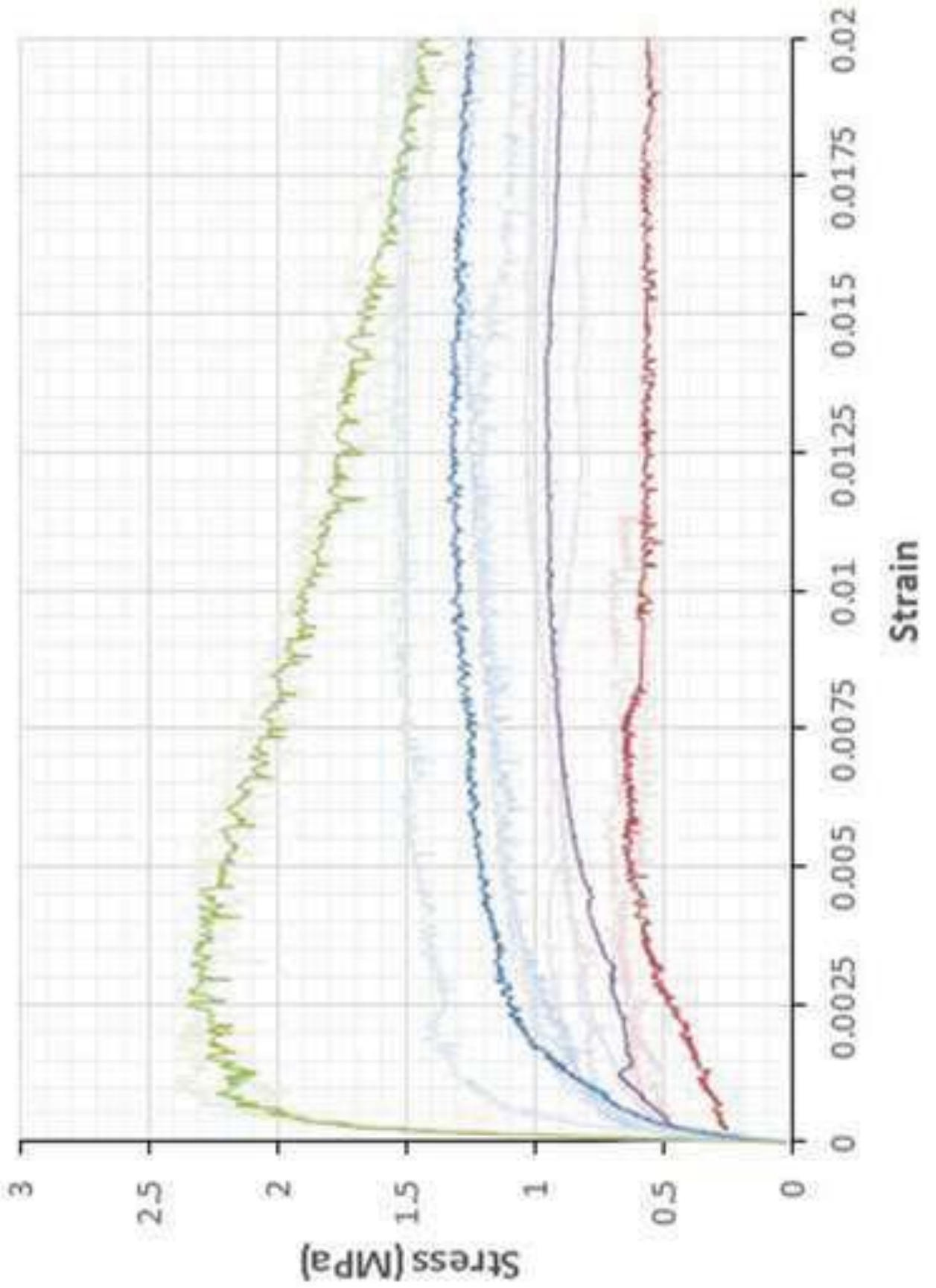




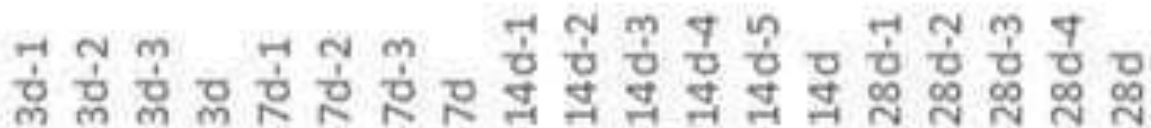

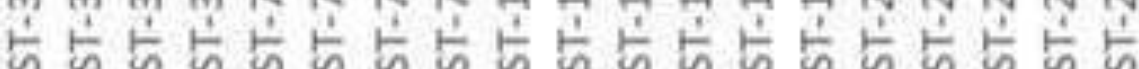

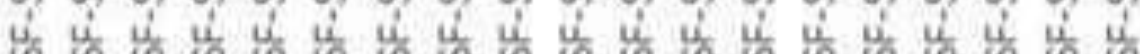
ว

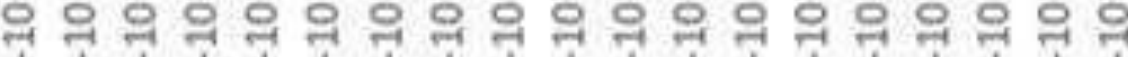

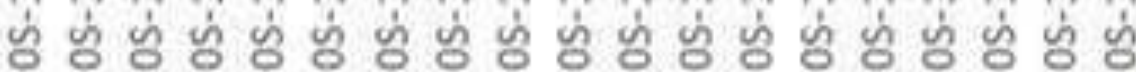

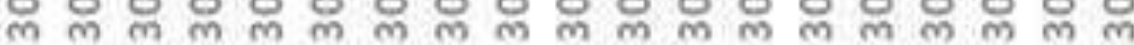

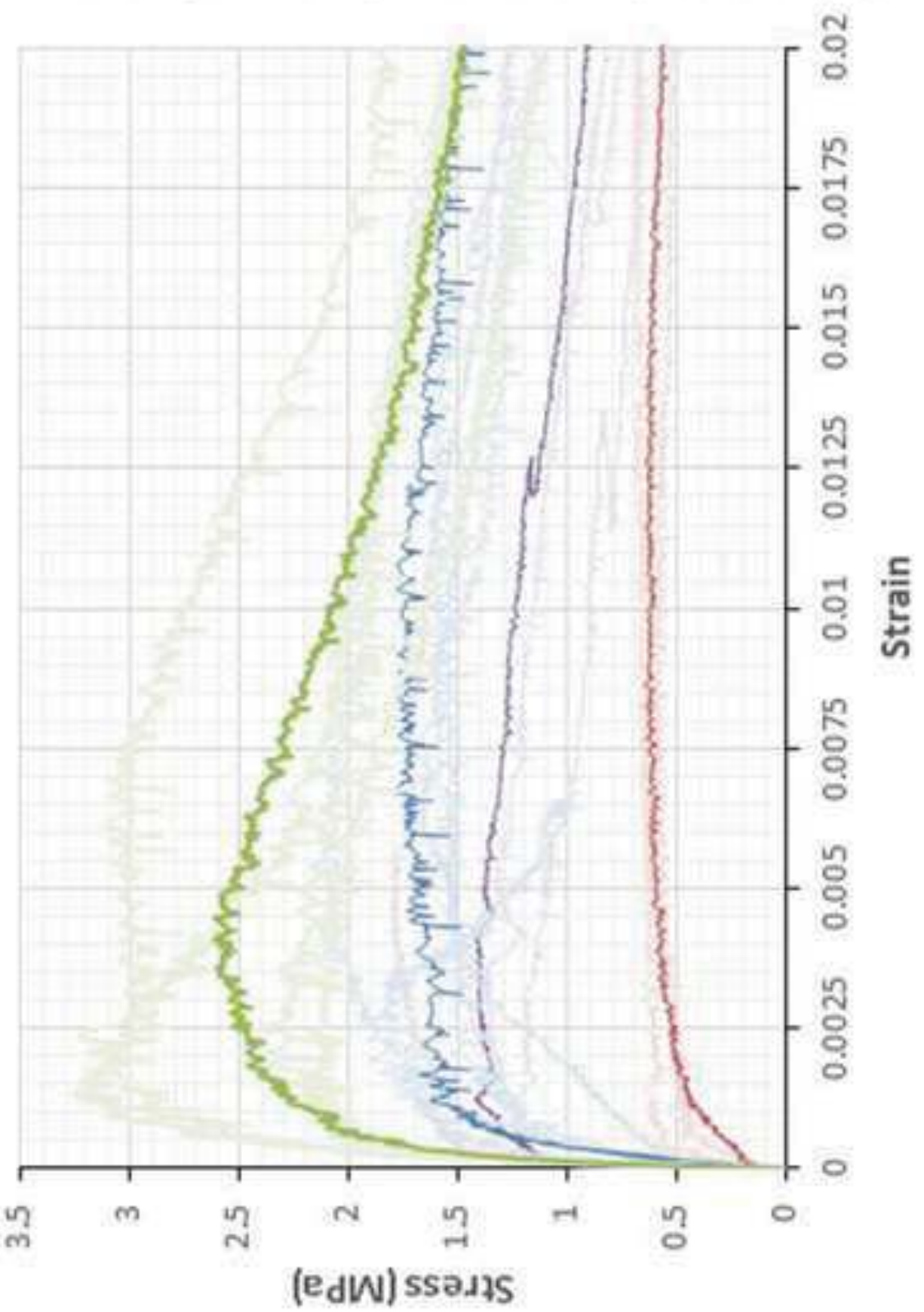




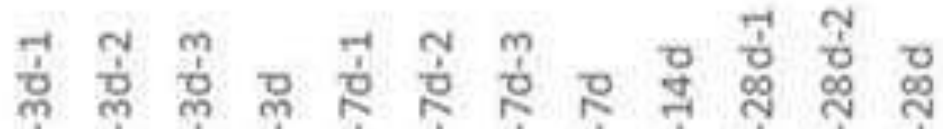

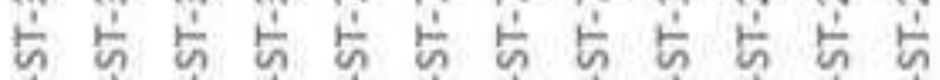

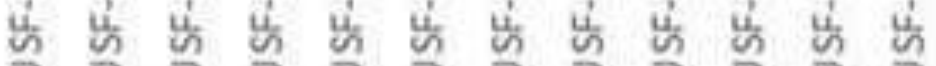

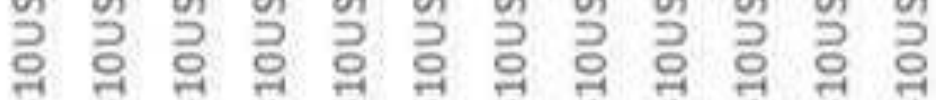

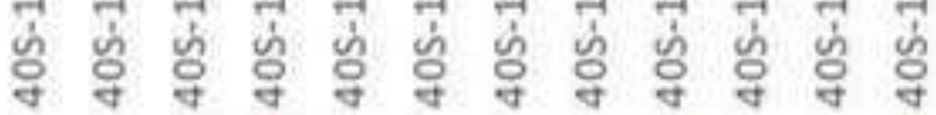

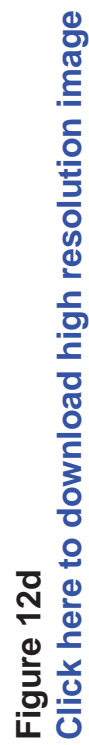

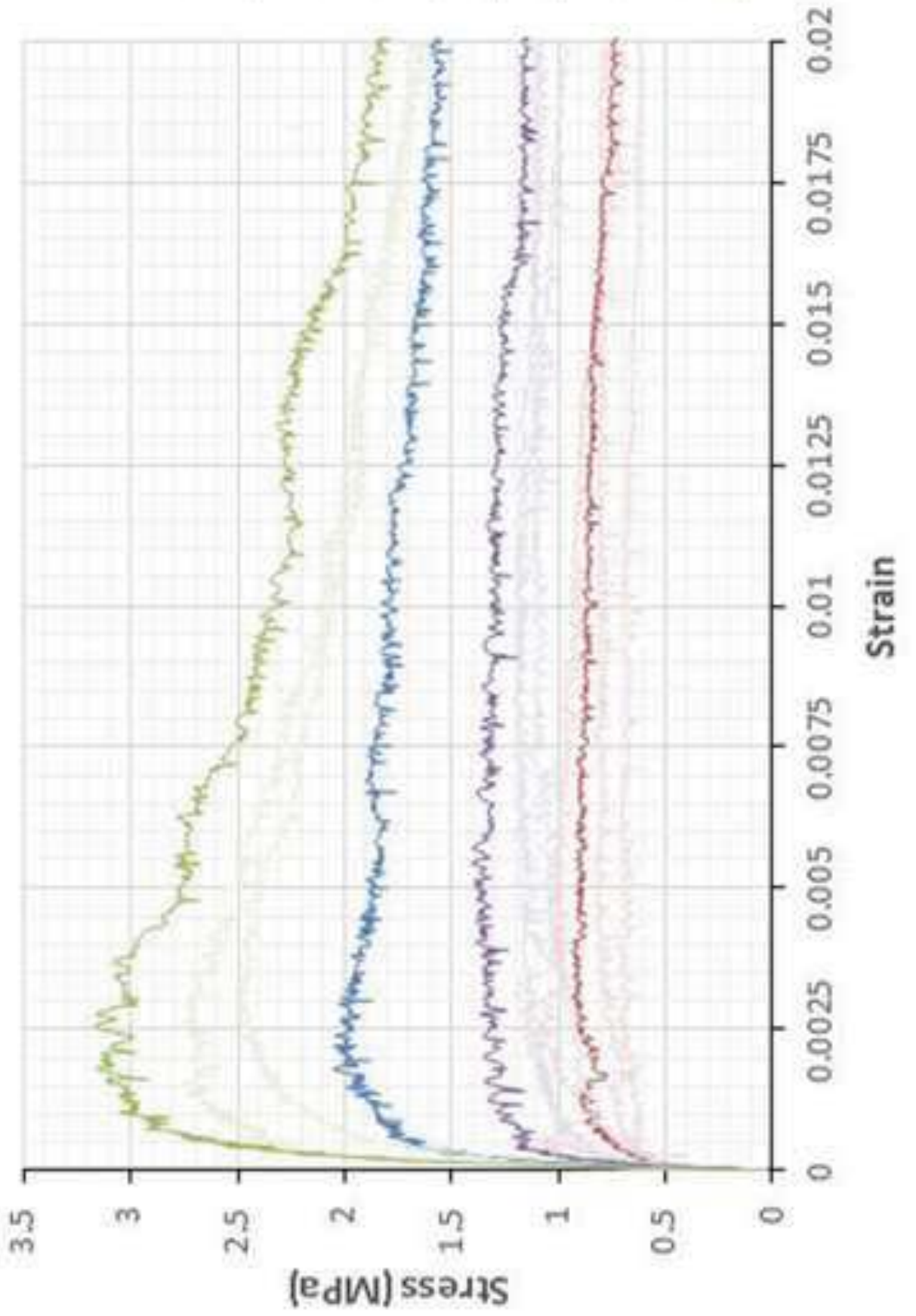




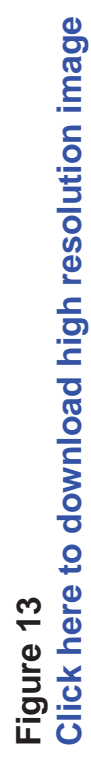

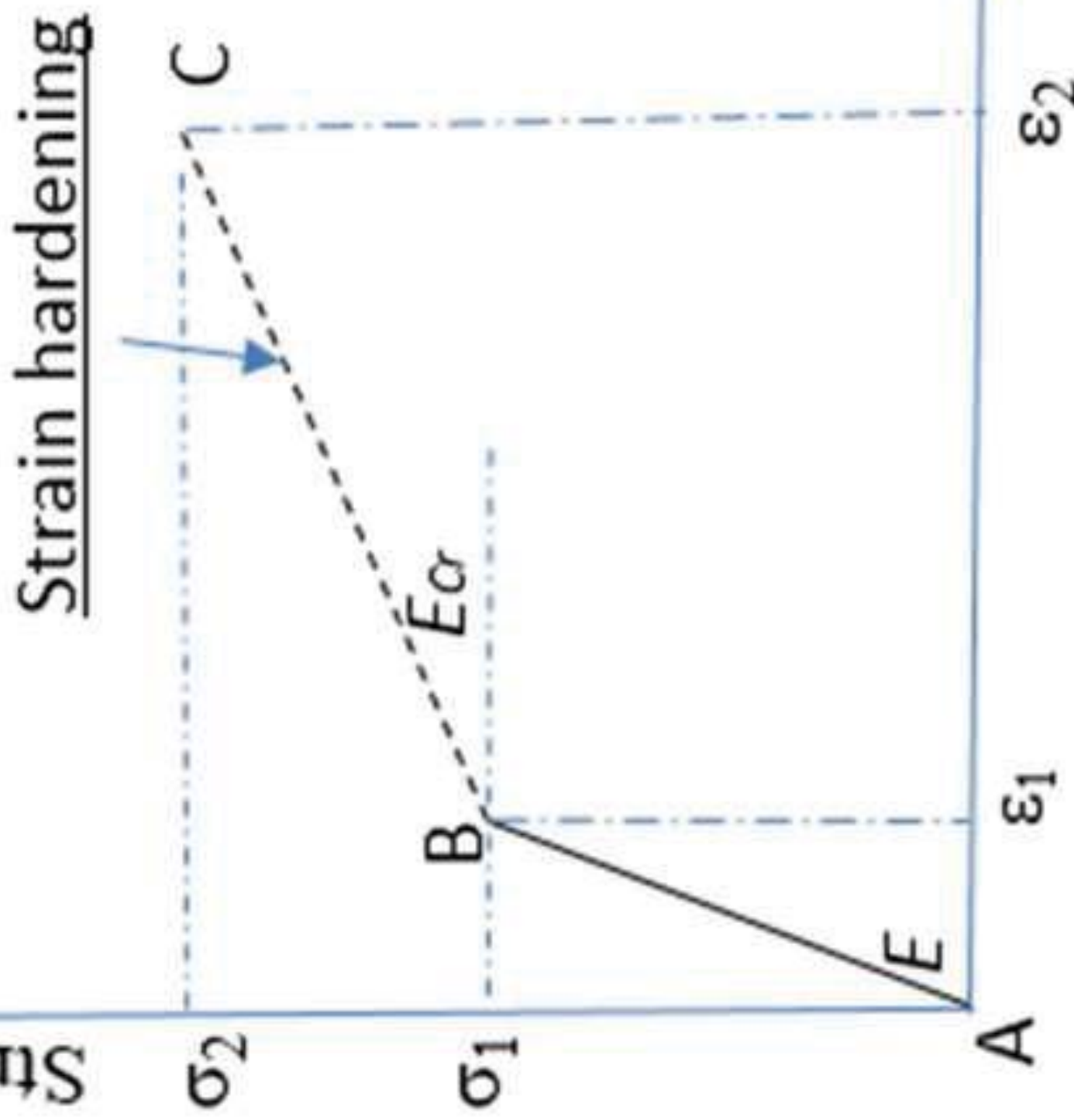




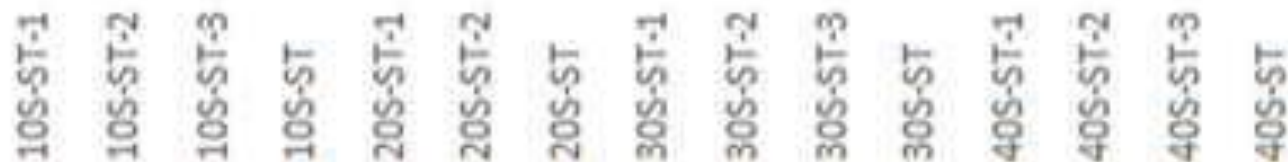
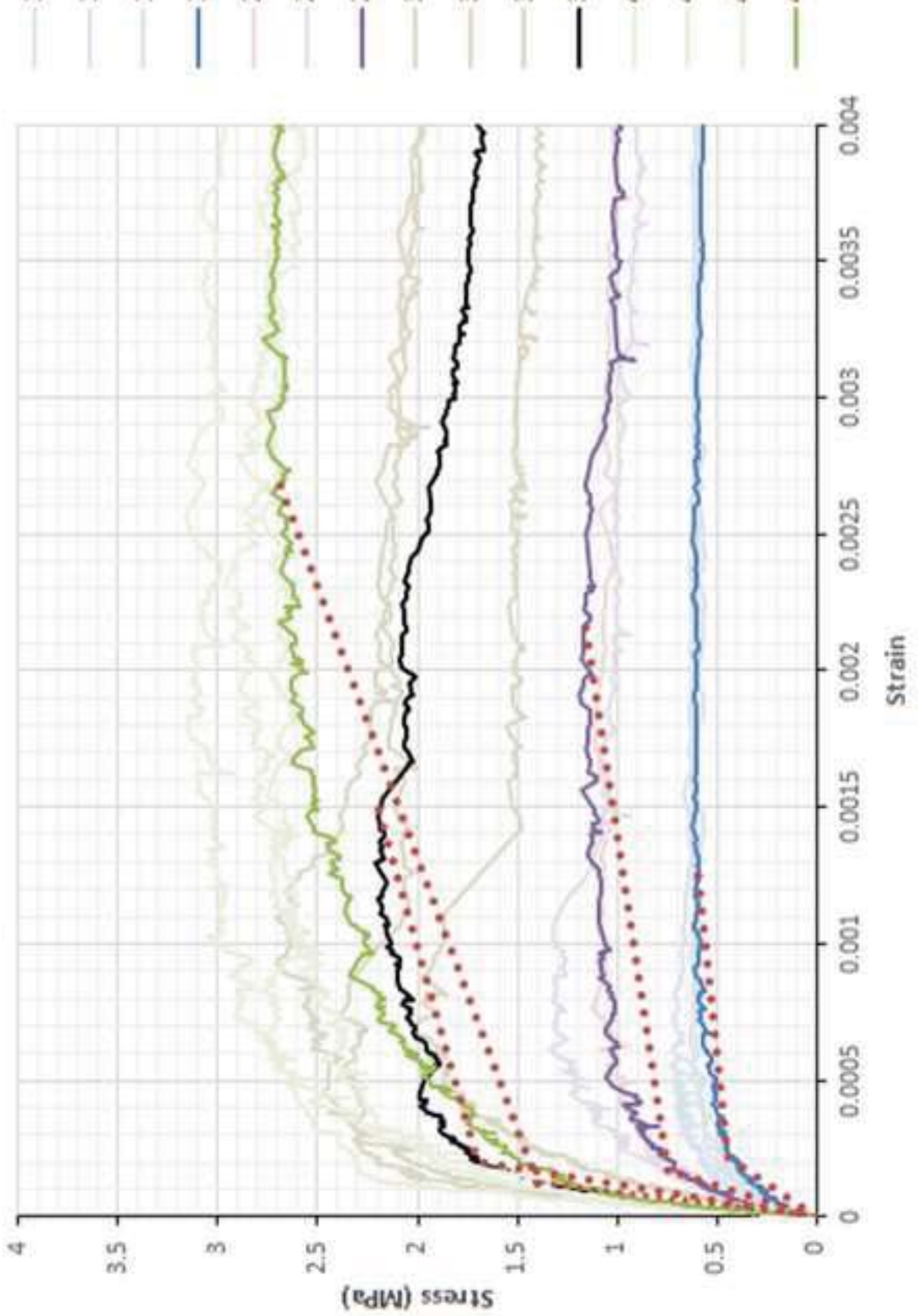

寸 

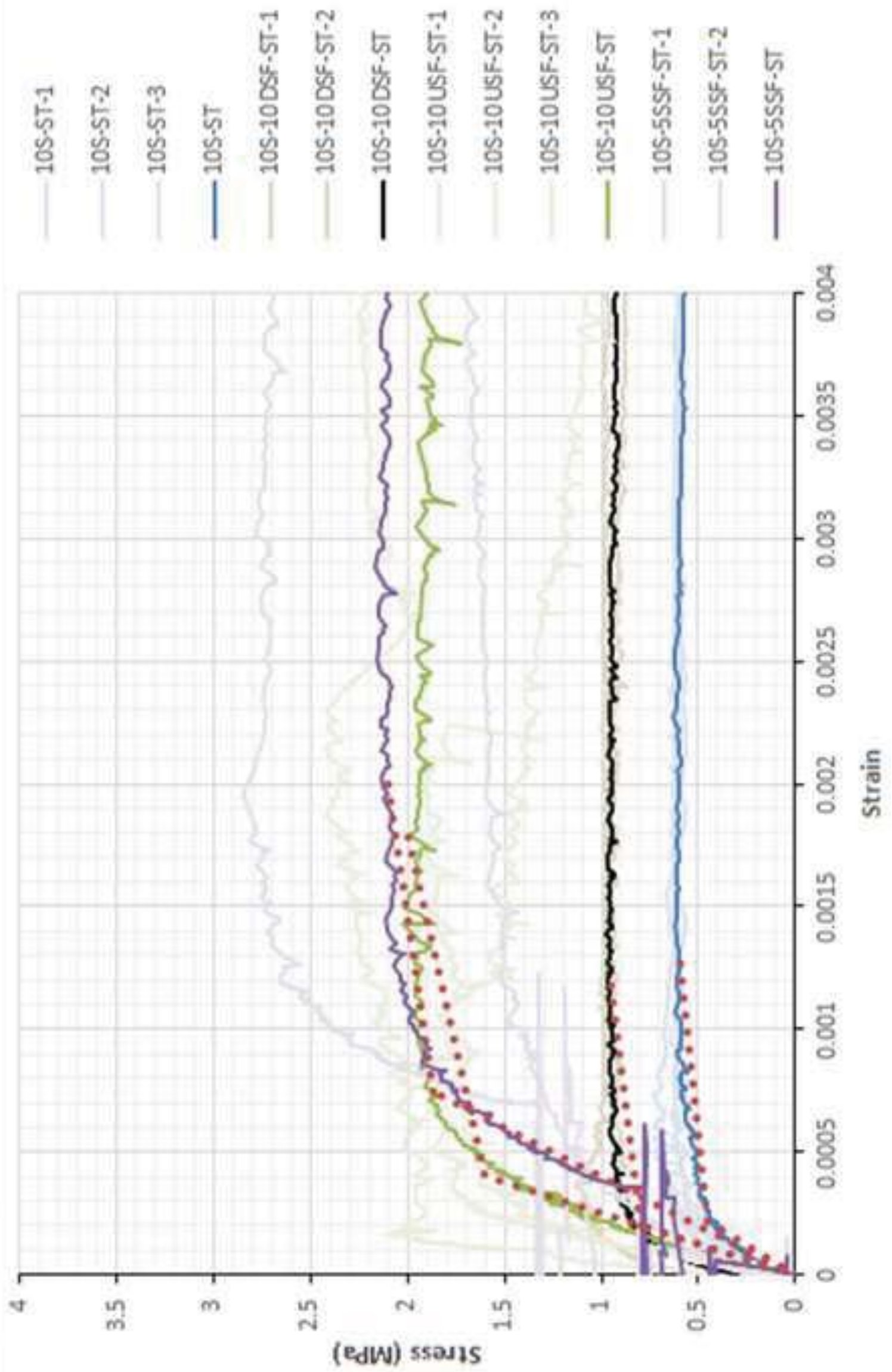

ㄸํㄴ

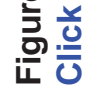




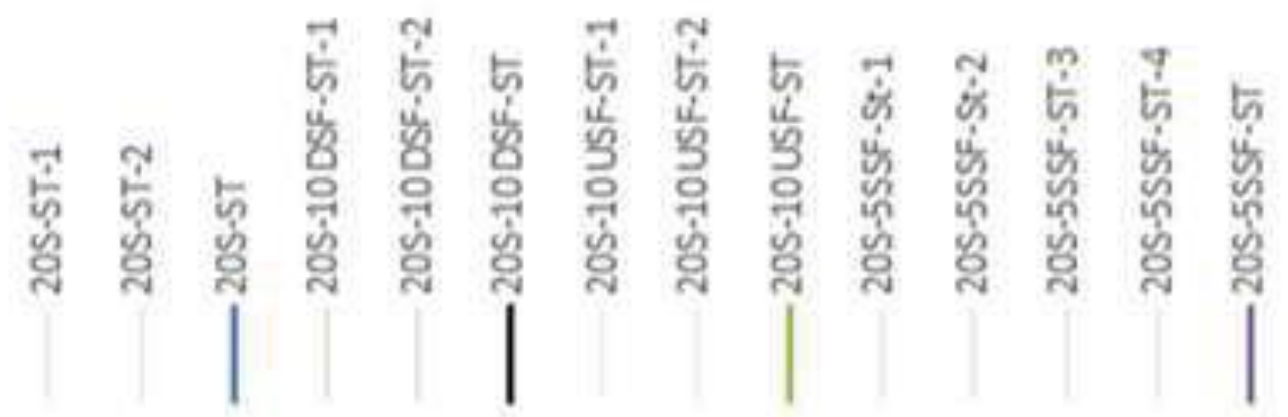

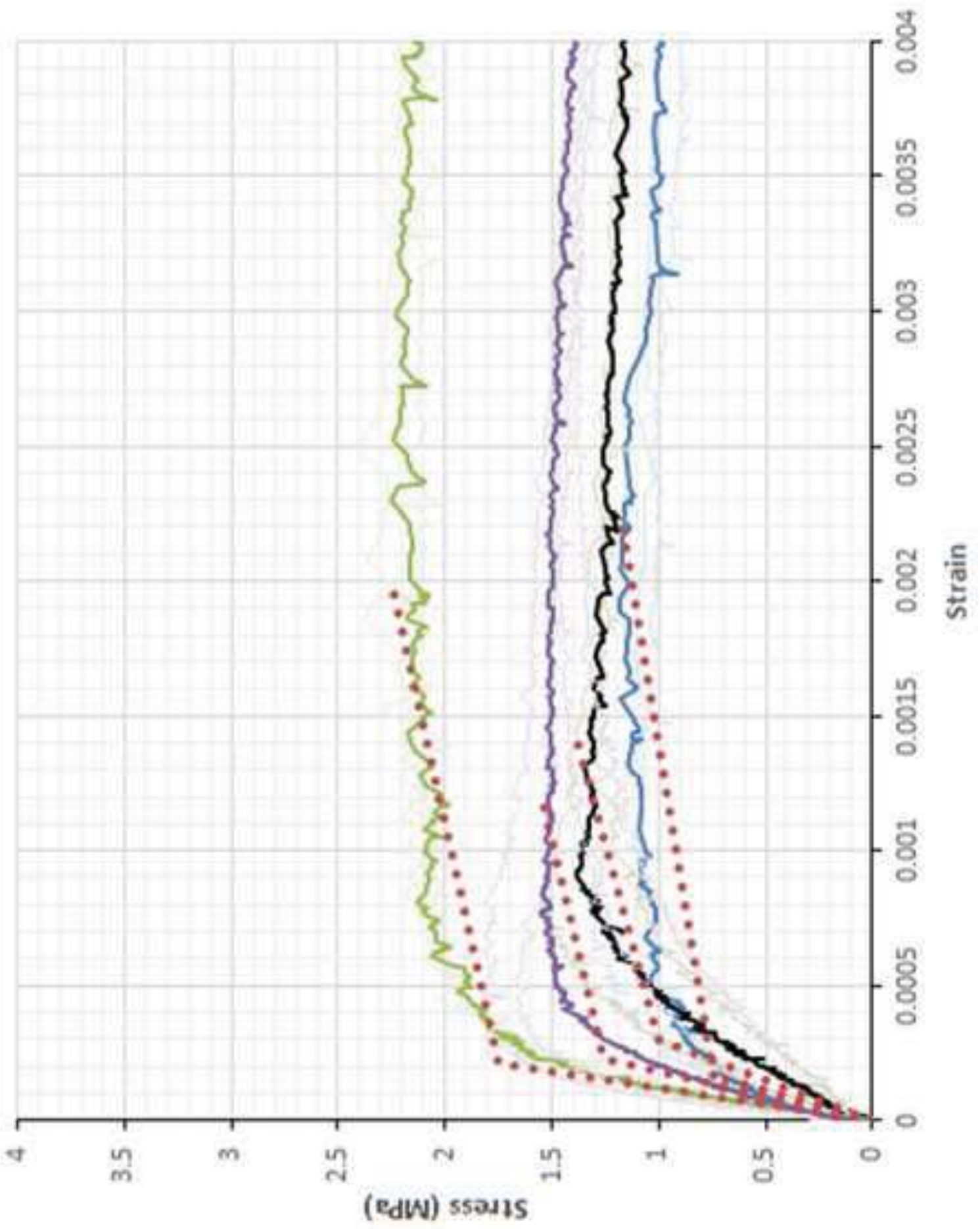

ㅇํㄴ원 


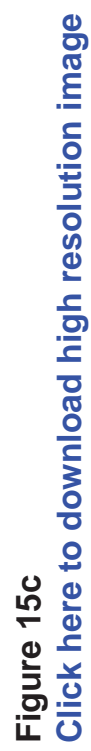

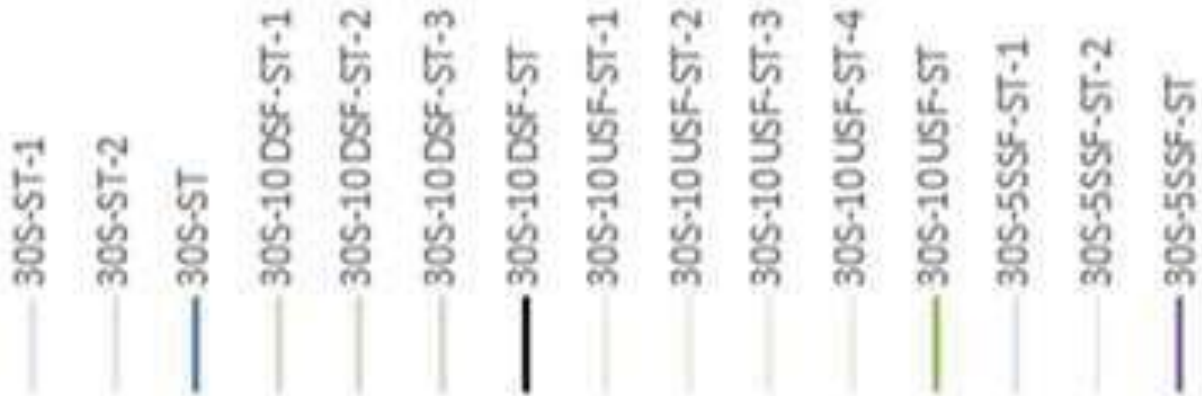

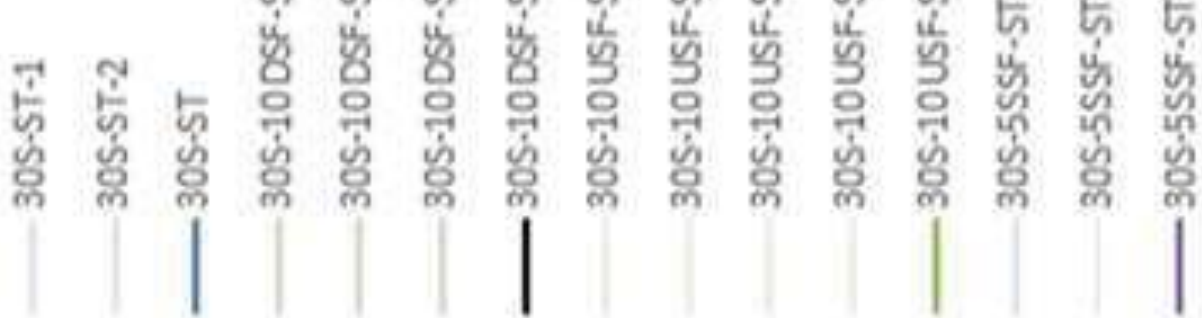

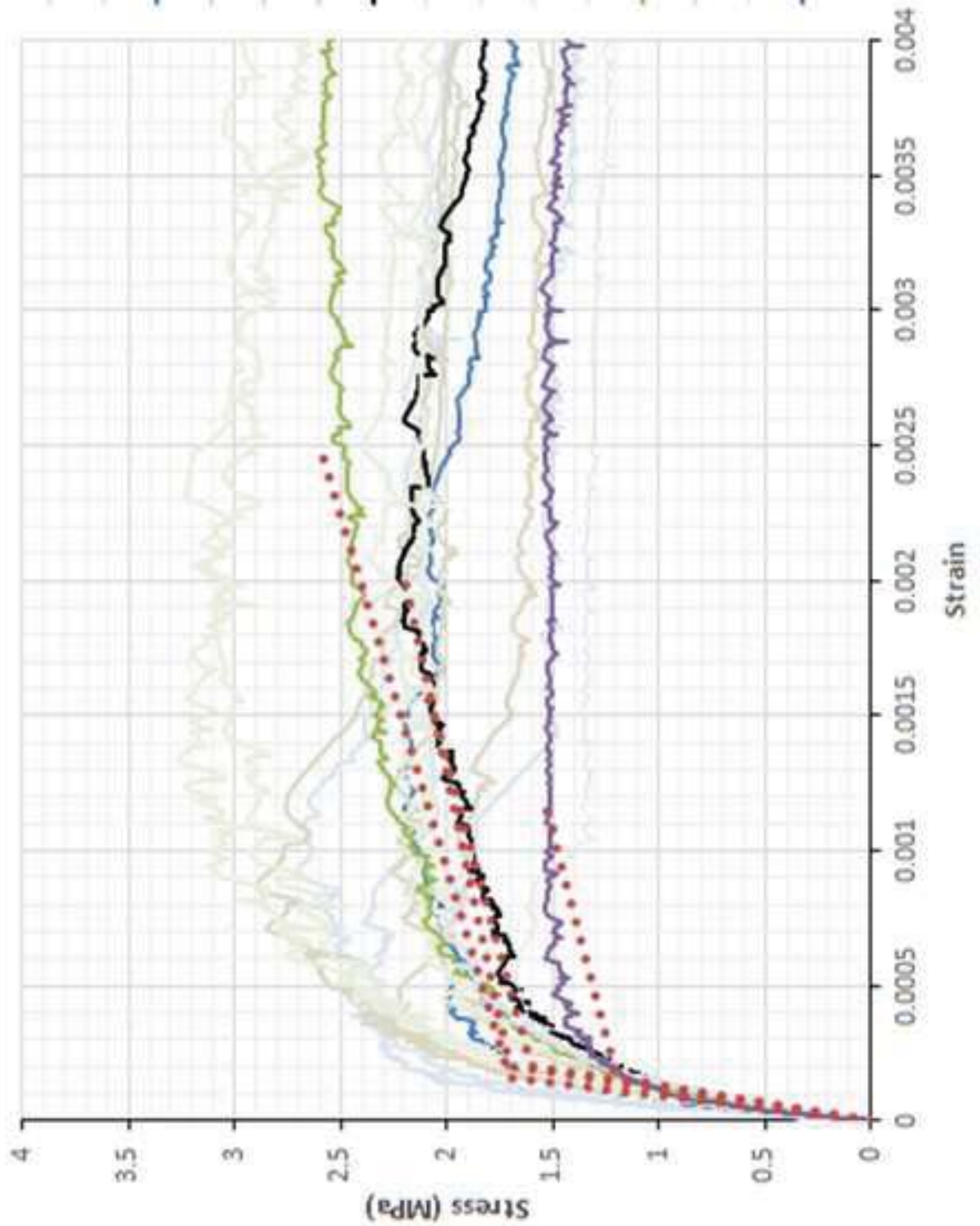



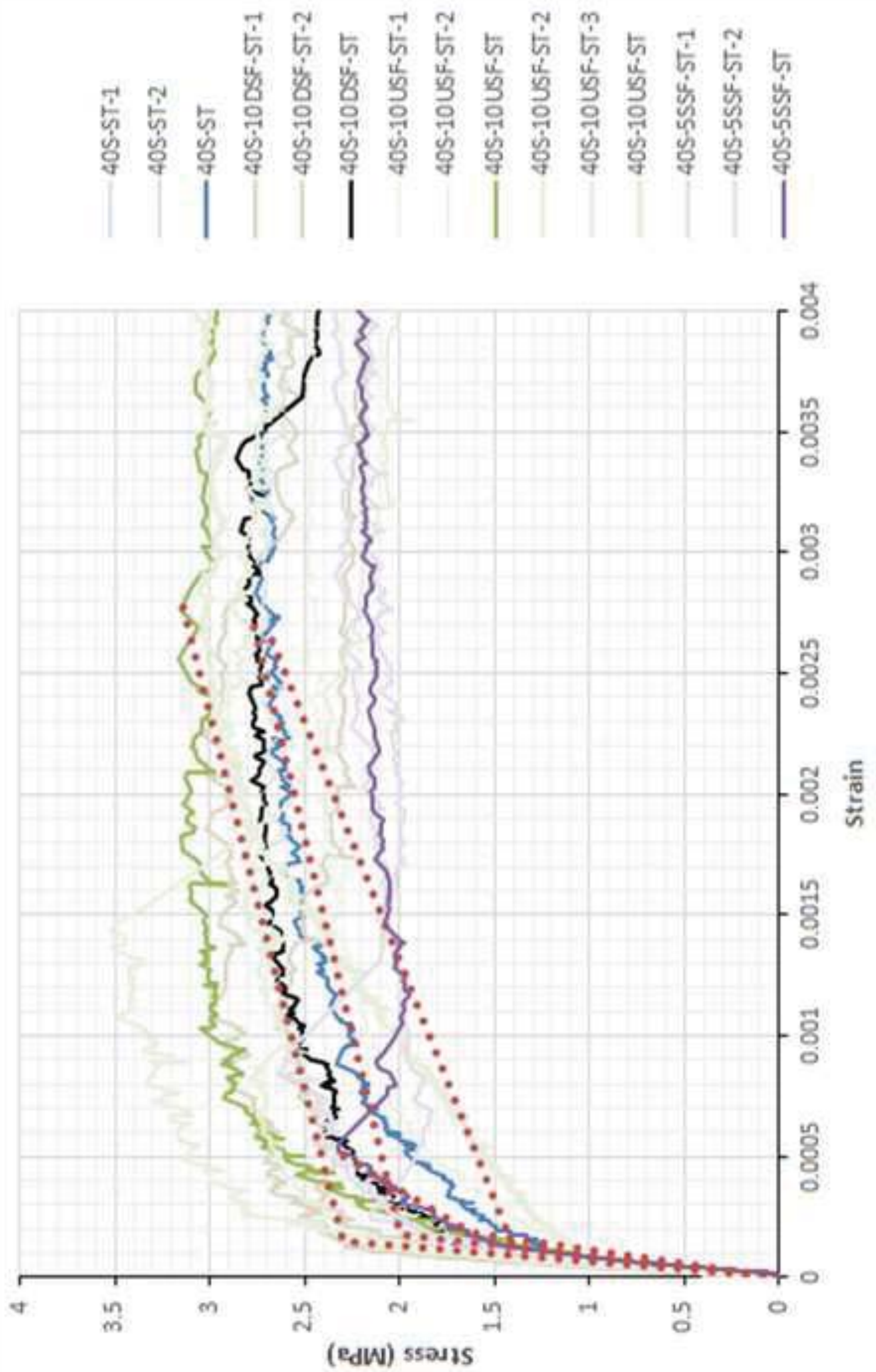

등 인 


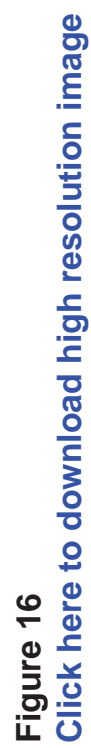

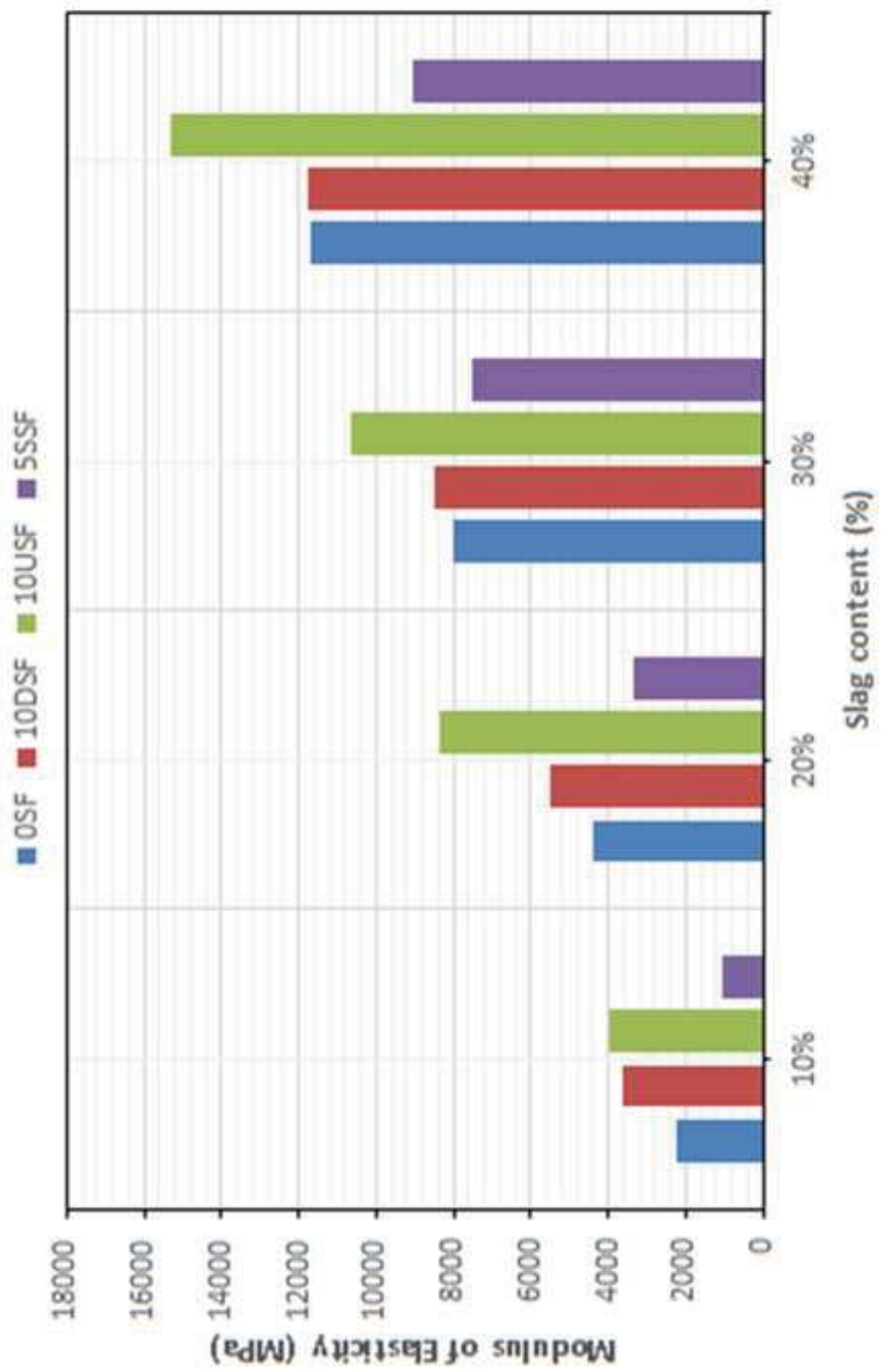




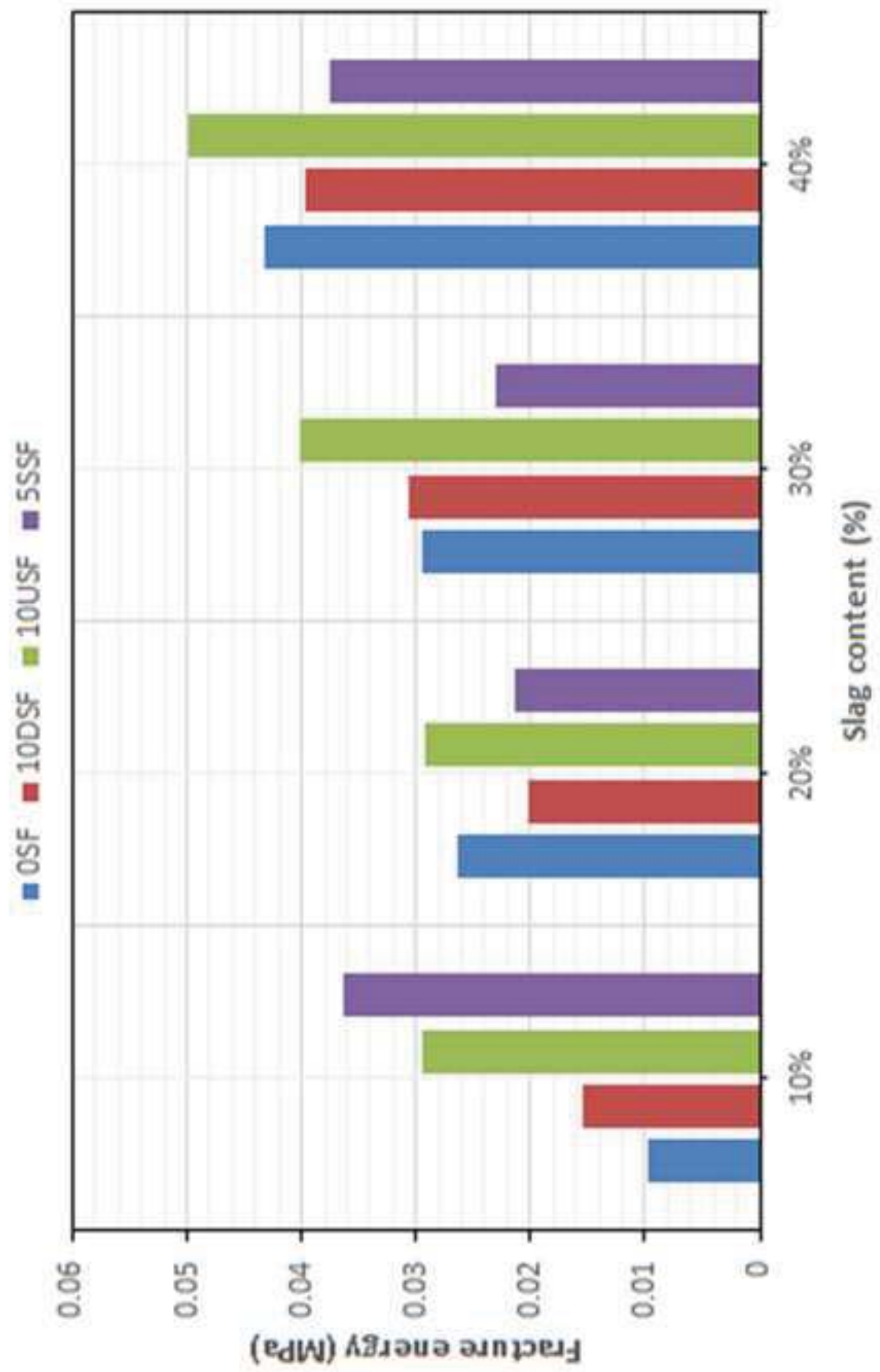

(1) 응 은 


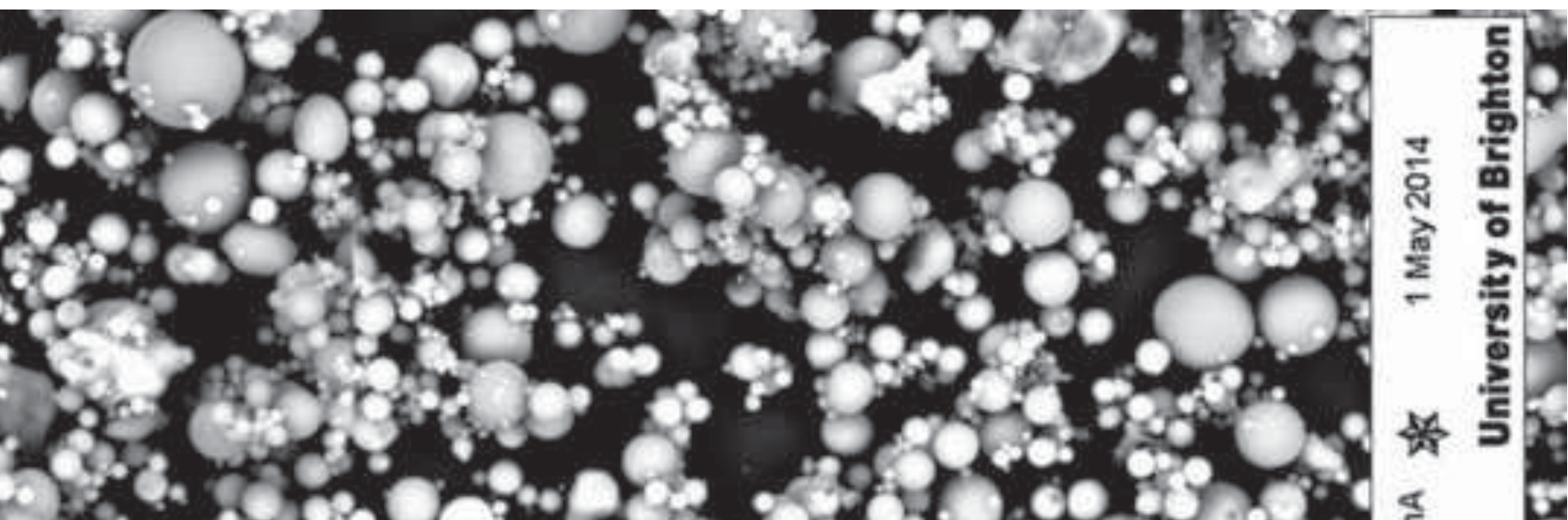

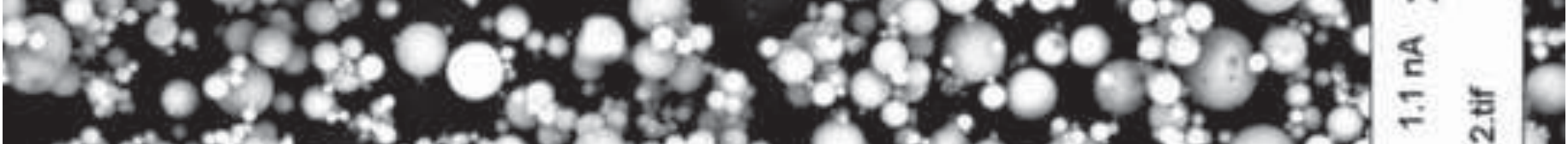

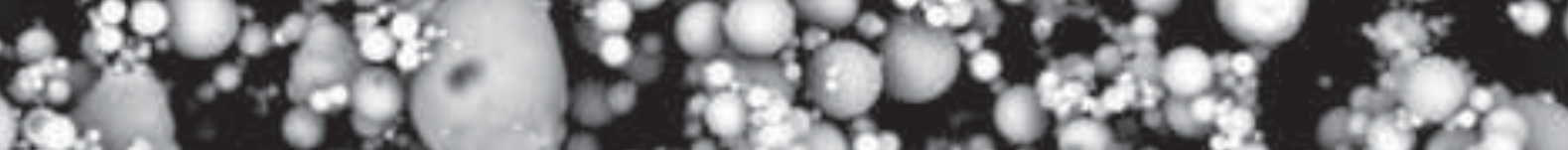

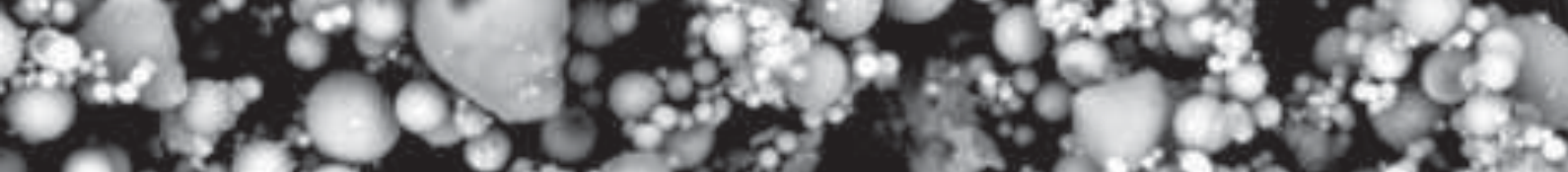

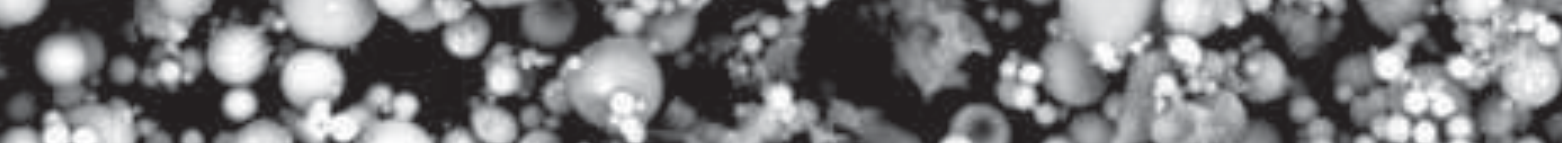

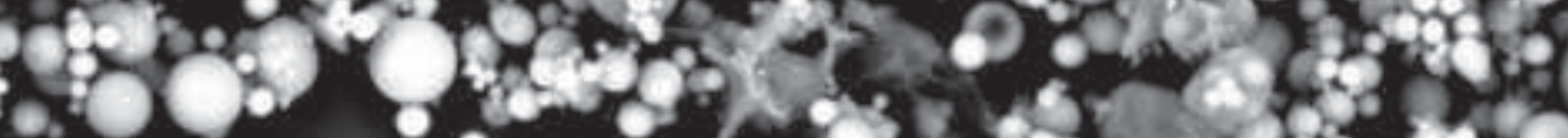

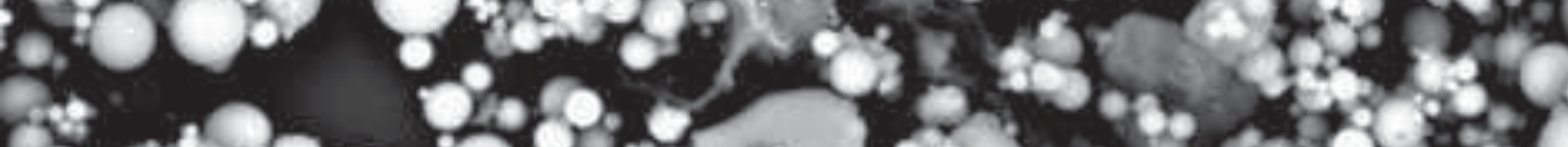

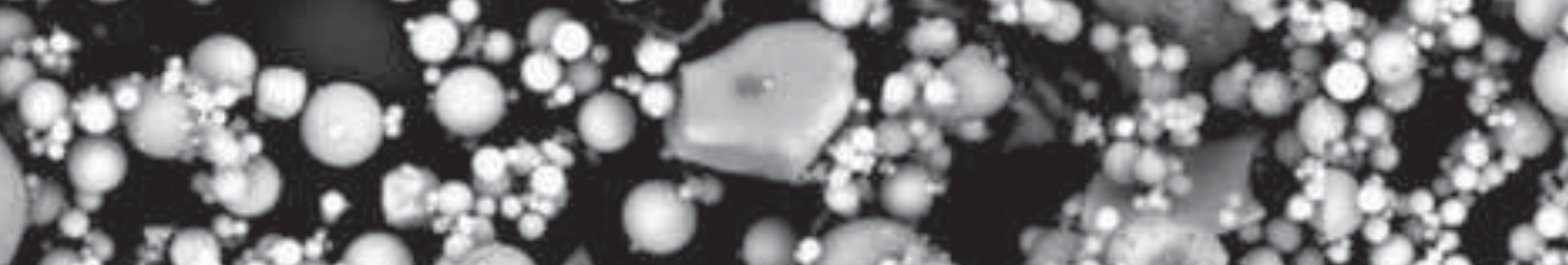

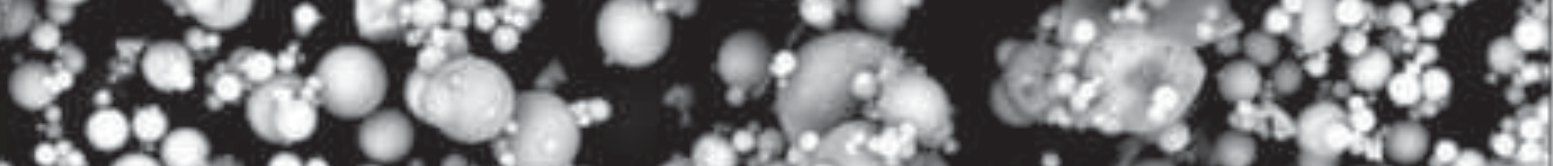

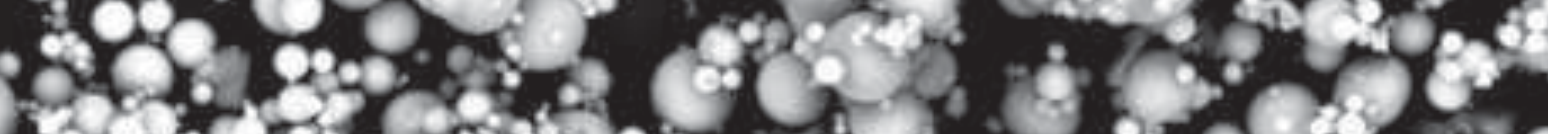

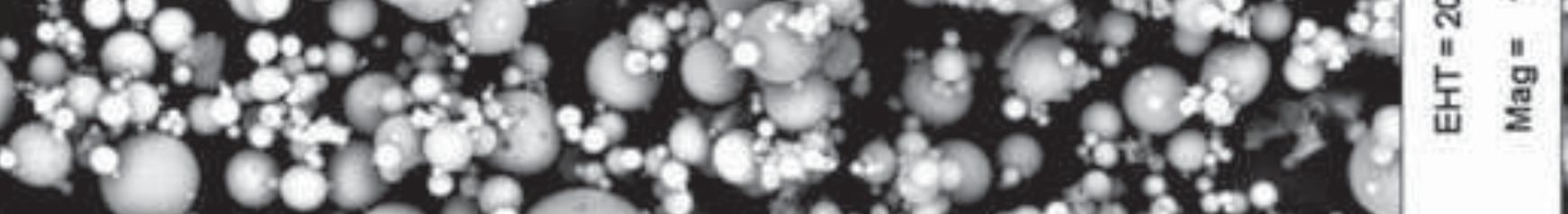

37 


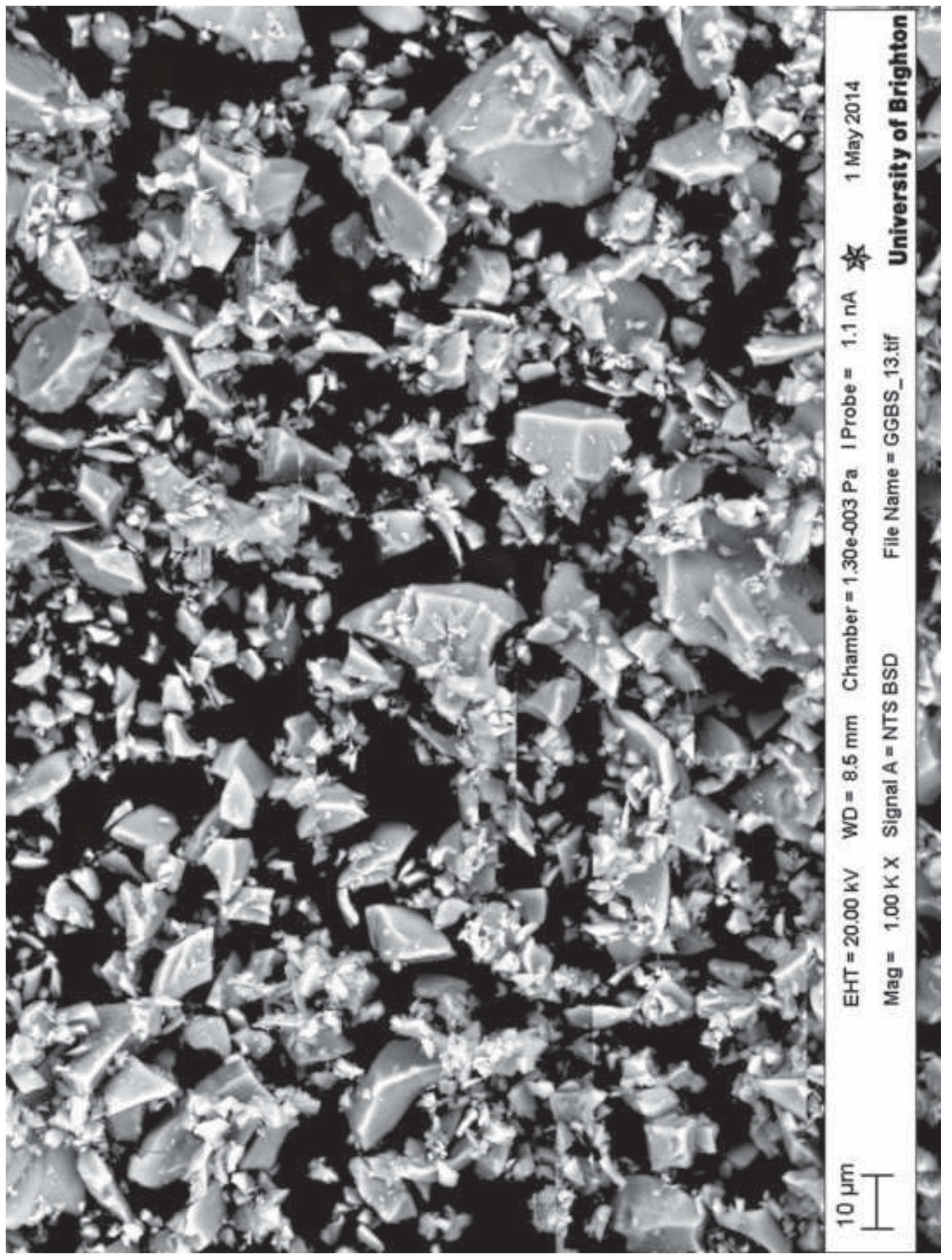




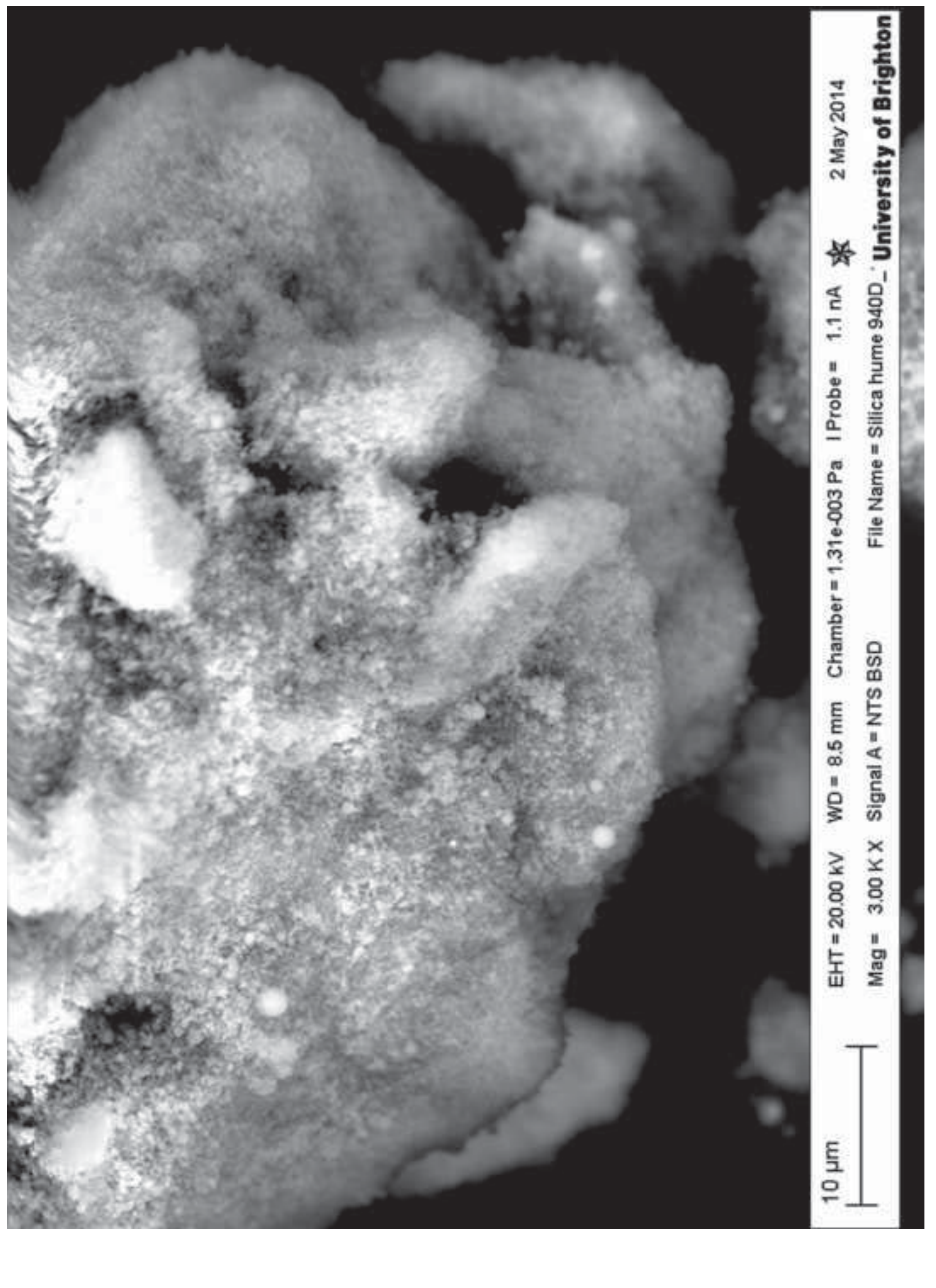




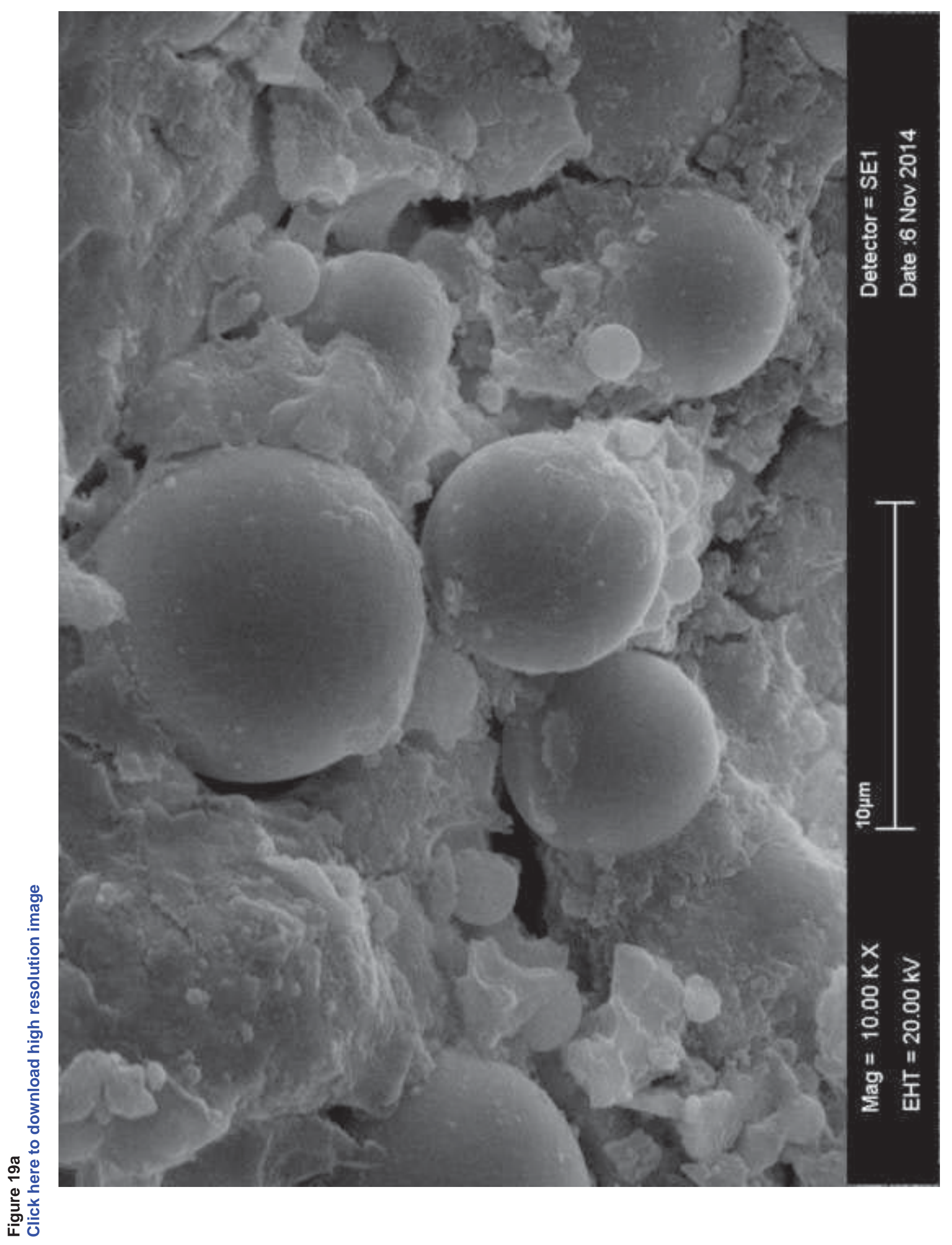




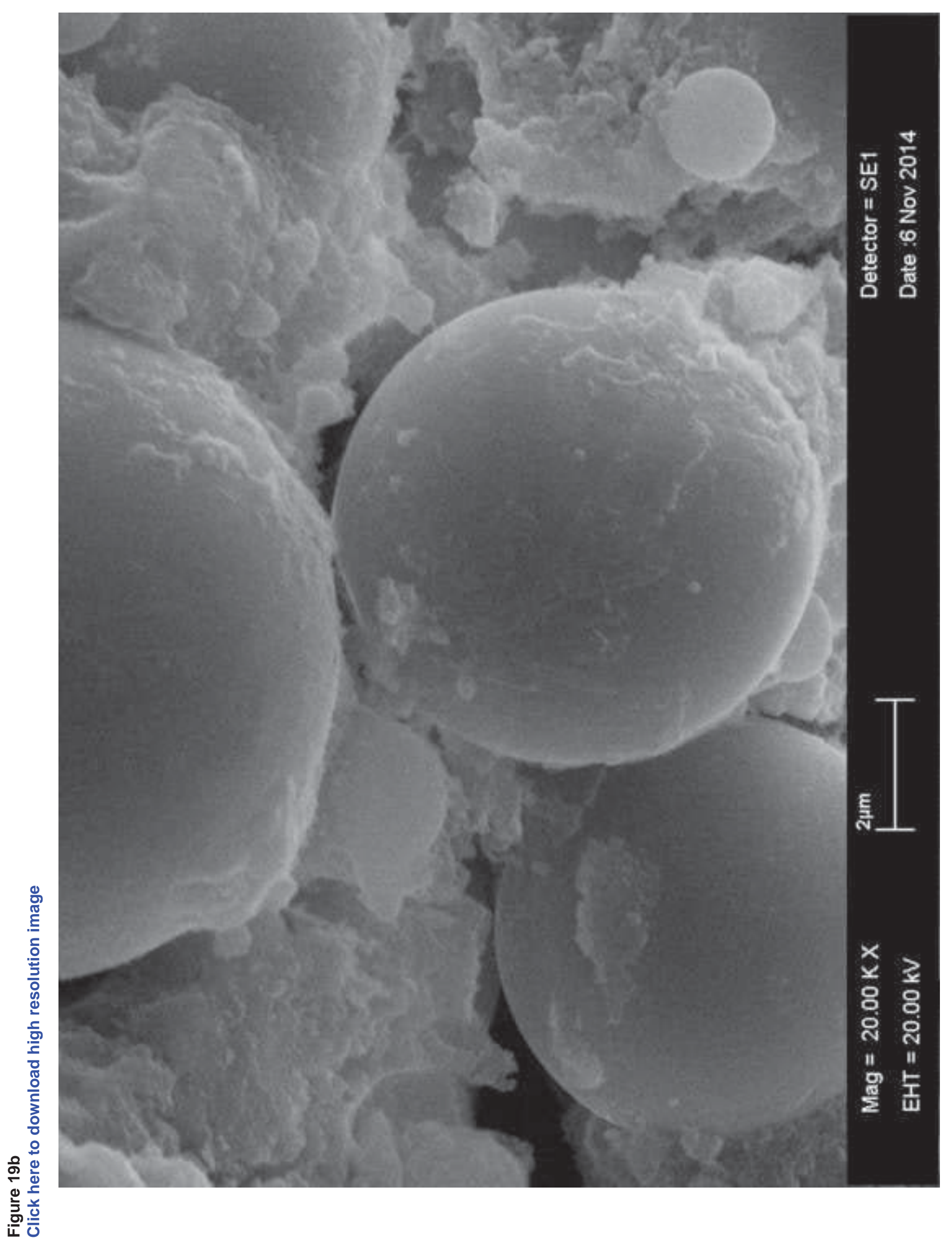




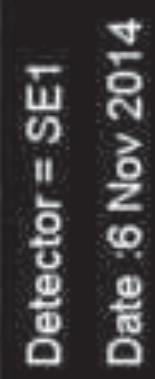

杰上

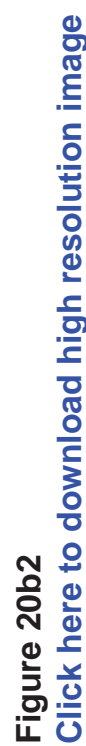




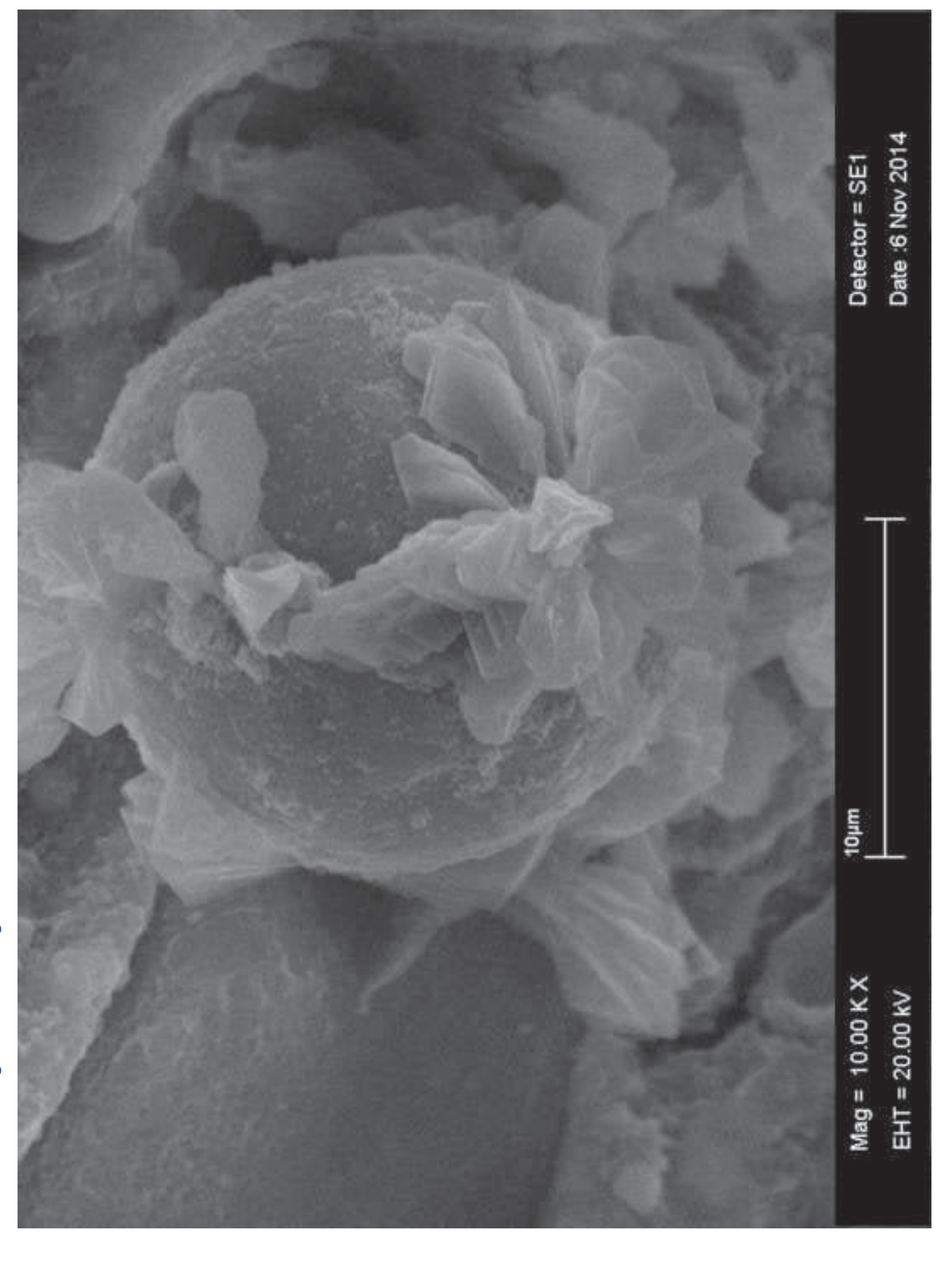




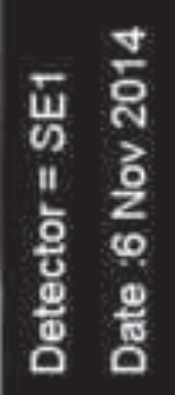

馬工

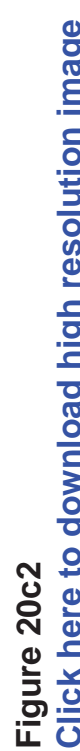




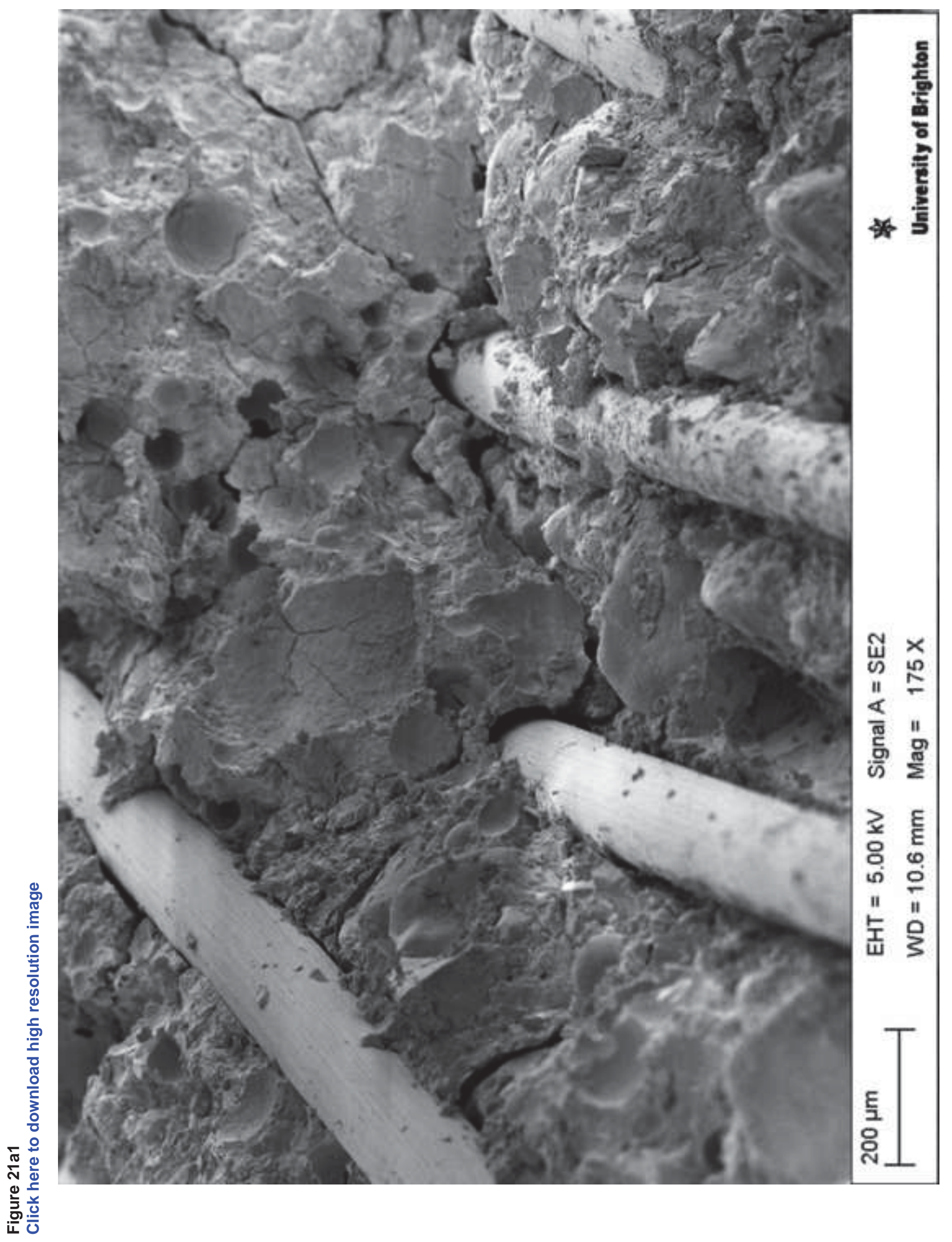




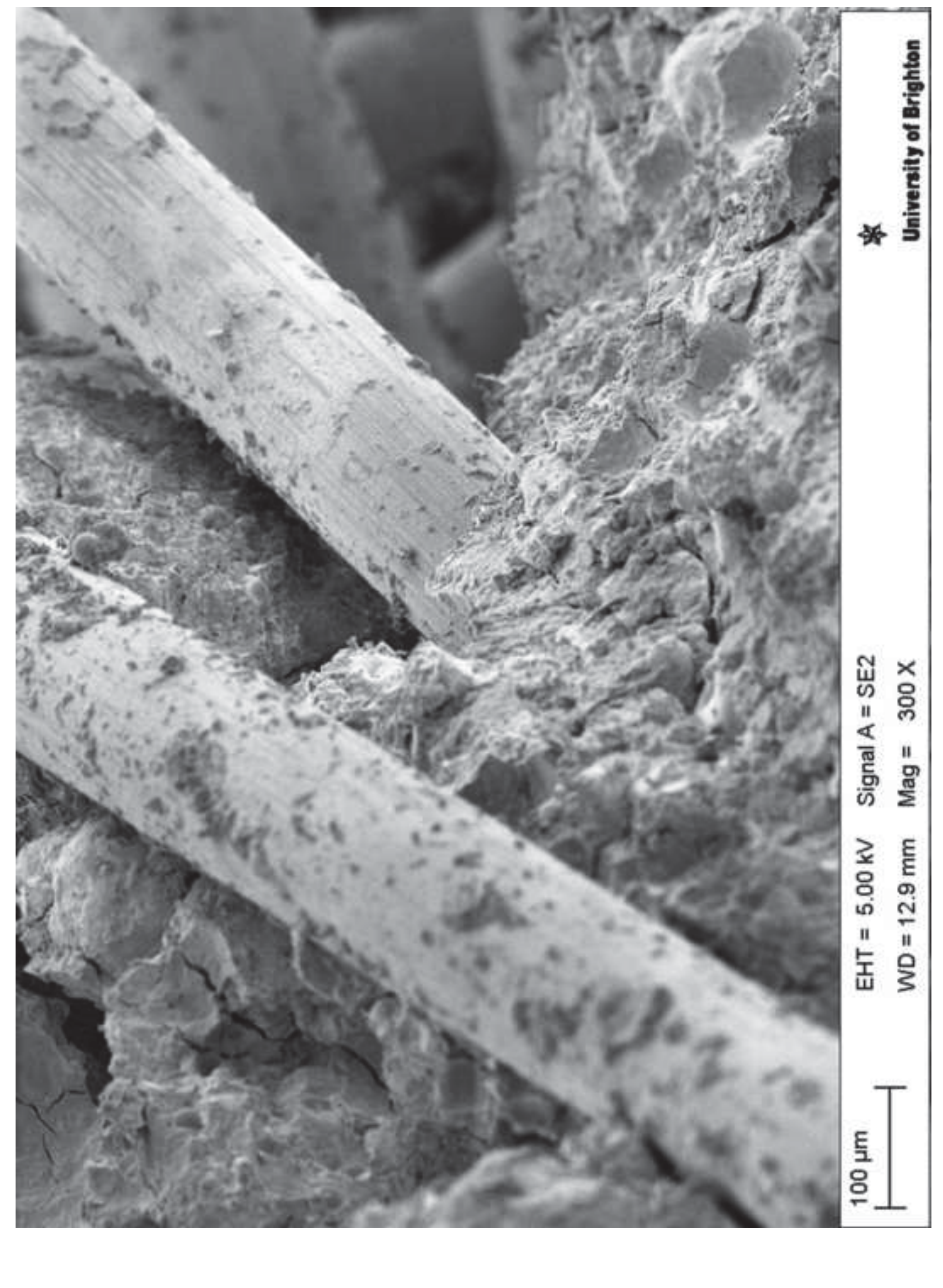




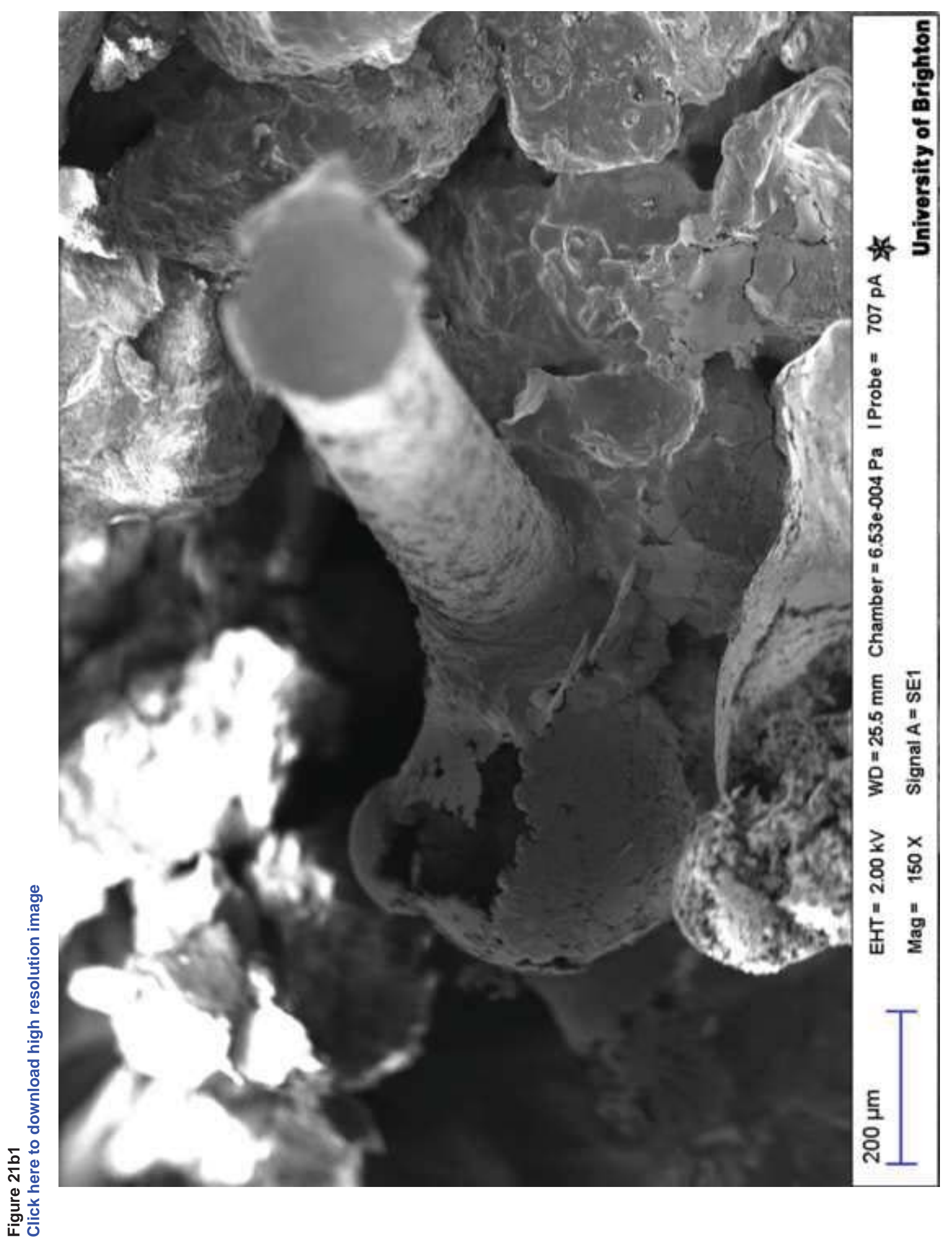




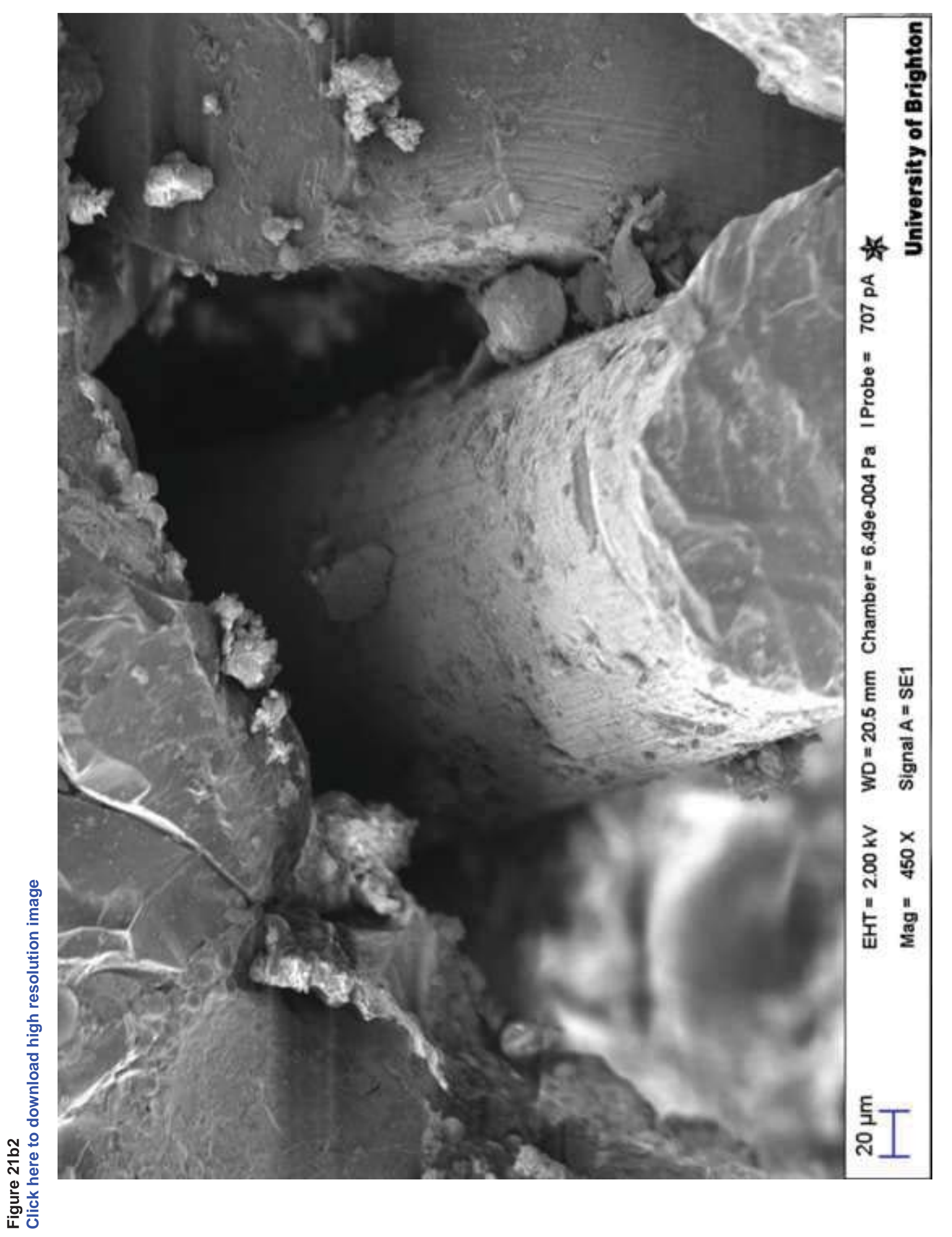




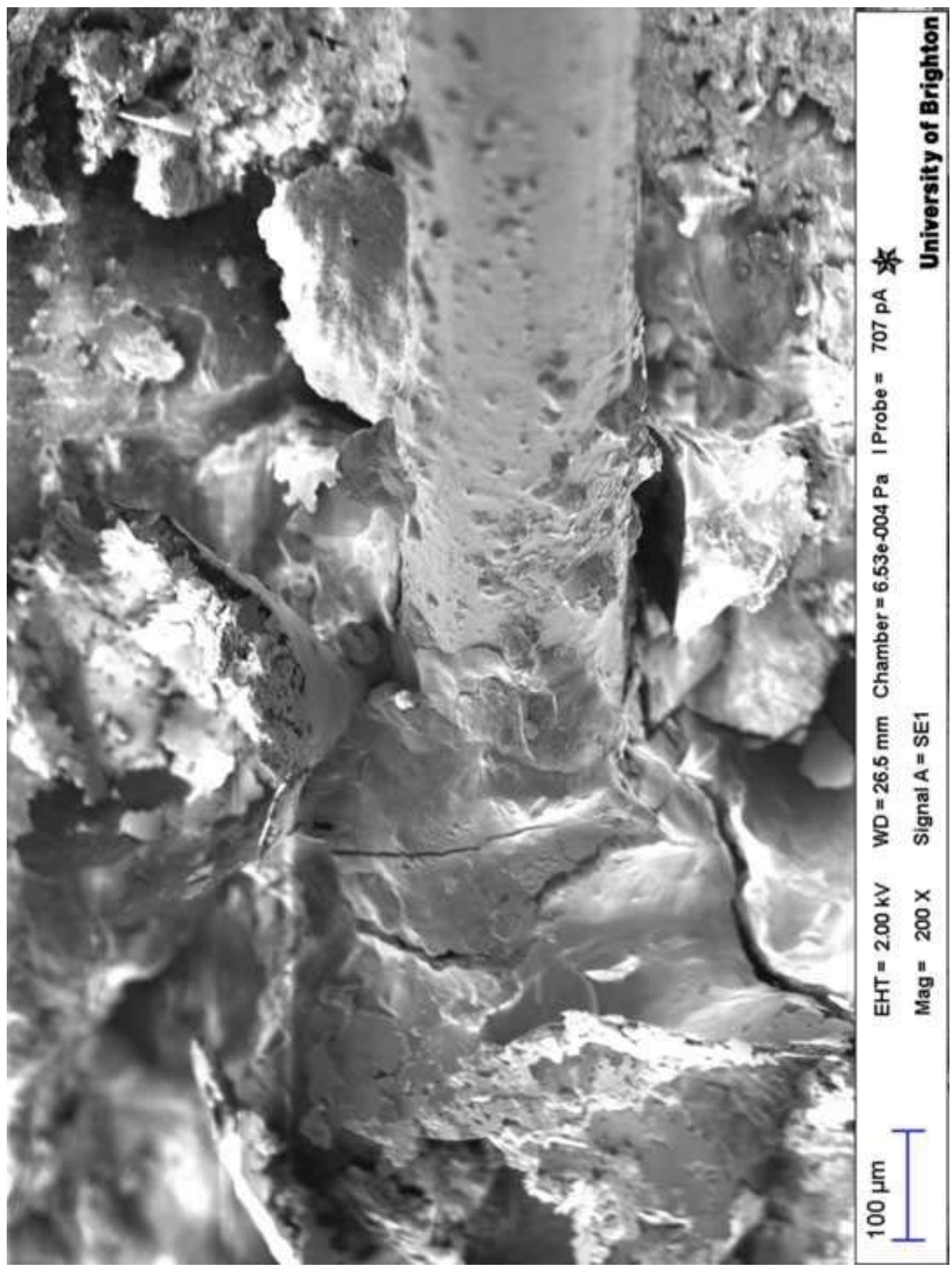

要 


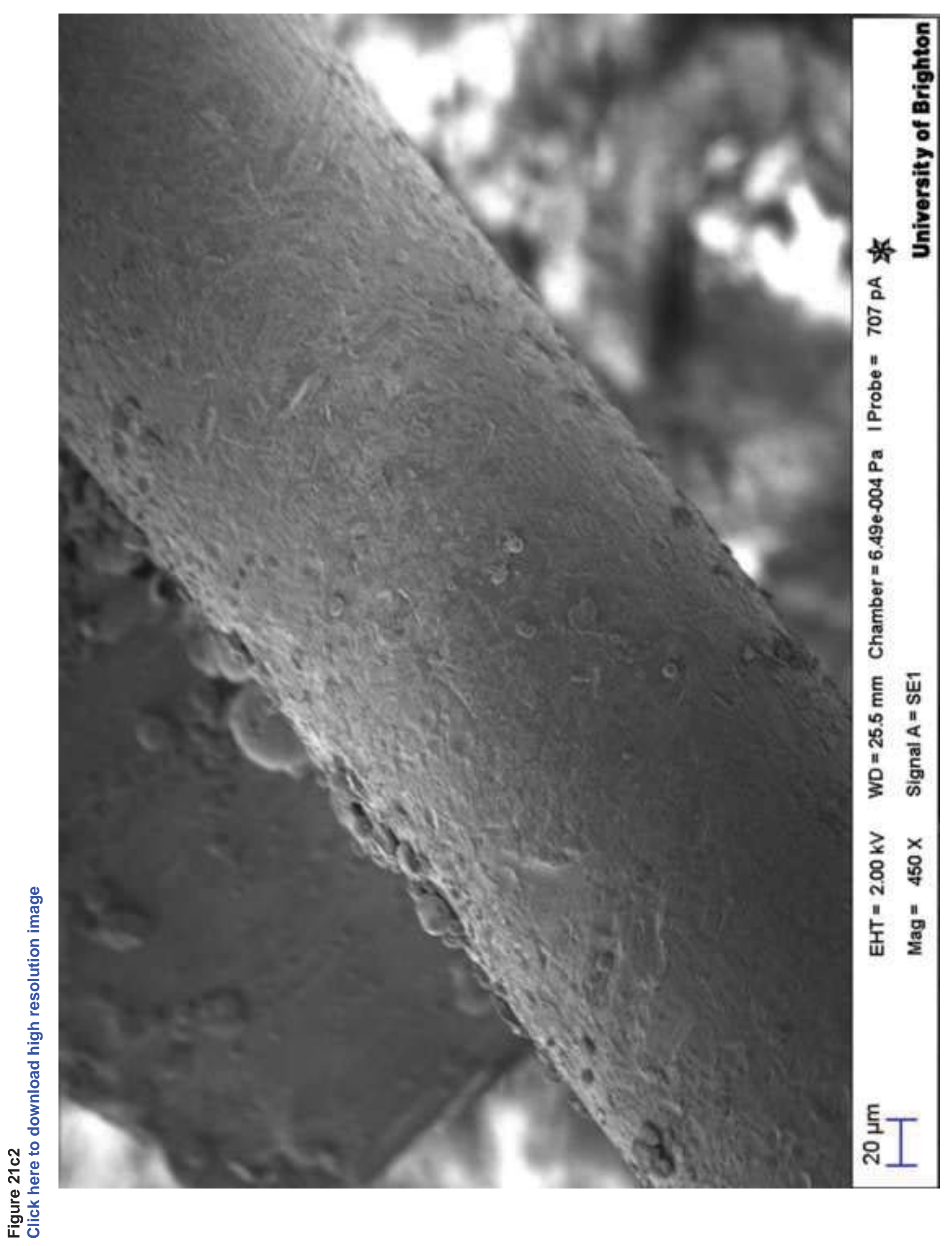

